\title{
MORE THAN WORDS: AN ANALYSIS OF COMMUNICATION ON TWITTER FOR
} AN APPAREL HERITAGE BRAND

\author{
By \\ Tasmina Afroze \\ A thesis \\ presented to Ryerson University \\ in partial fulfillment of the \\ requirements for the degree of \\ Master of Science in Management (MScM) \\ in the program of \\ Master of Science in Management
}

Toronto, Ontario, Canada, 2018

@Tasmina Afroze, 2018 


\section{Author's Declaration}

I hereby declare that I am the sole author of this thesis. This is a true copy of the thesis, including any required final revisions, as accepted by my examiners.

I authorize Ryerson University to lend this thesis to other institutions or individuals for the purpose of scholarly research.

I further authorize Ryerson University to reproduce this thesis by photocopying or by other means, in total or in part, at the request of other institutions or individuals for the purpose of scholarly research.

I understand that my thesis may be made electronically available to the public. 


\begin{abstract}
More Than Words: An analysis of communication on Twitter for an apparel heritage brand Tasmina Afroze

Master of Science in Management

Ryerson University

2018
\end{abstract}

Advances in technology and society have changed the way people use the Internet. While customers use online platforms for interactions and information exchange, businesses strive to create brand awareness or engagement. This thesis is an exploratory study to understand online communication of a heritage brand by analyzing its Twitter brand community. Using grounded theory approach, Dann's classification (2010) was used on branded and non-branded tweets to identify the types of messages that dominated the online community. Driven by the findings, types of users for non-branded communication was analyzed to expand understanding. The results suggest that engagement should be modified in accordance to the type of user for whom the message is addressed. The findings present new insights for marketers who are willing to explore the full potential of online communication. The study highlights the importance of online brand communities while expanding the understanding of Twitter communication through Dann's classification. 


\section{Acknowledgements}

I would like to thank many people for supporting me with completing my thesis at Ryerson University. First and foremost is my supervisor, Dr. Donna Smith without whose guidance and support, this thesis would not have been possible. Donna provided me with the resources, help and the motivation needed to make this thesis a reality. I will always be thankful for her belief in me.

I express my sincere gratitude to all the colleagues, mentors and professors at Ryerson University for their support.

I thank my wonderful parents for their unwavering love, support and sacrifices. My sisters for their friendship. And lastly, my amazing husband for always encouraging me to go the extra mile. Thank you for loving me unconditionally. 


\section{Table of Contents}

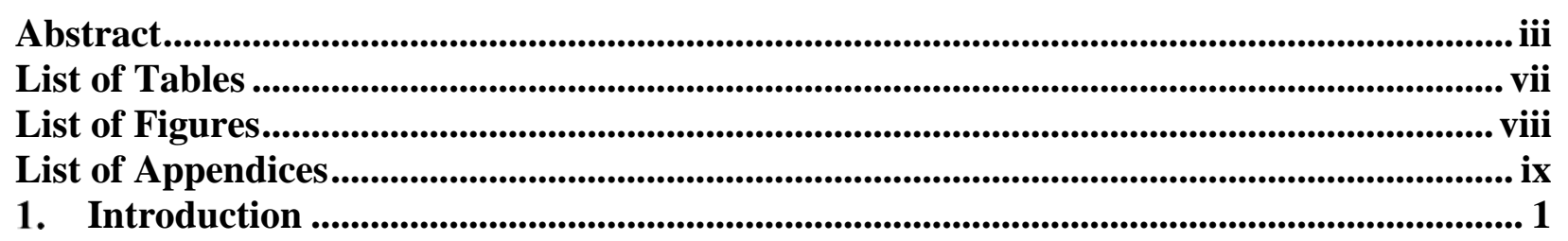

1.1. Research Scope ……………………………........................................... 5

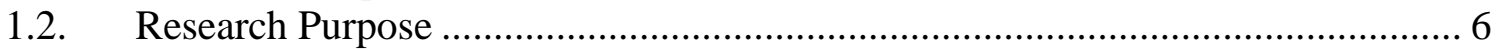

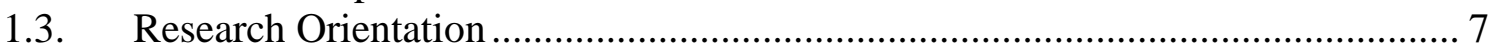

2. Literature Review .......................................................................................................................................... 8

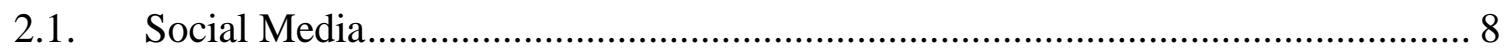

2.2. Online Brand Communities......................................................................... 12

2.3. Online Consumer Engagement................................................................... 16

2.4. Twitter for business/marketing....................................................................... 20

2.5. Apparel Industry and Jeans …………………………………………….... 23

3. Methodology ............................................................................................................................................ 25

3.1. Brand Selection ................................................................................... 25

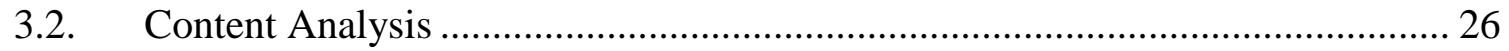

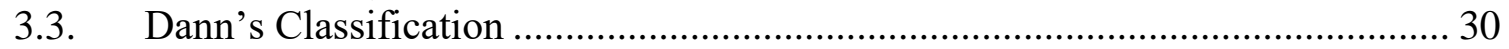

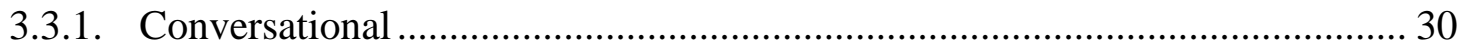

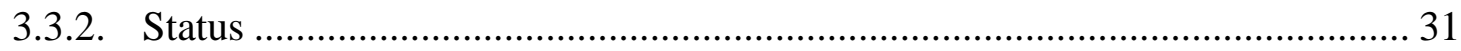

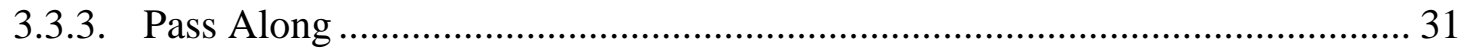

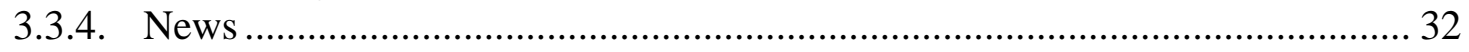

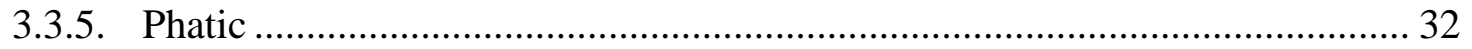

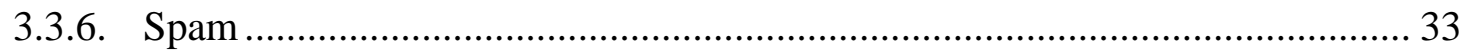

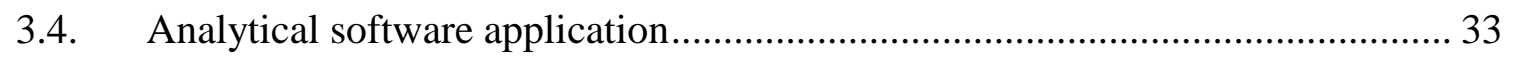

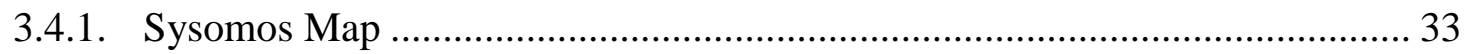

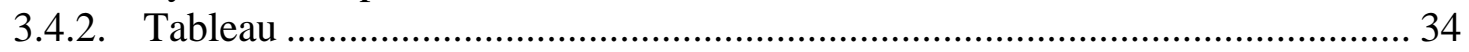

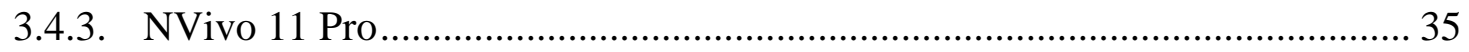

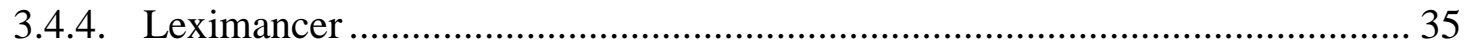

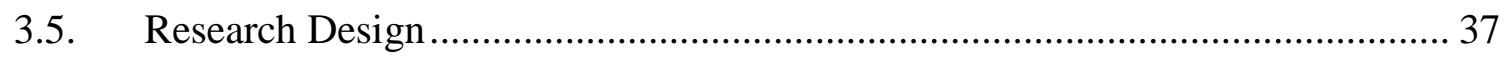

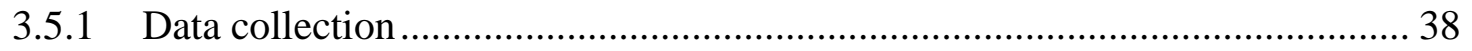

3.5.2 Organize and prepare data for analysis....................................................... 39

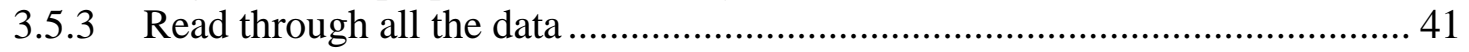


3.5.4 Detailed analysis with a coding process (Dann's Classification) ................... 41

3.5.5 Generate themes using on the categories listed in Dann's classification ........ 43

3.5.6 Interpret and represent themes in a qualitative narrative............................... 44

4. Findings …....................................................................................................................................................... 45

4.1. Categorization of Branded and Non-branded tweets ...................................... 46

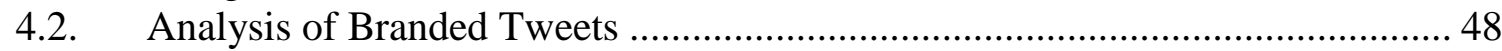

4.2.1. Analysis of Conversational category of Levi's branded tweets .................... 48

4.2.2. Analysis of Pass Along category of Levi's branded tweets .......................... 52

4.3. Analysis of Non-branded Tweets .................................................................. 55

4.3.1. Analysis of Conversational category of non-branded tweets ......................... 55

4.3.2. Analysis of Pass Along category of non-branded tweets ............................ 59

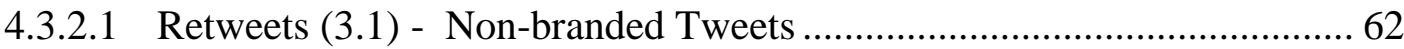

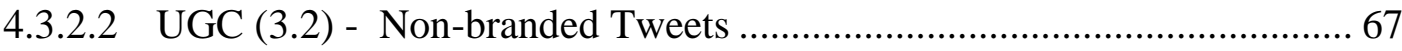

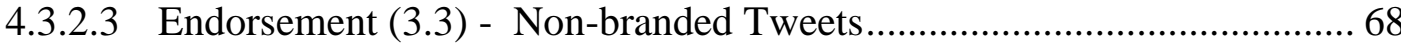

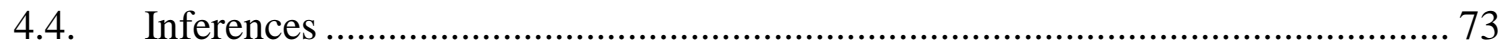

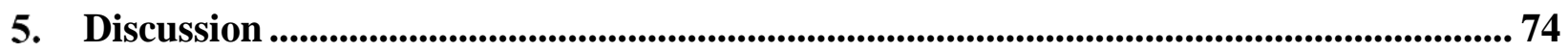

5.1. Branded Communication......................................................................... 76

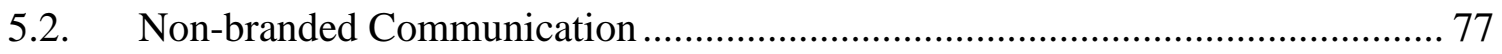

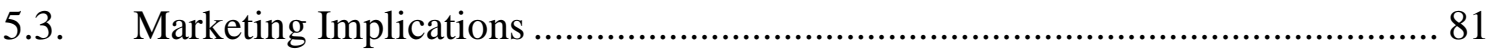

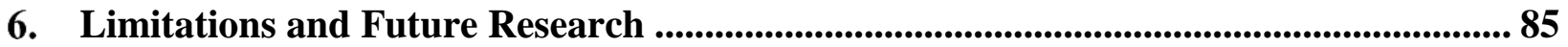

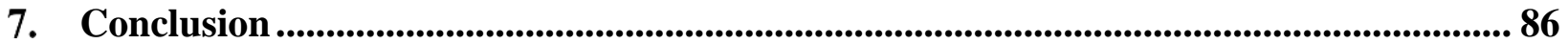

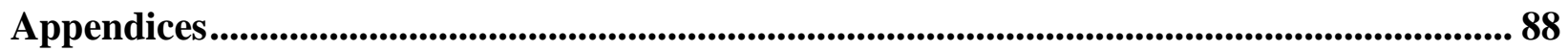

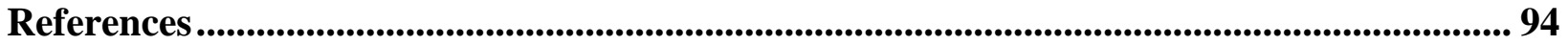




\section{List of Tables}

Table 1. Coding Schemas from Literature ................................................................ 29

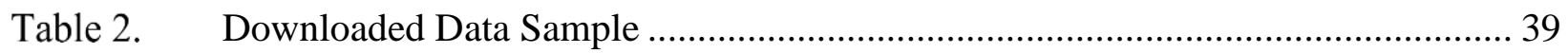

Table 3. Codes for categories and sub categories ........................................................ 41

Table 4. Interpretation of Kappa (Landis \& Koch, 1977) ............................................ 42

Table 5. $\quad$ SPSS Output showing Kappa coefficient to determine reliability ...................... 45

Table 6. Categorization of branded and non-branded tweets ........................................... 46

Table 7. Frequency of the top 10 words from branded Conversational tweets .................. 49

Table 8. Frequency of the top 10 words from non-branded Conversational tweets ............. 55

Table 9. Authors with high number of followers in Endorsement subcategory .................. 71

Table 10. Category Impressions for Conversational and Pass Along category...................... 73

Table 11. Proposed subdivision of Pass Along sub-categories ........................................... 83 


\section{List of Figures}

Figure 1. Data Analysis in Qualitative Research (Creswell, 2009, p. 185) ....................... 37

Figure 2. Preview of Boolean search for Levi's on Sysomos MAP ................................... 38

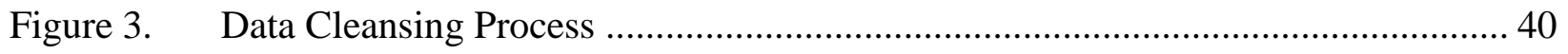

Figure 4. Top 100 words from branded Conversational category .................................... 49

Figure 5. Branded Conversational tweets arranged in chronological order......................... 50

Figure 6. Concept Map for branded Conversational tweets ............................................ 51

Figure 7. Top 100 words from branded Pass Along category ......................................... 53

Figure 8. Branded Pass Along tweets in Chronological order ........................................... 54

Figure 9. Concept Maps for branded Pass Along tweets ................................................... 54

Figure 10. Top 100 words from non-branded Conversational category ............................... 56

Figure 11. Non-branded Conversational tweets in Chronological order ................................ 57

Figure 12. Concept map for non-branded Conversational tweets ........................................ 58

Figure 13. Number of non-branded tweets in Pass Along category .....................................5 59

Figure 14. Non-branded Pass Along tweets in Chronological order................................... 61

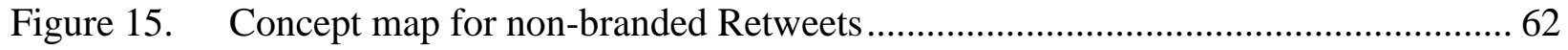

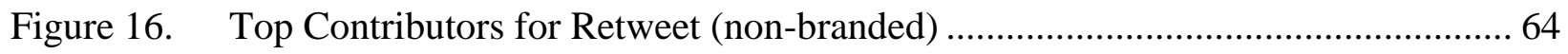

Figure 17. Top 100 words from non-branded Endorsement sub-category............................ 68

Figure 18. Concept map for non-branded Endorsement tweets ........................................ 69

Figure 19. Top Contributors for Endorsement (non-branded) ......................................... 70 


\section{List of Appendices}

Appendix A. Thematic Synopsis for Branded Conversational Category --------------------------88

Appendix B. Ranked Concepts Branded Conversational Category---------------------------------88

Appendix C. Ranked concepts branded Pass Along Category ------------------------------------89

Appendix D. Thematic Synopsis for Branded Pass Along Category ----------------------------89

Appendix E. Ranked Concepts non-branded Conversational Category----------------------------90

Appendix F. Thematic Synopsis for non-branded Conversational Category --------------------90

Appendix G. $\quad$ Ranked Concepts non-branded Retweet in Pass Along Category -----------------91

Appendix H. Thematic Synopsis for non-branded Retweet in Pass Along Category -----------91

Appendix I. $\quad$ Ranked Concepts non-branded Retweet in Pass Along Category -----------------92

Appendix J. Thematic Synopsis non-branded Endorsement in Pass Along Category ---------92

Appendix K. SPSS output showing degree of significance of Kappa calculation --------------- 93 


\section{Introduction}

With nearly 3.47 billion individuals having ready access to Internet in 2016, social media has become one of the most important communication channels to connect with family and friends, share sentiments, access entertainment and perform online shopping. (Statista, 2015). The growth of social media use is also amplified by the use of mobile technology like smartphones and wearable devices which make the internet ubiquitous (Euromonitor International, 2017a). Connectivity is no longer bounded by locations and consumers have more freedom to use social media wherever and whenever they want. Sharing content online has become an integral part of modern life and information gathered online vastly impacts decision making, attitudes and beliefs. Platforms such as social networking sites, blogs, content communities, online repositories and so on have increasingly become a source to gather information for consumption and decision making (de Valck et al., 2009; Gruzd, Staves, \& Wilk, 2012). Consumers may conduct pre-purchase searches about products or brands to make informed purchase decisions. They usually seek out opinions, user experiences, and product reviews from other consumers who share their experiences online (Gu, Park, \& Konana, 2012). Similarly, post-purchase, consumers may share their own experiences about a product or brand. Information exchange between online consumers "continues to grow exponentially" due to the success and credibility of social media platforms (de Valck et al., 2009, p. 185).

The rise in social media usage has revolutionized advertising in a way that organizations must compete in the online marketplace to stay relevant (Laroche, Habibi, \& Richard, 2013). Social media has become an integral part of the marketing mix through which brands aim to communicate and foster their relations with consumers. In a recent report, $89 \%$ of marketers 
confirmed that social media is important as it generated more awareness for their business which in turn increased online traffic (Stelzner, 2016). Without disclosing an exact number, businesses revealed that they received returns in terms of improved company sales within two years of engaging in social media marketing (Stelzner, 2016). Companies are increasing their investment in social media marketing campaigns to extract, analyze, and understand social media content. Whether the conversations generate a positive or negative impact, company's awareness and understanding of the content may allow marketers to create a positive online presence (Dickey \& Lewis, 2011; Mangold \& Faulds, 2009). Thus, this study investigates online content for the heritage jeans brand, Levi Strauss \& Co., to understand how marketers and consumers contribute to social media communications.

Organizations try to leverage social media to create successful business returns such as increased return on investment, improved brand knowledge, (Kumar \& Mirchandani, 2012) and sales growth (Duan, Gu, \& Whinston, 2008). Realizing the potential of social media for brand marketing, Nordstrom began to utilize Pinterest in 2013 to inspire customers through the development of a visual trend story. The fashion-oriented department store integrated their own website "shop.nordstrom.com" with Pinterest to leverage the social site. The company added a "save" button to their website so customers could easily pin their desired items and consequently spread Nordstrom Pins virally across Pinterest. Nordstrom also integrated actions of virtual consumers with the in-store experience by showcasing top pinned merchandising in-stores using Pinterest signage and iPad displays. Nordstrom's Pinterest community heavily influenced in-store displays due to which the company created an in-store app for salespeople that matches popular Pinterest items with current inventory for a department on a store-by-store basis (Lutz, 2013). An early adopter of Pinterest, Nordstrom strategized to drive consumer purchasing by making its 
followers a part of an exclusive community (Bruining, 2017). The company experienced positive results as many of Nordstrom 4.4 million customers chose to follow Nordstrom on Pinterest (Pinterest, 2017).

Another successful social media campaign, launched by Dove in 2013, was called the "Real Beauty Sketches". The campaign used a short YouTube video in which an FBI-trained sketch artist was used to draw women first based on their own self-perception and then based on that of a stranger. The results from the sketches showed that the stranger's descriptions were more attractive and accurate while the self portraits revealed the women's insecurities. The video was designed to boost women's self-esteem by revealing how women undervalue their own beauty. The company anticipated that consumers would remember the positive emotions the video caused and associate them with Dove products. Uploaded in 25 languages to 46 Dove YouTube channels, the video achieved over 163 million views globally and became the most watched online ad in 2013 (Dove, 2017). Additionally, it was shared 3.74 million times across a variety of platforms and became the third most shared film of all time (Stampler, 2013). The video was able to successfully elicit a strong emotional response from viewers that resonated with the campaign's tagline "you are more beautiful than you think" (Dove, 2017).

Successful social media campaigns can also result in direct sales growth. One such example is Old Spice's “The Man Your Man Could Smell Like” campaign. The campaign created a recognizable character to act as the brand's spokesman who appeared in several personal videos as responses to comments on social media sites such as Facebook and Twitter from fans, bloggers and celebrities. About 186 videos were created which generated six million views and over 22,500 video comments (Donald, 2015). By the end of the campaign, their 
Twitter followers had increased by $2,700 \%$, Facebook fan participation had increased by $800 \%$, and their website traffic had increased by $300 \%$ (Baboushkin, 2013). With increased online interactions, Old Spice saw over 40 million views on YouTube and a 107\% increase in body wash sales within 30 days of the launch of the campaign (Donald, 2015).

Social media has become a critical area of interest for both marketing practitioners and scholars. The substantial volume of content generated and exchanged by online users, from individuals to organisations, creates exciting new research possibilities across varied disciplines, such as media and communication studies, sociology, psychology, information and computer science, linguistics and education (Weller et al., 2014). Diverse, high volume online data provides the opportunity to tap into the conversations and extract insights that may have significant implications (McCay-Peet \& Quan-Haase, 2017). Ideas and sentiments that are popular online can be examined and validated in traditional and contemporary research settings. While some findings may be platform specific, others may be applicable to multiple platforms increasing the scale of application. Researchers have used information on social media to understand consumer perception, gather ideas for product innovation and to share critical information (Fuller, Matzler, \& Hoppe, 2008). The importance of social media in research has already been illustrated by numerous studies. For example, the research by Kim, Bae, \& Kang (2008) demonstrated that online feedback helped digital product manufacturers in Korea to gain insight into customer needs, desirable features for new products, and trends for future development. Better understanding of consumers' online behavior has also been a critical topic for several researchers (i.e. Kim, Sung, \& Kang, 2014; Stieglitz \& Dang-Xuan, 2013). Other researchers have focused on particular groups or user type for their research. Uzunoglu \& Kip (2014) researched on the impact of online bloggers on business engagement while Roshanaei \& 
Mishra (2015) measure behavioral attributes of Twitter users to understand the nature of their positivity and negativity traits. With consumers embracing social media platforms, researchers and marketers are keen to learn about to the emergence and implications of different online platforms.

\subsection{Research Scope}

While research has been extensively conducted on a user's or brand's participation separately, research that combines the evaluation and contribution of both brand's and nonbrand's conversation in the digital space was not found during exploring the topic. Previous research has concentrated on analyzing online behaviour, consumer loyalty and trust, or brand community characteristics, among others. For example, Parrott, Danbury, \& Kanthavanich (2015) reviewed advocacy behaviour within luxury brand communities to analyze influencing power over purchase intention, while evaluating their impact on fashion brand love. On the other hand, Jothi, Neelamalar, \& Prasad (2011) analyzed the effectiveness of brand communication strategy in promoting and advertising their brand in social networking sites that were mainly accessed by Indian users. Similarly, Taecharungroj (2016) evaluated Starbucks' online strategy by categorising the types of content used to communicate with their consumer. These researchers focused on either the brand's perspective or the consumers' perspective. They do not combine the brand and non-branded voice within the online community and the contribution each makes to the conversation. This research attempts to fill the gap by combining both branded and nonbranded communication within one community. Understanding the difference between branded and non-branded communication may present useful information for marketers who seek to engage users through inexpensive yet convincing marketing communications strategy. It may 
also improve brand image and relations within the community (Kim, Sung, \& Kang, 2014).

Findings from the research may reveal ineffective customer interactions and encourage brand communications that foster customer loyalty and participation.

\subsection{Research Purpose}

The purpose of this exploratory study is to analyze tweets from a recognized, heritage apparel brand and categorize the data into a thematic framework to create an overall overview of all the content used in a single online platform. Using a grounded theory approach to content analysis this research classifies Twitter content into a six-category framework developed by Stephen Dann (2010) to identify the types of tweets that dominated the information flow online.

For the investigation, an online data analytic tool called Sysomos (2017) was used to gather information from Twitter. Dann's classification (2010) was used to categorize Twitter data to understand the contextual meaning of the messages. The categories were then assessed by generating automated themes and analyzing the results using qualitative methods. Existing literature on brand communication and customer engagement were applied to the findings to understand the Twitter content of Levi's jeans. Research methods adopted for the data collection the investigation and analysis drew from previous research on grounded theory and Twitter ( i.e Andéhn et al., 2014; Creswell, 2009) and future implications are mentioned based on the findings. 


\subsection{Research Orientation}

A study of epistemology enables researchers to understand what kind of knowledge is possible by identifying its nature and limits (Audi, 2014; Blaikie, 2010). Epistemology is concerned with the question of "what is regarded as acceptable knowledge in a discipline" (Bryman, 2015, p. 27). In qualitative research epistemological assumptions are based on the notion that within a paradigm social phenomena are so complex and intertwined that they cannot be reduced to isolated variables (Edwards, 2012). In this research, Twitter conversations are systematically analyzed, described, and interpreted. A grounded theory approach is used as an inductive methodology where patterns, categories, and themes are formed by arranging the Twitter data into increasingly more abstract units of information (Creswell, 2007).

Grounded theory has been defined as a set of procedures that allows researchers to build inductive theories with "successive level of data analysis and conceptual development" (Charmaz, 2005, p. 507). It is an exploratory process in which the theory is developed through a constant interplay between the data and the analysis phases (Corbin \& Strauss, 1990; Eriksson \& Kovalainen, 2016). Grounded theory is often regarded as a strong analytical strategy to generate theories or concepts out the available data (Bryman, 2015). However, the highly qualitative nature of the results created by grounded theory can make it difficult to present them in a manner that is usable in real life scenarios.

The data retrieved from Twitter will be examined to identify the categories that can be linked or grounded to the underlying themes of the data (Berg, 2009). A combination of manual and automated approach is undertaken for the research. For the manual process, coders manually 
categorized the tweets according to Dann's framework while automated techniques are used to deduce themes in each category. The automated techniques used in the software use algorithms to identify correlational patterns and provides a visual presentation of the correlations (Lai \& To, 2015). All the information used in this research is secondary in nature and there was no direct interaction with any of the online users for any part of the research. Thus, the data collection and analysis did not require an ethics review.

\section{Literature Review}

\subsection{Social Media}

Social media are "web based services that allow individuals, communities, and organizations to collaborate connect interact and build community by enabling them to create, co-create, modifies, share and engage with user-generated content that is easily accessible" (McCay-Peet \& Quan-Haase, 2017, p. 56). It encompasses modern technologies combined with established online practices whereby users exchange information and experiences. This definition also supports previous description of social media that explained it as "a group of internet-based applications that builds on the ideological and technological foundations of Web 2.0, and it allows the creation and exchange of user-generated content" (Haenlein \& Kaplan, 2010, p. 61). With the increase in ubiquitous internet access and modern hand-held technologies such as smartphones and iPads, social networking has become a staple of modern life. Individuals can enjoy constant connectivity through instant access to various social media platforms. 
Social media provides a diverse array of online platforms which include video/teleconferencing tools such as Skype, live-streaming platforms like Periscope and Blabb, image sharing platforms like Instagram and Flickr, ephemeral messaging application like Snapchat, to microblogging sites like Twitter and social networking sites like Google+, LinkedIn, and Facebook among numerous others (Gruzd, Staves, \& Wilk, 2012; Sloan \& QuanHaase, 2017; Stelzner, 2016). Individuals may use multiple platforms to connect with friends and family, stay informed with latest news and trends and gather information for nearly all aspects of life. A survey conducted in 2016 found that more than half of online adults use two or more social media platforms (Shannon, Andrew, \& Maeve, 2016). Users engage online to seek out the information that provides ultimate gratification and thereby fulfills their personal needs (Whiting \& Williams, 2013). Additionally, social interaction, information seeking, convenience and entertainment are some of the few reasons why people use social media. The rise of social media has made it possible for one person to connect with thousands or even millions of internet users, creating circulating or gathering information as they please (Mangold \& Faulds, 2009).

Social media, therefore, can be considered as a space for collaboration, sharing of information and experiences between existing customers and potential customers, and also among customers and retailers (Smith, Hernández-García, Peregrina, \& Hair, 2016). It comprises of users such as individual users, bloggers, online reviewers, e-commerce and news sites among many others that generate, circulate and utilize information about products, services, brands or current trends (Whiting \& Williams, 2013). It is used to educate others about major global issues as well as minor concerns that a user may want to share. Users like to share their experiences and feeling with their colleagues, friends, family and group or individual that they would love to compare themselves with (Darban \& Li, 2012). One of the main reasons people may share 
stories, news, and information is because they contain useful information (Berger \& Milkman, 2012). Sharing content online allows users to inform others of issues they care about, influencing opinions or encouraging action. It also helps them interact with other members who share their interests, advocate for a product, or cause and feel more involved in the world. Interactions in a virtual world can provide additional benefits beyond that of information exchange and dissemination (Tafesse, 2016). Individuals who are active online may seek self-expression and self-identification. Their involvement in the community creates a sense of being together and belonging to a group. It allows them to express themselves to others and feel self-fulfilled.

Consumers seek many types of information that can be used to satisfy their consumption needs. They are becoming increasingly dependent on their digital (and mobile) devices to make purchases. Search criteria typically includes a number of alternatives, price variations, significant attributes and performance of each alternative product (Babin, Murray, \& Harris, 2014). Consumers can make several pre-purchase searches to evaluate products and services from multiple online sources, giving them the capability to make informed decisions. Likewise, postpurchase, a consumer can voice their options to share their experiences or opinions.

Communication fluctuates from traditional and one-to-one or one-to-many approach to the many-to-many and many-to-one communications (Mangold \& Faulds, 2009). Information flow, therefore, increase exponentially, making social media platforms a valuable source of information to both consumers and marketers.

Consequently, marketers can no longer overlook the interactions among consumers. They must analyze, understand and positively influence consumers with online media and advertising (Dickey \& Lewis, 2011). According to Forrester's US Digital Marketing Forecast 2014 to 2019, 
spending on social media marketing will achieve an 18\% CAGR and may reach up to $\$ 17$ billion by 2019 from $\$ 7$ billion in 2014 (VanBoskirk, 2014). Successful use of social media can help marketers improve customer relationships, discover new opportunities, build brand trust, and promote positive word-of-mouth communication (Taecharungroj, 2016).

The evolution of social networking sites has given rise to a new e-commerce concept called social commerce (s-commerce). Social commerce is a blend of e-commerce with the use of social networking sites to carry out business transactions (Kim \& Park, 2013). It offers favorable opportunities for retailers to shorten the path to purchase for customers. Social networking sites are utilized to interact with consumers and execute online buying and selling of products and services. Facebook, considered as the most popular site for direct purchasing, incorporated the "Buy" call-to-action button on ads and posts which allows users to buy directly from a business, without leaving the networking site (Chahal, 2016; facebook, 2014). Similarly, Pinterest contains buyable pins that allow users to find and buy products without leaving their sites (Pinterest, 2017). While direct purchase might not be available for all types of social networking sites, social media platforms such as Twitter and Yelp utilize user ratings, recommendations, online communities, and social advertising to develop trust in their consumers (Pothong \& Sathitwiriyawong, 2016).

Research on WOM proved that external WOM sources have more influence on sales than company-generated WOM (Gu, Park, \& Konana, 2012; Rodgers \& Wang, 2011). Hence, social platforms enjoy a high degree of trust as product recommendations are non-commercially linked and are, therefore, regarded as more reliable than those on business-related websites $(\mathrm{Gu}$ et al., 2012). Building a trustworthy environment positively effects consumer's purchase 
intention which in turn facilitate business transactions (Casaló, Flavián, \& Guinalíu, 2007). The rise of social commerce has brought a new wave of opportunities for business as retailers can not only market their products but also make direct sells through social networks using shopping features such as a "buy" or "shop now" button.

Most social media advertising is less expensive than traditional advertising, so businesses don't have to spend a lot of money to reach bigger audiences in order to grow their business (Stieglitz \& Dang-Xuan, 2013). It provides real-time results and gives businesses the ability to learn more about consumers, potential opportunities and collect feedback (Tafesse, 2016). Having a strong and active social media presence may create an affable image where consumers evaluate brand through emotions and eventually identify themselves with the projected brand image. It promises an exponential reach with higher exposure and greater engagement through active communication.

\subsection{Online Brand Communities}

A brand community is a "specialized, non-geographically bound community, based on a structured set of social relationships among admirers of a brand"' (Muniz \& O'Guinn, 2001, p. 412). This definition supports the description from Internet pioneer Howard Rheingold (1993, p. $\mathrm{xx}$ ) who explained online communities as "social aggregations that emerge from the Net when enough people carry on those public discussions long enough, with sufficient human feelings, to form webs of personal relationships in Cyberspace." Online communities may be hosted by the companies or common users and have a neutral, low risk environment which gives the users the choice to voice their opinions, improve understanding and develop relationships with others 
(Quinton \& Harridge-March, 2010). Dialogue within that community is usually about positive qualities of brand or any conflicting matter that can harm the brand. The core focus of the online brand community is the brand itself and the community thrives due to information flow and the relationships among its members (Wirtz et al., 2013). Thus, each community is different depending on the brand, the users, and the platforms used.

When a brand community is formed, the brand becomes a form of identity for the brand community members (Popp \& Woratschek, 2017; Wang, Butt, \& Wei, 2011). Whether it is a positive feeling or a harsh criticism, members feel the need to share their experience with other community members. The need to share information is fueled by the desire to form connections and creates a sense of social attachment. Thus, membership in a brand community may lead to social identity and provides the members a distinctive sensation. Interactive communication may develop positive attitude toward the community as well as the brand, which, in turn, enhances the level of commitment to the community (Jang et al., 2007).

The members of the community may have little or no prior relationship with one another and in some platforms, may maintain anonymity if they desire. User hosted communities develop voluntary interpretation of the brand and create community characteristics that determine interactions, quality of information shared, trust, and leadership (Jang et al., 2007). The members' commonalities give rise to the community's practices, traditions, and a sense of obligation towards the brand. Within these communities, members may not only exchange information, but they may also develop friendships based on their common interest or passion. Desire for social interaction is said to be one of the reasons why members engage in content generation activities in online brand communities (Laroche, Habibi, \& Richard, 2013). Users join 
online brand communities to satisfy their psychological need for belongingness. Attachment between members can nurture strong bonds, which may evolve into offline activities (Quinton \& Harridge-March, 2010). Research by Dhanasobhon, Chen \& Smith (2007) and Chan \& Li (2010) demonstrated that online communities provide high levels of trust and emotional commitment which facilitate commerce. Their findings suggested that members' interest and desire to participate increases engagement and brand value.

Relationships in online communities are facilitated by the members' ability to trust in each other (Quinton \& Harridge-March, 2010). As more members with common interests share information it fosters a sense of loyalty to the product or brand (Jin \& Kim, 2006). Thus, the members may develop trust and devotion to the mutual interest of the community. Increase in trust mitigates the feelings of uncertainty that arise when information about the brand is unknown or scarce (Van Der Heijden, Verhagen, \& Creemers, 2003). The more the members trust each other the more they will trust the knowledge that is shared in the community. Thus, they may feel less indecisive in evaluating the information about the brand. Each time they have a positive experience with the brand based on the information received in the community, their relationship with the brand community grows stronger. The long-term survival of online brand communities depends greatly on its members' trust and continued participation in the community relationships (Brogi, 2014).

In their extensive research on traditional brand communities McAlexander et al. (2002) demonstrated that participation in communities leads to stronger relationships with the brand. Their research explained how community members derive a significant part of their understanding of the brand from the relationship they build with one another. They concluded by 
demonstrating that members who are highly involved in a brand community are psychologically devoted in the company's welfare and inherently want to contribute to its success. High engagement and loyalty in brand communities, therefore, may ensure a "continual stream of business throughout a customer's lifetime" (Smith, Hernández-García, Peregrina, \& Hair, 2016, p. 26) . Research on Twitter communities by Kwon, Kim, Sung, \& Yoo (2014) concluded that members that actively communicate about brands and are receptive to advertising will have positive attitudes towards brand communications.

Involvement in online brand communities may also directly affect consumer purchase behavior. Product reviews, experience stories or brand familiarity shared within the community influences consumer's opinion or attitude towards the brand. Information gathered online are from various groups of people, not only from acquaintances (Darban \& $\mathrm{Li}, 2012$ ). This reduces source biases, making the information more credible with which consumers can make their purchase decisions. Positive information received from online communities, therefore, may reduce uncertainty and has a positive influence on consumer purchase intention (Duan, Gu, \& Whinston, 2008; Khan, Ramzan, Shoaib, \& Mohyuddin, 2015).

In sum, members with strong online brand community commitment usually have stronger brand commitment and they may become engrossed in the successes and failures of that brand (Shih-Tse, Lily, Chen, \& Tsai, 2012; Wirtz et al., 2013). Online communities demonstrate greater social connections and stronger reciprocal relationships than both brand and consumption communities (Kim, Choi, Qualls, \& Han, 2008). Such commitment can manifest in several ways, including a willingness to support the brand against competitors or defend it from any criticism (Wang, Butt, \& Wei, 2011). 
Companies can leverage the discussion in the communities to help with new ideation, strategic withdrawal or possible product modification or evolvement (Adjei, Noble, \& Noble, 2010; Andersen, 2005; Chou, Yang, \& Jhan, 2015). Online communities can also be treated "as individual market segments that are of interest in their own right and may be of noteworthy size" (Kozinets, 2002, p. 70). Online brand communities, therefore, act as a data source from where marketers can assess the opinions of their brand or strategy. From a marketer's perspective formation of brand communities is a cost-effective way to gather consumer opinions, build trust, rapidly disseminate information, and maintain connections with consumers (e.g. Kim, Choi, Qualls, \& Han, 2008; Laroche, Habibi, Richard, \& Sankaranarayanan, 2012; Thomas, Peters, \& Tolson, 2007)

\subsection{Online Consumer Engagement}

With the growth of social media, marketers are increasingly recognizing its potential to foster consumers' participation and information sharing about brands (Kim, Sung, \& Kang, 2014). In tradition consumption community, engagement marketing can improve the experience of the core offerings and positively affect long-term customer relations (Harmeling, Moffett, Arnold, \& Carlson, 2016). Online engagement has been defined as "a cognitive and affective commitment to an active relationship with the brand as personified by the website or other computer-mediated entities designed to communicate brand value.” (Mollen \& Wilson, 2010, p. 923). Through consumer engagement marketers aim to create a relationship that will transcend the regular purchase behavior. They try to tap into consumers' psychological and behavioral inclination to interact positively with brands and other consumers in social media (Tafesse, 2016). 
Consumer engagement may also act as an initialization to join a brand community (Wirtz et al., 2013). These communities act as an additional communication channel and create an opportunity to connect with devoted members (Jang et al., 2007). Positive experiences from these interactions help to strengthen the relationship with the brand and nurture brand identity (Swani, Brown, \& Milne, 2014). These experiences increase the interest to participate and preserve of the essence community. Engaging with the brand may foster devotion and establish a relationship based on trust. Customers may then dedicate cognitive, emotional or physical resources based their brand interactions (Hollebeek, 2011). Thus, consumer engagement involves a motivational need that leads to increased interaction in online brand activities. Additionally, specific behavioral and cognitive responses, such as "liking" and "commenting" or creating brand specific content may also trigger the need to engage online (Tafesse, 2016). Members share their experience, join discussion groups, debate issues or express their sentiments. Therefore, cognitive and social benefits motivate members to improve interactive communications with the organization leading to increased brand engagement (Zailskaite-Jakste \& Kuvykaite, 2012).

Engagement in these communities may create a sense of loyalty to the brand. Active engagement in the community in the form of membership continuance, contribution, exchanging recommendations with other community members may transform into brand devotion and customer advocacy (Wirtz et al., 2013). According to Brodie et al. (2013, p. 110) engagement in online communities can be focused at the brand or at other community members and it develops through five stages, namely, learning, sharing, co-developing, advocating and socialising. Therefore, as members moves through these stages their relationship with the brand becomes stronger. 
Companies effort to engage consumers is motivated by several benefits provided by these virtual communities. Engagement in social media helps the company to promote the name of organization or brand, facilitate loyal online community, and gather insights on consumer experience or expectations (Zailskaite-Jakste \& Kuvykaite, 2012). It provides them with the opportunity to connect with customers using richer media with greater reach at anytime and anywhere (Sashi, 2012). The relationship formed on previous experiences with the organization give rise to consumer engagement. Persistent engagement within a community allows organizations to maintain continuous dialogue with its consumers by utilizing the connectivity, delivering new content and sharing serviceability of social media (Cabiddu, Carlo, \& Piccoli, 2014).

Stronger engagement positively influences customer attitude towards the brand. In their research "Impacts of Luxury Fashion Brand's Social Media Marketing on Customer Relationship and Purchase Intention,” Kim and Ko (2010) demonstrated that social media marketing has positive effects on customer relationships and purchase intention. Engagement can be measured through emotional attachment, interest and dialogue within the community (Brodie et al., 2013). Customer engagement behaviors such word-of-mouth recommendations, blogging and writing reviews are also measures of successful engagement (Wirtz et al., 2013). Additionally, the presence of social media measuring tools also enables organizations to measure engagement rate by calculating number of interaction to the posts (likes, shares, comments or brand mentions) divided by the number of posts from the brand or the number of followers (Coelho, Oliveira, \& Almeida, 2016; Drula, 2012). Consumer engagement in online communities is a continuous interaction between a company and its consumers which may be beneficial for a brand as it 
ensures constant communication and may enhance brand equity measures such as brand awareness, brand associations and brand loyalty (Zailskaite-Jakste \& Kuvykaite, 2012)

With real time access to online information, consumers now can easily seek data about competing brands. They can retrieve or share information anytime, anywhere, which provides them with more choices and a convenient way to voice their opinion. The power to control the brand image is shifting from businesses to consumers due to numerous ways of interaction amongst consumers or companies and consumers (Darban \& Li, 2012). This compels businesses to interact with the consumer to ensure that a positive image of the brand is communicated in their conversations. Additionally, content generated by online users also increases brand communication due to its perceived unbiased that increases message credible and trustworthy. (Schivinski \& Dabrowski, 2015). Therefore, while communication from the brand may increase brand awareness, user-generated content is more effective in creating brand loyalty and brand identity. Marketers strive to tap into the communication process and engage consumers by utilizing user-generated content to accomplish marketing goals. For example, online retailers such as Amazon and eBay invite consumers to write product reviews and have developed their businesses on a reputation raking system based on buyers' and sellers' comments (Rodgers \& Wang, 2011).

Research on online apparel purchases indicated that businesses that create a familiarity with the brand among consumers experiences increased purchase intention (Park \& Stoel, 2009). Additionally, engaged consumers have a stronger attachment to the brand, which typical leads to them serving as brand advocates (Sashi, 2012). Thus, marketers need to actively engage with 
consumers online so that they willingly contribute to a brand's marketing function, going beyond financial patronage (Harmeling, Moffett, Arnold, \& Carlson, 2016)

\subsection{Twitter for business/marketing}

Twitter was first launched on 2006 as an interactive social media platform that allows its users to post short messages. Since the launch, Twitter's influence has continuously expanded with approximately 313 million active users at the end of January 2017 (Twitter, 2017). A recent study found that $42 \%$ of Twitter users are daily visitors while $23 \%$ visit their account more than once a day (Shannon et al., 2016). Tweets are short messages with limited characters and are used to broadcast and discover topics of interest on a large-scale network in real time (Boyd, Golder, \& Lotan, 2010). At the time of this research, each tweet was limited to a maximum of 140 characters. These short messages allow users to keep in touch with each other easily and to share opinions with possible hyperlinks and attached photos. Such Popular tweets are retweeted frequently and can be used to reinforce a message as they are repeated among groups of users who are strongly connected (Boyd, Golder, \& Lotan, 2010)

Twitter, essentially used to disseminate information, gradually became a powerful marketing channel for businesses (Vargo, 2016). Compared to traditional media such as television or radio, Twitter has very low-cost offering a reach of over 1,000 people for less than \$3 (Singh, 2016). Businesses can incorporate traditional marketing campaigns with Twitter campaigns and evaluate their success rate with the network's analytic tool. Like other social platforms, marketing campaigns on Twitter can be modified if required and brand strategies can be adjusted to match potential customer's behavior (Zhang, Jansen, \& Chowdhury, 2011) 
Twitter enables businesses to engage directly with their consumers on a one-to-one basis or one-to-many basis. One-to-one interactions through private messages, retweets or replies encourages interpersonal communication with individual users (Taecharungroj, 2016). Communications in Twitter is also a potentially rich eWOM venue for companies to evaluate their brand strategy (Zhang, Jansen, \& Chowdhury, 2011). Tweets posted are in real-time due to which marketers can instantaneously know what is being said about the brand. This gives them an opportunity to understand consumer opinion and make appropriate changes to their online marketing activities.

Twitter campaigns can be used to leverage the relationship with followers, change brand perception, and boost sales. Starbucks with its 11.9 million followers on Twitter has become an exemplary model for "social media excellence in the corporate world" (Twitter, 2017; Wakefield, 2012). In 2013, Starbucks launched a Twitter campaign called "Tweet-A-Coffee" through which customers could share $\$ 5$ gift card with their Twitter friends and followers. Within five weeks, the campaign not only increased Starbucks' reach by 54,000 users but also generated about $\$ 180,000$ of sales by 27,000 retail consumers (Radhakrishnan, 2016). Successful campaigns may provide several benefits such as generating in store traffic, strengthening bonds with consumers, identifying potential leads and foster a positive perception of the brand (Saladino, 2012).

Gruzd \& Wellman (2014) indicated that Twitter offers multiple ways in which brands can influence online users. This includes direct communication, use of hashtags to link communities of shared interest, and retweets to increase information sharing. Therefore, marketers can use Twitter as responsive channel for replies and queries or an interactive platform where they can 
use hashtags, retweets and brand specific URL to promote positive brand image (Taecharungroj, 2016).

Twitter has faced some criticism where practitioners considered the platform as a temporary hype which is not so useful for business marketing purposes (Bulearca \& Bulearca, 2010; Dann, 2010). Several articles presented Twitter as failure, representing its inappropriateness as a marketing tool due to mishandling of information and time required to develop trust and relationship with consumer. The volume of personal or unverified information limits the value that Twitter can add to a business (Dann, 2010). However, with consistency, commitment and a clear understanding of its objective, Twitter campaigns can be strategically implemented to yield desired results (Taecharungroj, 2016).

With the increase in the use of social media and microblogging, Twitter gets new content every day. Thus, information accumulated is anticipated to be broad and informative. Networks on Twitter do not depend on person to person interactions and users generally have more followers than they are aware (Gruzd, Wellman, \& Takhteyev, 2011). This means there is an asymmetric connection among users where one user may follow another without being followed in return. Moreover, Twitter's @Username and hashtag features act as communicative channels that helps to interact, connect, and thus increase a user's social network. Twitter provides the facility to track trends with the help of hashtags and retweets. In addition, Twitter offers diverse audiences ranging from individual users to marketers, celebrities, reviewers etc. As result, varied information can be gathered from distinct social and interest groups in different countries (Pak \& Paroubek, 2010) . 


\subsection{Apparel Industry and Jeans}

The product selected for the study is jeans. A product from the apparel industry was chosen because clothing brands have created an enormous presence across different online platforms like Facebook, Twitter, Instagram and Pinterest. The global fashion industry is estimated to be worth over US\$ 1.75 trillion and most of its consumers are active on social networking sites (Maloney, 2015). Leading retailers in the industry are incorporating digital technologies and the industry has become a tech-driven, omni-channel marketplace. These retailers are collaborating with multiple social media platforms to introduce new features. For example, online platforms like Facebook, Instagram, Twitter, and Pinterest have experimented with and are introducing purchasing tools through which users can directly purchase from the social media platforms. Additionally, with the rise in digital devices and mobile technology the number of social commerce users is expected to experience exponential growth by 2021 when mobile commerce will account for almost two thirds of total digital purchases value (Euromonitor International, 2017a). Brands continue to invest in online marketing and consumer engagement via social media, on the other hand online consumers use social media to discuss the brands and their activities (Euromonitor International, 2017a). Currently, fashion labels are constantly discussed in social media leading to massive conversation data that can be extracted for the research (Song, Hwang, Kim, \& Kwak, 2013).

Jeans is selected, as it remains one of the main choices for most people due to its comfort, hardwearing, and ability to be glamourized or deglamorized. It represents a constant staple of the wardrobe and are available in daily go-to versions as well as fashionable, dressed-up versions of jeans. Even though the product is facing a lot of competition due to a shift in 
consumer preferences to the athleisure trend, it is still expected to have market growth at a compound annual growth rate (CAGR) of 2\% at constant from 2016 to 2021. (Euromonitor International, 2017b). To compete with the athleisure trend, the jeans category is going through a metamorphosis shifting their focus from regular, casual jeans to stylish, great fitting and stretchy jeans. This transformation is achieved through innovation in fabric and design that matches current trends (Euromonitor International, 2016).

Trends vary significantly with age and gender. According to Euromonitor International (2016), older consumers provide a stable base for traditional denim and exhibit more interest in luxury apparel. Younger customers prefer fashionable, skinny and stretchy jeans and are more inclined towards lower-price segments due to the inability to differentiate between super premium and inexpensive economy and standard jeans. As a result, jeans by fast-fashion retailers such as H\&M and Forever 21 recorded growth in 2016 due to their fashionable yet low-cost jeans offerings (Euromonitor International, 2017b). Thus, it is expected that the consumer range will be broad for the product. In the US, Jeans is expected to remain one of the leading choices for a "bottomswear" product with manufacturers, retailers and fashion experts promoting it as an essential fashion product, which may create an interest in fashion-savvy consumers. Additionally, when consumers increased their investment in jeans again, the category displayed slight growth in 2016 after experiencing declines for two years (Euromonitor International, 2017b). 


\section{Methodology}

This research uses content analysis with Dann's classification (2010) to study the communication of an apparel brand community on Twitter. A grounded theory approach was used for this qualitative research to systematically analyse messages in the brand community. The brand was selected based on availability, market share, and familiarity with consumers. Twitter data for one year was retrieved using a social media research tool, Sysomos Map (Sysomos, 2017). The data gathered was cleansed to remove incorrect or incomplete messages before analysis. Due to comparatively low number of tweets from Levi's account, all the tweets posted from their account were used in the branded communication analysis. On the other hand, a random sample was pulled from the remaining data, which functioned as the non-branded voice within the community. Using the categories specified in Dann's (2010) classification the data was then manually coded. The categories that had the highest number of tweets for branded and non-branded communication were then systematically assessed using multiple programs suited for qualitative analysis. Findings from the research are based on manual and automated analyses where the data was subjected to several assessments to triangulate the results.

\subsection{Brand Selection}

For this research the brand selected was Levi Strauss \& Co. Levi’s was the leading company in jeans industry in 2016 with an $11 \%$ market share in US (Euromonitor International,

2017b) The company retained its number one position with respect to market share even with a $2 \%$ decline in value terms. It identifies itself as a heritage brand because it draws inspiration from over one hundred and fifty years of manufacturing experience (Levi Strauss \& Co, 2017). It 
evokes nostalgia by using products from the past to create contemporary designs. The brand focuses on longevity, creativity and innovation. As a heritage brand, Levi's has managed to build a long-term brand reputation by emphasizing its long lineage and product quality to create an emotional connection with customers.

Additionally, it opted for mid-market positioning with the price-value for their jeans ranging from economical to premium jeans (Euromonitor International, 2017b). This ensures that the brand caters to all age groups. Furthermore, the brand has successfully created a social media presence online to communicate with millennial consumers. Millennials exhibit the willingness to spend on clothing and are more aware of the latest fashion trends. Levi's aimed enter their digital lives through social sites to promote its product using latest fashion trends and styles. It is active on several social media platforms such as Facebook, Twitter, Instagram, YouTube, Tumblr and Pinterest. The company shares information about new products, events, or news related to the brand. Additionally, it regularly posts pictures of their products, retail stores, or even celebrities wearing their products to increase brand recognition and promote sales. On Twitter, the brand generates hashtags such as \#LiveInLevis and \#iamlevis aiming to create buzz among the hashtag generation. Activity on Twitter can be viewed as a part of integrated market campaign as the brand works on different social media platforms simultaneously to promote their products.

\subsection{Content Analysis}

Content analysis is "careful, detailed, systematic examination and interpretation of a particular body of material in an effort to identify patterns themes biases and meaning” (Berg, 
2009, p. 338). Typically, content analysis focuses on the contextual meaning of the data with an emphasis on what is said or implied. Thus, with content analysis not only the manifest content can be examined to study the apparent subject of the corpus but latent content can also to examined to understand the underlying meaning that lie beneath the superficial surface (Bryman, 2015).

Scholars and researchers use content analysis to study communication messages and develop "inferences concerning the relationship between messages and their environment" (Weare \& Lin, 2008, p. 272). Through systematically analyzing texts researchers can use qualitative content analysis to classify their data into meaningful categorization and recommend valid inferences by interpreting and coding textual material (Pennington, 2017). Content analysis is a highly flexible method and can be applied to different kinds of unstructured textual data (Bryman, 2015). As a result the method has been used by a wide range of disciplines including communications, psychology, sociology, business, art, organizational theory, and political science (Berg, 2009; Weare \& Lin, 2008). It can be adopted to both online and traditional forms of communication.

Researchers can gain a holistic and factual description of the contents by systematically analyzing the text. Content analysis using a grounded theory approach involves studying textual data and identifying variables or themes and their interrelationships. It categorizes data into themes, which may be used for verifying theories. The process involves data collection, systematic coding of text, categorization, identify and examine isolated meaning patterns and report results (Berg, 2009). Coding procedures aim to discover connections between themes and develop explanatory model during their search for the themes (Murthy, 2017). As a research, 
method content analysis provides several advantages. It allows both qualitative and quantitative analysis and is relatively cost effective (Berg, 2009). In addition, it does not require interaction with message source as researchers can utilize the data to gain insight into complex models of human thought and language use. One key limitation of content analysis is that some steps may involve human subjective interpretation (Lai \& To, 2015). Coders must draw upon their knowledge and expertise to interpret and code the materials, which may influence process. The analysis may, therefore, be subject to issues of reliability and validity.

To decrease the amount of human dependency researchers are utilizing computer aided tools for content analysis. These sophisticated tools help to restructure, analyze and find insights in unorganized or qualitative data (Lai \& To, 2015). The software can work with large, unstructured data while decreasing the risks of human errors. Based on algorithms and statistics different types of software packages are available for content analysis. The functions differ in each program, ranging from word counts to conceptual network building (Berg, 2009). In social media, information is constantly added resulting in massive data that are available for research. Researchers may utilize computer-aided content analysis on customer reviews, advertisements, or other big data to organize, analyze and find insights in unstructured, or qualitative data. This research used the latest version of NVivo 11 Pro and Leximancer to gain richer insights and understand the relationships, if any, between the different categories suggested in Dann's classification (2010).

Dann's Classification was selected as the coding schema as its main focus is on a detailed content of the Twitter corpus. Other schemas examined for the content analysis emphasized more on content source or subject matter classification. Table 1 compares different coding schemas 
examined for the thesis. The coding manual developed for the content analysis shown in the table were specific to the research questions and platforms under study. For example, the coding schema used by Lovejoy \& Saxton (2012) was based on posts from organizations and therefore would not be applicable to this research. As a result, Dann's Classification was selected as it focused on content analysis in the context of Twitter and could be applied to understand branded and non-branded conversational within the virtual space

\begin{tabular}{|c|c|c|}
\hline Research & Coding Schemas & Analysis \\
\hline $\begin{array}{l}\text { Lovejoy \& } \\
\text { Saxton (2012) }\end{array}$ & $\begin{array}{l}\text { Messages by organizations were } \\
\text { used to develop the coding schemas }\end{array}$ & $\begin{array}{l}\text { Classification on the basis of the } \\
\text { organization posting the tweets }\end{array}$ \\
\hline $\begin{array}{l}\text { Nishioka, } \\
\text { Scherp, \& } \\
\text { Dellschaft } \\
(2016)\end{array}$ & $\begin{array}{l}\text { Used three classification } \\
\text { approaches: hashtag classifier, } \\
\text { machine classifier \& human } \\
\text { classifier }\end{array}$ & $\begin{array}{l}\text { Compared automated analysis } \\
\text { with human annotators for } \\
\text { classifying tweets. }\end{array}$ \\
\hline Tafesse (2016) & $\begin{array}{l}\text { Brand experience literature used to } \\
\text { develop coding manual with } \\
\text { operational definitions and relevant } \\
\text { examples }\end{array}$ & $\begin{array}{l}\text { Analysis emphasised experiential } \\
\text { content of Facebook messages }\end{array}$ \\
\hline $\begin{array}{l}\text { Rosa et al. } \\
(2011)\end{array}$ & $\begin{array}{l}\text { Popular hash-tags were categorized } \\
\text { in six topics: News, Sports, } \\
\text { Entertainment, Science, } \\
\text { Technology, Money, and "Just for } \\
\text { Fun" }\end{array}$ & $\begin{array}{l}\text { Clustered tweet topics using } \\
\text { hashtags as indicators of topics }\end{array}$ \\
\hline Dann (2010) & $\begin{array}{l}\text { Developed codes based on detailed } \\
\text { descriptions of the prior research } \\
\text { paper's different content categories }\end{array}$ & $\begin{array}{l}\text { Analysis focused on the tweet } \\
\text { content to categorize the data } \\
\text { accordingly. }\end{array}$ \\
\hline
\end{tabular}

Table 1. Coding Schemas from Literature 


\subsection{Dann's Classification}

To classify online tweets Dr. Stephen Dann combined sixteen existing Twitter studies with his own research, creating a six-category framework. This framework comprises six categories: 'conversational', 'status', 'pass along', 'news', 'phatic' and 'spam'. In his research Dann (2010) shows that Twitter content can be considered more than either "serious business" or "conversations about nothing" (Dann, 2010). The broad, 6-category classifications are further divided in to 23 specific sub categories. Each of the sub-categories provide richer insight about the Twitter conversations. Using Twitter data for approximately 2 years from his own timeline Dann created the six categories described below

\subsubsection{Conversational}

Conversational content comprises of all the tweets that are direct interactions between two or more users. It uses the “@username” to address the designated users. Additionally, tweets ending in questions are also categorized at conversational. Conversational content is therefore based on the reciprocity between Twitter users and their followers (Dann, 2010). Conversational Category is further divided into four sub-categories. These were:

1. Query-Messages with questions, question marks or polls

2. Referral - @ response, which contains URLs or recommendation of other Twitter users.

3. Action- Activities involving other Twitter users

4. Response - Catch-all classification for conversation @ tweets 


\subsection{2. $\quad$ Status}

Tweets that indicates current state or activity is referred as status. Therefore, any statement that contains personal sentiments, expresses present activity or recent action are placed under this category (Dann, 2010). Dann also grouped comments regarding user's location, time, work or mechanical experience as sub-category for Status. There are eight subcategories under Status, making it the most diverged category in the framework. The subcategories are listed below:

1. Personal- Personal status that conveys positive or negative emotion

2. Temporal- Messages containing reference to dates, location or time-based statements such as "waiting" and "time to".

3. Location-Tweets with geographic references and location statements

4. Mechanical- Tweets relating to any form of technology or mechanical systems

5. Physical- Tweets expressing bodily/physical sensations

6. Work- Status referencing to any work-related activity

7. Automated-Automated status updates prompted by third party applications such as software or games

8. Activity- Tweets stating user's current activity.

\subsubsection{Pass Along}

According to Dann (2010), Pass Along can be sub categorized into retweets, sharing user generated content, and endorsement of other contents with full length or shortened URL. This category "recognize[s] Twitter as a distribution channel for personally created content" as well 
as its ability as a message diffusion channel (Dann, 2010). The Pass Along category has three subcategories

1. RT-Tweets formed by replicating another Twitter status using the via @ or RT protocol

2. $U G C$ - tweets containing links to content created by the user (blog/video/picture)

3. Endorsement-Messages with links to web content that was not created by the sender

\subsubsection{News}

Mainstream media issues, events, live coverage, online news and other identifiable news are referred as news content (Dann, 2010). In this category, Dann (2010) removed any retweet or rebroadcasted news have been classified under the Pass Along category.

1. Headlines- Tweets reporting breaking news and eye-witness narratives of news events

2. Sport- Content comprising of results from sporting events

3. Event- Tweets broadcasting Live of identified or identifiable event

4. Weather- Messages stating weather conditions

\subsubsection{Phatic}

Tweets that represent the connected presence between users in a network without any specific theme are categorized as Phatic communications. These are usually directed to the entire Twitter community instead of an individual or organization and transmit random thoughts (Dann, 2010).

1. Greeting- Greeting statements for the general Twitter community

2. Fourth wall - Textual equivalent of comments made directly to camera in television or cinema 
3. Broadcast- Tweets stating undirected statements of opinion or monologue

4. Unclassifiable- Tweets that can be classified

\subsubsection{Spam}

Spam comprises of junk posts or automated posted that can be classified as unethical or malware (Dann, 2010).

Dann developed the framework using his own Twitter account. Therefore, the categories were designed based on an individual timeline and was not generalized for several users. Twitter users may have different usage styles and therefore the categories may need to be refined to obtain more reliable results. Additionally, during research it was found that theories suggested by Dann (2010) have been used in medical research and the categories formed have not been applied to business or fashion brand context.

\subsection{Analytical software application}

\subsubsection{Sysomos Map}

Sysomos Inc., developed as a result of academic research at the University of Toronto, can extract information from more than 500 billion online conversations. With access to Twitter handles from over 189 countries, Sysomos offers real-time and historic data for one year (Sysomos, 2017). Data can be provided in 186 languages and allows Sysomos users to broadly investigate online communications, communities and central users, i.e. influencers. The specific application used for this thesis is called Sysomos MAP (Sysomos, 2009). Sysomos MAP is a social media research engine that provides comprehensive insights into users and their 
conversations. It offers access to data from Twitter, Facebook, Instagram Tumblr among others. Custom filter option allows to filter the search by location, language and other demographics. Sysomos MAP can be used to provide insights into how Twitter communities form and interact and who are the top influencers on specific topics across different communities. It can also identify trends over time and investigate the topics that causes conversations spikes.

One crucial aspect for online data retrieval is the presence of spam. However, Sysomos uses a 4-step spam-filtering to segregate spam from actual content, discarding nearly $40 \%$ of the contents it receive from various social media platforms (Sysomos, 2017). For this research, access to Sysomos Map was available through a partnership between Ryerson University and Sysomos Inc.

\subsubsection{Tableau}

Tableau 10.2 is an interactive data visualization software that provides instantaneous insight by converting data into visually appealing, sharable dashboards (Tableau, 2017). The software offers automated exploration of large datasets without data coding or programming. Furthermore, the data types can be modified by splitting, joining, blending information, and optimizing the results received. Multiple data sources can be used to aggregate data and bring in additional information for the analysis. Researchers can also filter or exclude required data during analysis to achieve precise insights. Additionally, the software offers drag-n-drop interface to create interactive reports, which enables the users to communicate complex ideas with ease. 


\subsubsection{NVivo 11 Pro}

NVivo 11 Pro is a data analysis software that that supports qualitative and mixed methods research (QRS International, 2017). The software can work with data from various sources such as interviews, focus group, open-ended survey responses, articles, social media and web content. Social media content can be collected through its "add on" web extension called Ncapture, which gathers data from online platform such as Twitter, Facebook, and YouTube.

NVivo 11 was mainly designed for qualitative researchers to organize, examine unstructured or qualitative data and discover insights through both manual and automated text analysis and visualization. Exact words or keywords with similar meaning can be examined using its powerful search options (Gruzd, Mai, \& Kampen, 2017). This provides researchers the opportunity to detect connections and links within the corpus that would be difficult to identify manually. Additionally, the software offers query tools that empower researchers to learn trends or recurring ideas in the data set

\subsubsection{Leximancer}

Leximancer is a visual text analytic technique that can be utilised to detect themes based on the co-occurrences of words across a textual data source. The software identifies the characteristic distribution of words and how they relate to each other. It uses occurrence and cooccurrence of key terms to process thematic conceptual model from the corpus provided (Smith, 2017). Conceptual maps formed by Leximancer illustrate the themes and concepts in the form of circles and dots, where circles represent key themes in the data while the dots represent individual concepts. Each theme is associated with a subset of related concepts based on co- 
occurrence and repetition of words. These are delivered as visual "concept map" outputs that links several themes together. Different concepts can be classified under one theme based on inter-concept relatedness. The themes are presented in the form of a heatmap to indicate importance. As a result, the most important theme is shown in red, the second in orange and so on. The positioning of the circles and dots, as well as the distance between them demonstrate how concepts relate to one another. Thus, if two concepts are in close proximity then they have a stronger semantic relation (Leximancer, 2017). Similar concepts can be grouped together under the most prominent concept of the theme group.

Concepts can be analyzed using name-like and word-like concepts that are ranked by their frequency of occurrence in the corpus. The ranking contained that count relevance of each concept. Count relevance which is an indicator of the relative strength of a concept's frequency of occurrence (Leximancer, 2017) This means that the concept ranking indicates the relevance of the concepts in accordance to their occurrence in the corpus. The interactive features of the software enable researchers to explore all the messages that contributed to the creation of the concept. Thus, all related concepts can be thoroughly analyzed to understand the formation of the theme. 


\subsection{Research Design}

The methodology used in this research was adapted by a process outlined by Creswell (2009), shown in Figure 1, where he suggests an upward hierarchical approach for qualitative data analysis. Additionally, it incorporated Dann's classification (2010) to categorise the data while multiple computer-aided software was used for data analysis and to triangulate results. The research methods used for the research is explained in the following sections.

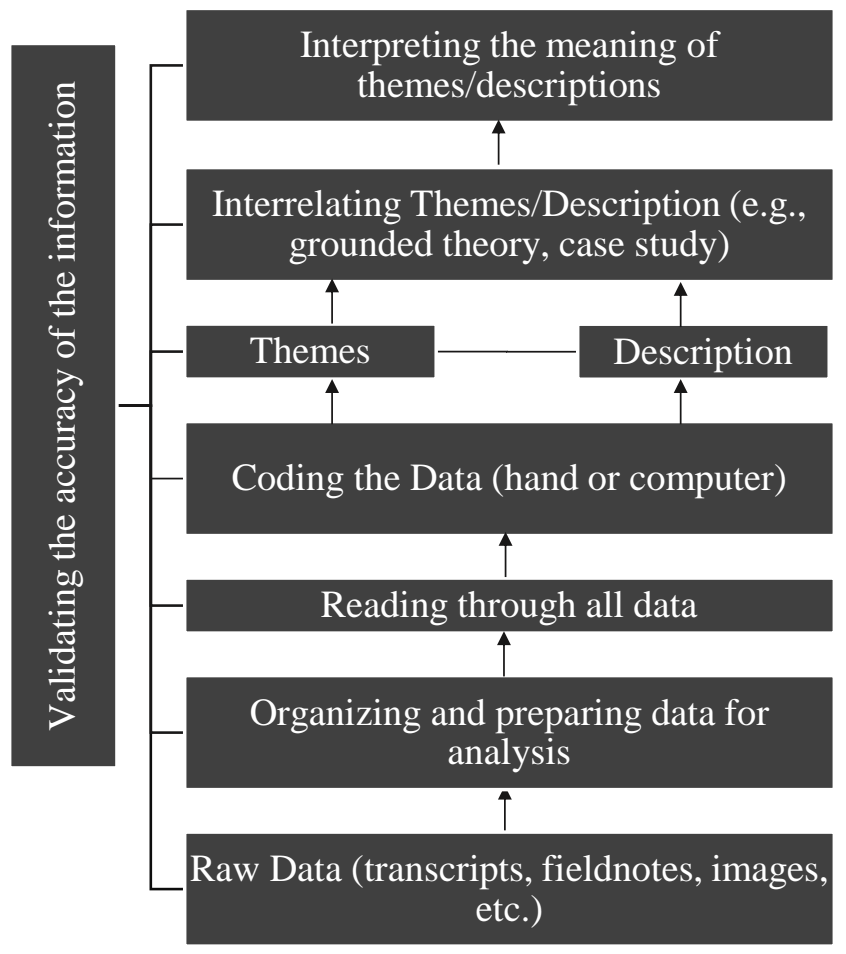

Figure 1. Data Analysis in Qualitative Research (Creswell, 2009, p. 185) 


\subsubsection{Data collection}

Raw data was collected using Sysomos Map. It comprised of messages from January 12, 2016 to December 20, 2016 and was restricted to USA only. A detailed Boolean search was created for Levi's to ensure that the search contains every possible way a user can type the brand name. To eliminate the possibility of missing any relevant content, multiple spelling was also used in this process. This reduced the possibility of missing out any post due to a spelling error. Additionally, brand specific hashtags and “@” signs were also included. A special feature of Sysomos MAP allows its users to input key search terms that might improve the search results. The terms "jeans" OR "jean" were used to ensure that the results are for conversations on jeans and not on other types of apparel. The Boolean used for data collection is given below:

$$
\begin{aligned}
& \text { "Levi’s" OR "Levis" OR "\#LEVIS" OR "@LEVIS" OR “\#LEVI’S” OR "LEVIS denim" } \\
& \text { OR "levis jeans" OR "LEVIS jean" OR "LEVI" OR "LEVI jeans" OR "LEVI DENIM" } \\
& \text { OR "\#LEVI" OR "@LEVI" }
\end{aligned}
$$

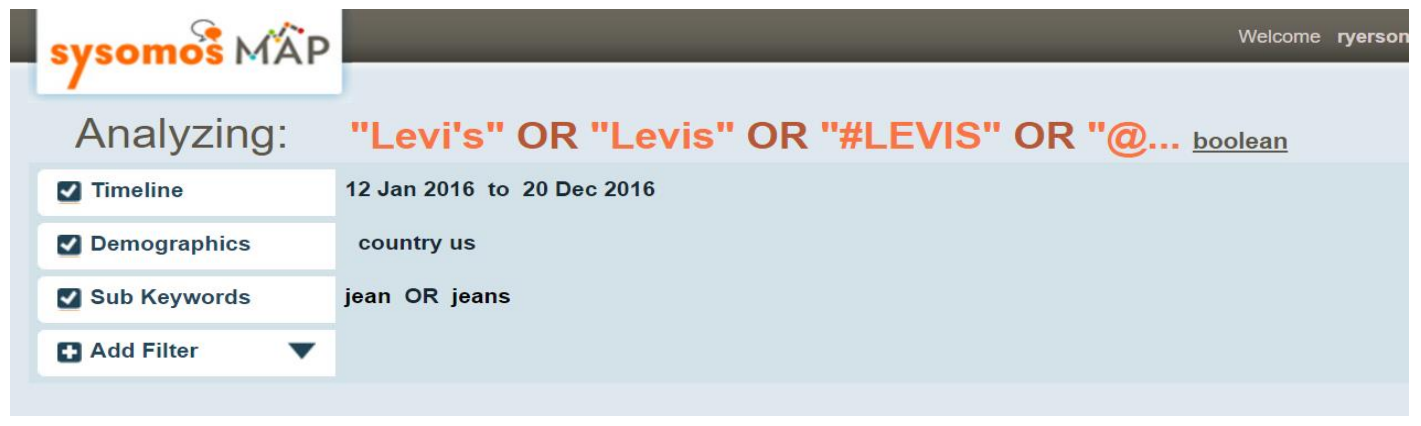

Figure 2. Preview of Boolean search for Levi's on Sysomos MAP

The data collected contained the link the to the tweet, tweet time, authority score, number of followers, number the account is following, location, content, unique id for each tweet and the author name as illustrated in Table 1 . The link to the tweet is the url of the tweet which can take 
to the tweet page. It is followed by the time and date on which the tweet was posted and the authority score. Authority score indicates the degree of engagement and influence of the Twitter handle and is automatically calculated by Sysomos on a scale from 0 to 10 . The higher the score of a user, the more authority that the user has over the community. The authority score is followed by the number of people that are following the user's account and the number of people that the user is following. Similar to the authority score, a higher number of followers means that the account has a bigger reach. Lastly, the data included the location as indicated by the Twitter account, the message, unique tweet id and the name of the account.

\begin{tabular}{|l|l|c|c|c|c|c|c|c|c|c|}
\hline host & link & time & auth & follower & following & country & location & content & uniqueid & $\begin{array}{c}\text { auth } \\
\text { name }\end{array}$ \\
\hline $\begin{array}{c}\text { http://t } \\
\text { witter.c } \\
\text { om/use } \\
\text { nname }\end{array}$ & $\begin{array}{c}\text { http://twitter } \\
\text { com/accou } \\
\text { ntname/stat } \\
\text { uses }\end{array}$ & $\begin{array}{c}2016- \\
12-20 \\
00: 10: 2 \\
3\end{array}$ & 6 & 876 & 453 & US & $\begin{array}{c}\text { Boston } \\
\text { MA }\end{array}$ & $\begin{array}{c}\text { Jeans } \\
\text { gotta be } \\
\text { Levi }\end{array}$ & $\begin{array}{c}8.11001 \mathrm{E} \\
+17\end{array}$ \\
\hline
\end{tabular}

Table 2. $\quad$ Downloaded Data Sample

\subsubsection{Organize and prepare data for analysis}

A total of 69,583 tweets were collected and saved on an excel spreadsheet. Initial screening of the raw data revealed inconsistency in the downloaded records. Tweets from authors with "levi" as their account name who did not post anything about the brand were removed. Also, tweets that were removed by Twitter due to violation of their policy, but were included in the data file, were deleted. These tweets were removed by twitter as they breached their policy and therefore in the Sysomos download the tweets were downloaded as a message from Twitter. For example, "This tweet has been removed in accordance with Twitter's policy. Twitter requires all its partners to remove tweets from their systems as soon as they are deleted on Twitter itself." 
To ensure consistency in data fields for purposes of the analysis, any tweets that had key missing data, such as missing comments or a missing author, were removed.

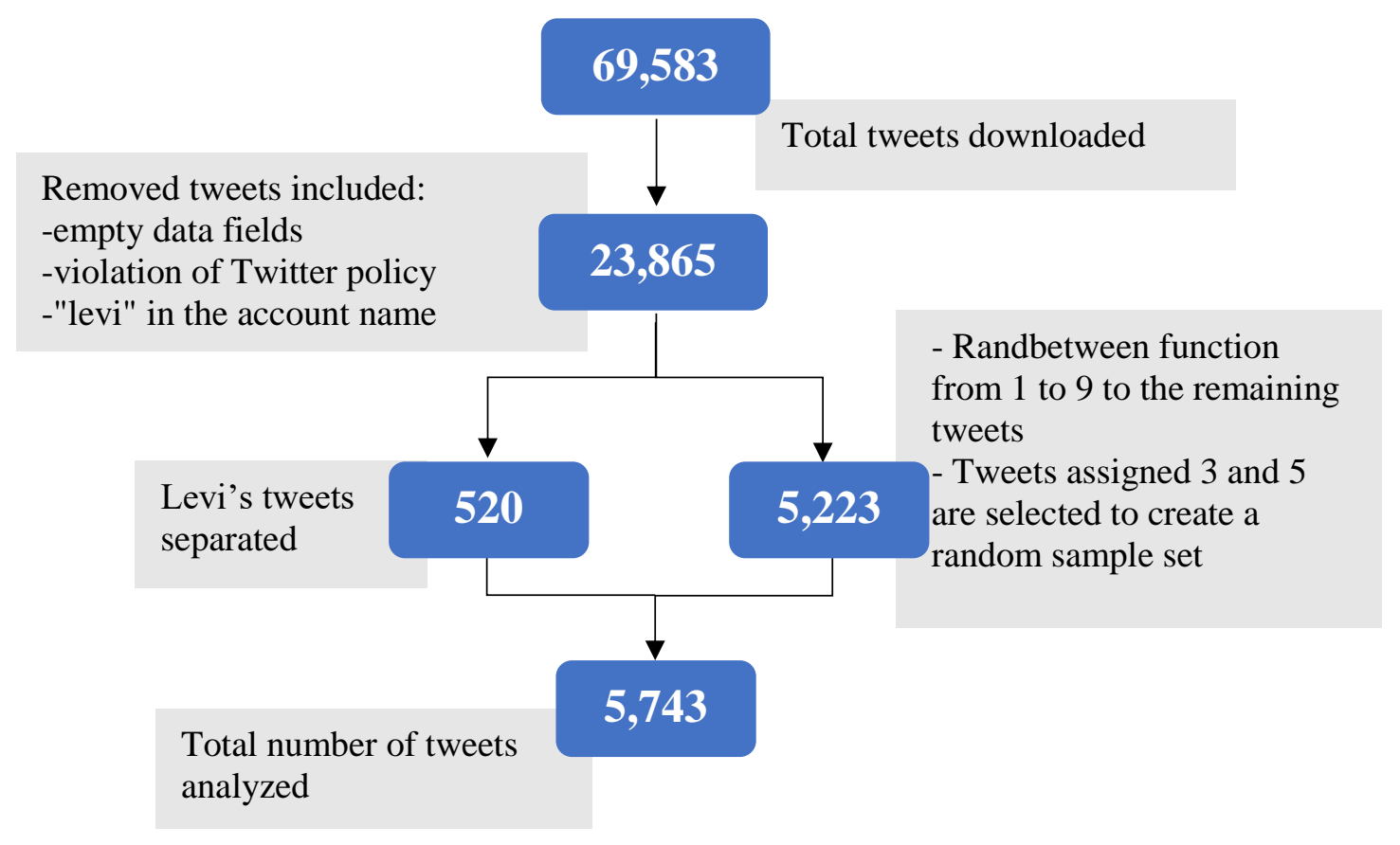

Figure 3. Data Cleansing Process

During cleansing 45,781 tweets were removed from the data set. By removing the inconsistencies, a new file was created where all the cleansed data was compiled. A total of 23,865 tweets were retained. Next, all tweets from Levi's official accounts were extracted. There were 520 tweets from Levi's which were then saved in a separate file. For the remaining tweets, a stratified sampling technique was used where the tweets were randomly divided into different groups and then random groups were selected to ensure heterogeneity of the final sample used for the analysis (Albaum \& Smith, 2010). A random number between 1 to 9 was assigned to each tweet. This was done using RANDBETWEEN functions already built-in MS Excel. Tweets that were assigned the numbers 3 and 5 were then separated to create a random 
sample for the analysis. The randomization provided 5,223 tweets, which were then used for the analysis.

\subsubsection{Read through all the data}

To obtain a general idea about the messages Creswell (2009) suggests reading all the data before beginning the analysis. For this paper, the second step overlapped the first as the data was already thoroughly scanned during the cleansing process.

\subsubsection{Detailed analysis with a coding process (Dann's Classification)}

\begin{tabular}{|c|c|c|c|c|c|c|c|c|c|c|}
\hline \multicolumn{2}{|c|}{ 1.Conversational } & \multicolumn{2}{|c|}{ 2.Status } & \multicolumn{2}{|c|}{ 3.Pass Along } & \multicolumn{2}{|c|}{ 4.News } & \multicolumn{2}{|c|}{ 5.Phatic } & \multirow[t]{2}{*}{ 6.Spam } \\
\hline Code & $\begin{array}{l}\text { Sub- } \\
\text { Category }\end{array}$ & Code & $\begin{array}{l}\text { Sub- } \\
\text { Category }\end{array}$ & Code & Sub-Category & Code & $\begin{array}{l}\text { Sub- } \\
\text { Category }\end{array}$ & Code & $\begin{array}{l}\text { Sub- } \\
\text { Category }\end{array}$ & \\
\hline 1.1 & Query & 2.1 & Personal & 3.1 & RT & 4.1 & Headlines & 5.1 & Greeting & \\
\hline 1.2 & Referral & 2.2 & Temporal & 3.2 & UGC & 4.2 & Sport & 5.2 & $\begin{array}{l}\text { Fourth } \\
\text { wall }\end{array}$ & \\
\hline 1.3 & Action & 2.3 & Location & 3.3 & Endorsement & 4.3 & Event & 5.3 & Broadcast & \\
\hline \multirow[t]{5}{*}{1.4} & Response & 2.4 & Mechanical & & & 4.4 & Weather & 5.4 & $\begin{array}{l}\text { Unclassifi } \\
\text { able }\end{array}$ & \\
\hline & & 2.5 & Physical & & & & & & & \\
\hline & & 2.6 & Work & & & & & & & \\
\hline & & 2.7 & Automated & & & & & & & \\
\hline & & 2.8 & Activity & & & & & & & \\
\hline
\end{tabular}

Table 3. Codes for categories and sub categories

Dann's classification (2010) was used for the coding process. Coding is the process of assigning data to data categories and numbers are assigned to identify them with the categories (Albaum \& Smith, 2010). Each of the six categories and their subcategories were assigned a number which were used by the coders for the analysis. The numbers were treated as the codes in the coding process, where the coders allotted these codes for each tweet. Codes were assigned to 
simplify the classification process and any analysis that may follow. Table 2 presents the codes assigned to each category and sub-category. As seen in the table Conversational was assigned as "1" and its subcategories were labelled as "1.1", "1.2" and so on. Similarly, the other categories were coded using consecutive numbers and their subcategories were numbered accordingly.

Fourth-year students from Retail Management program at Ryerson University were hired as second coders. The students had completed social media marketing and research courses and therefore had sufficient knowledge about social media research techniques. In addition, they learned Dann's classification (2010) through one of their courses, which gave them credible knowledge about the context of the research. The tweets were individually coded manually, using MS Excel. The first coding attempt revealed that that tweets could be categorized in more than one category and therefore the coders mutually decided to independently select the most appropriate category for each tweet. The process was repeated twice to negate biases. Using more than one coder for the process created reliability while iterations of the coding process created validity for the results. To overcome any possibility of individual biases Dann's detailed interpretation of each of the 6 categories and their 23 subcategories was strictly followed throughout the process.

\begin{tabular}{|c|c|}
\hline Kappa Statistic & Strength of Agreement \\
\hline$<0.00$ & Poor \\
\hline $0.00-0.20$ & Slight \\
\hline $0.21-0.40$ & Fair \\
\hline $0.41-0.60$ & Moderate \\
\hline $0.61-0.80$ & Substantial \\
\hline $0.81-1.00$ & Almost Perfect \\
\hline
\end{tabular}

Table 4. Interpretation of Kappa (Landis \& Koch, 1977) 
Inter-coder reliability was measured using Cohen's kappa coefficient. Cohen's kappa is a quantitative reliability test, designed to estimate the degree of agreement between two coders (Stemler \& Tsai, 2008). It is a statistical measure used to calculate interrater reliability for qualitative variables. A commonly cited scale is represented in Table 3 . While there is no standard or base percentage of agreement, larger kappa values indicating better reliability. Using SPSS, a statistical software, reliable Kappa value was achieved (see Table 5) and the results from the process were used for further analysis.

\subsubsection{Generate themes using on the categories listed in Dann's classification}

Qualitative software was used to delve further into the language used to examine the content or contextual meaning of the text. With qualitative content analysis, the data was inductively analyzed to find reoccurring themes that may exist at a surface level or may signify deeper meanings (Pennington, 2017). Using NVivo 11 Pro (QRS International, 2017) the most frequently used words were identified using with word frequency query. Words like "levis", “jeans" and "https" were excluded from the key words because they represent the basis of the study rather than key attributes. Similarly, unclassifiable or incorrect words were also removed. These mostly comprised of portions of URL mentioned in the tweets, for example, "Ti14LegyOW". The frequency query was next carried out using "stemmed words" function in NVivo 11 Pro which groups together words that have very close meaning. For example, result for the word size would compile similar words like "sizing", "sized" and \#size. Further analysis was executed using the text search feature in NVivo11 Pro. The main difference between word frequency and text search is that word frequency tabulates the words with highest count while 
text search can search for alternative words or phrases even if they are not in the top 1000 (Bazeley \& Jackson, 2013).

The tweets categorized using Dann's classification (2010) were then analyzed for further understanding. Percentage of tweets in each category was measured to check which type dominated Twitter conversations. Tweets from non-branded sources and Levi's account were analyzed separately to determine brand participation in online conversations. The top category

for branded and non-branded sources were determined using the tweets counts. Leximancer was used on the top categories that dominated the branded and the non-branded tweets. Themes were derived from each category and comparison was made between Levi's and non-branded tweets.

Top categories derived from Dann's classification (2010) were further analyzed using the data visualization software called Tableau 10.2 (2017). This included assessing frequency of most used words, analyzing the themes and the number of tweets in each category. Additionally, the authors for non-branded tweets who contributed the most were extracted and their messages were examined to identify their association with the brand. This would help to recognize if the connection with the brand is for personal use or for commercial use such as online stores, magazines or other e-commerce sites.

\subsubsection{Interpret and represent themes in a qualitative narrative.}

The findings from analysis was interpreted to understand the branded and non-branded voice within the community. These interpretations will be used to get an overview of the tweets used for the communications and subsequently aligned the results with future implications. The 
results are presented in qualitative narrative where the findings will be explained using theories and concepts from the literature

\section{Findings}

The first step after coding was to check the intercoder reliability to measure the degree of agreement among raters. The initial assessment was computed in SPSS resulted with kappa coefficient at 0.87 . Although the level of agreement was well above the moderate acceptability, the coders discussed and negotiated differences, refining the coding procedure accordingly. This was done by sharing individual understanding of the categories and subsequently getting better understanding of each sub-category. The coders agreed that some tweets could be categorized in more than one classification and through discussions decided to independently select only one category in cases where they felt two or more codes could be used. The coding process was repeated and Cohen's kappa was recalculated $(\mathrm{k}=0.979)$, as shown in Table 4 , to ensure reliability. As the data was already cleansed before the coding process no spam was found by any of the coders.

\begin{tabular}{|ll|r|r|r|r|}
\hline & & \multicolumn{1}{|c|}{ Value } & \multicolumn{1}{c|}{$\begin{array}{c}\text { Asymp. Std. } \\
\text { Error }^{\mathrm{a}}\end{array}$} & Approx. Tb & Approx. Sig. \\
\hline Nominal by Nominal & Phi & 2.600 & & & .000 \\
Measure of Agreement & Cramer's V & .983 & & & .000 \\
N of Valid Cases & .979 & .003 & 113.575 & .000 \\
\hline
\end{tabular}
a. Not assuming the null hypothesis.
b. Using the asymptotic standard error assuming the null hypothesis.

Table 5. SPSS Output showing Kappa coefficient to determine reliability 


\subsection{Categorization of Branded and Non-branded tweets}

\begin{tabular}{|c|c|c|c|}
\hline Sub-Category & $\begin{array}{c}\text { Number of } \\
\text { Levi's Tweets }\end{array}$ & Sub-Category & $\begin{array}{l}\text { Number of Non- } \\
\text { Branded Tweets }\end{array}$ \\
\hline Query- & 193 & Query- & 91 \\
\hline Referral- & 154 & Referral- & 228 \\
\hline Action- & 2 & Action- & 7 \\
\hline Response- & 59 & Response- & 18 \\
\hline CONVERSATIONAL & 408 & & 344 \\
\hline \multicolumn{4}{|c|}{ Total Percentage (Branded and Non-branded): 13\% } \\
\hline Personal- & 4 & Personal- & 192 \\
\hline Location- & 1 & Location- & 1 \\
\hline \multirow[t]{2}{*}{ Activity- } & \multirow[t]{2}{*}{1} & Automated & 195 \\
\hline & & Activity- & 1 \\
\hline \multirow[t]{2}{*}{ STATUS } & 6 & & 389 \\
\hline & \multicolumn{3}{|c|}{ Total Percentage (Branded and Non-branded): $6.87 \%$} \\
\hline RT- & 76 & RT- & 1,134 \\
\hline UGC - & 21 & UGC - & 8 \\
\hline Endorsement - & 8 & Endorsement & 2,705 \\
\hline \multirow[t]{2}{*}{ PASS ALONG } & 105 & & $\mathbf{3 , 8 4 7}$ \\
\hline & \multicolumn{3}{|c|}{ Total Percentage (Branded and Non-branded): $68.8 \%$} \\
\hline Headlines- & 1 & Headlines- & 449 \\
\hline \multirow[t]{5}{*}{ NEWS } & 1 & & 449 \\
\hline & \multicolumn{3}{|c|}{ Total Percentage (Branded and Non-branded): $7.8 \%$} \\
\hline & & Broadcast & 175 \\
\hline & & Unclassifiable & 19 \\
\hline & & PHATIC & 194 \\
\hline & \multicolumn{3}{|c|}{ Total Percentage (Branded and Non-branded): $3.37 \%$} \\
\hline
\end{tabular}

Table 6. Categorization of branded and non-branded tweets

The results from Dann's classification were reviewed and analyzed to reveal reoccurring themes for each category or sub category. The number of tweets under each category was calculated and the results are tabulated in Table 5. At 68\%, the Pass Along category had the highest number of branded and non-branded tweets while the remaining four remained close to 
or under 10\% individually. Endorsement under Pass Along dominated the conversation (47.24\%) for both branded and non-branded communications. Another large quantity of the tweets belonged to RT-Pass Along covering 21.08\%, however, this segment was expected to be larger as tweets of interesting topics are often retweeted multiple times by followers (Boyd, Golder, \& Lotan, 2010). Conversational contained the second largest quantity of tweets (13\%) followed by News, Status and Phatic consecutively. Additionally, Conversational category was the only classification that had content in all four sub categories for branded and non-branded messages. Tweets belonging to News and Status categories had moderate presence while Phatic had lowest with 194 tweets.

From Levi's account, there were 520 branded tweets in total of which 408 belonged to conversations, 106 to Pass Along, 6 to Status and 1 to the News category. There were no messages that were categorized under the Phatic category from branded conversations. Query, from the Conversational category, had the highest number of tweets, closely followed by Referral. Additionally, these two sub-categories were the only ones that individually contained more than one hundred tweets within branded tweets. From the branded Pass Along category, Retweet contained the highest quantity followed by UGC.

From non-branded tweets, the Pass Along category contained the highest number of tweets (3,847 tweets) where with 2,268 tweets Endorsement and RT covered $73.5 \%$ of the tweets. This was followed by News with 449 tweets and Status with 389 tweets. Conversational, which was the largest category from Levi's branded tweets, contained 344 tweets and ranked as one of the smallest categories for non-branded tweets. Phatic, with 194 tweets, had the smallest quantity of tweets in all the categories. 
The top categories from branded and non-branded tweets were next analyzed using the analytical software to identify themes or repeated words in the tweets. NVivo 11 Pro was used to evaluate the word frequency in each corpus while Leximancer was used to automate themes. In addition, Tableau 10.2 was used to calculate the frequency of post in each category and evaluate user type. In the Levi's branded categorization, the Conversational category contained the highest number of tweets, while from non-branded categorization Pass Along had the highest number. As result these two categories were further analyzed to gain deeper insights on the types of tweets that dominated the conversation flow in the community.

\subsection{Analysis of Branded Tweets}

\subsubsection{Analysis of Conversational category of Levi's branded tweets}

Delving more into the content of the message it was found that the branded tweets under conversations were customer service oriented where the brand either recommending products for purchase or trying to resolve complaints. Furthermore, the brand opted for similar terminology to interact with different users. It provided the same response to different customers who may have shared bad product experience with the brand. For example, “@users Hi there - sorry about your jeans! Where are you located?". The word frequency function in NVivo 11Pro was performed to examine the 100 most frequent words used in the tweets. Table 6 shows the frequencies of the first 10 words generated from the query while Figure 4 illustrates the word cloud that represents the conversation in this category. 


\begin{tabular}{|c|c|c|c|c|}
\hline Word & Length & Count & Weighted Percentage (\%) & Similar Words \\
\hline sorry & 5 & 263 & 7.09 & Sorry* \\
\hline please & 6 & 119 & 3.21 & Please* \\
\hline hear & 4 & 114 & 3.07 & Hear* \\
\hline support & 7 & 111 & 2.99 & support* \\
\hline customer & 8 & 110 & 2.96 & Customer* \\
\hline team & 4 & 100 & 2.70 & Team* \\
\hline located & 7 & 80 & 2.16 & located, location \\
\hline reach & 5 & 79 & 2.13 & reach, reached, reaching \\
\hline thanks & 6 & 54 & 1.46 & thank, thanks \\
\hline call & 4 & 53 & 1.43 & call, called, calling \\
\hline
\end{tabular}

Table 7. Frequency of the top 10 words from branded Conversational tweets

The search was done by using the stemmed words feature in NVivo 11Pro which combines different forms of the same word providing the weighted percentage of each word. The weighted percentage is the frequency of the word relative to the total words counted in the data while the similar words presents similar words stemmed together, as shown in Table 6.

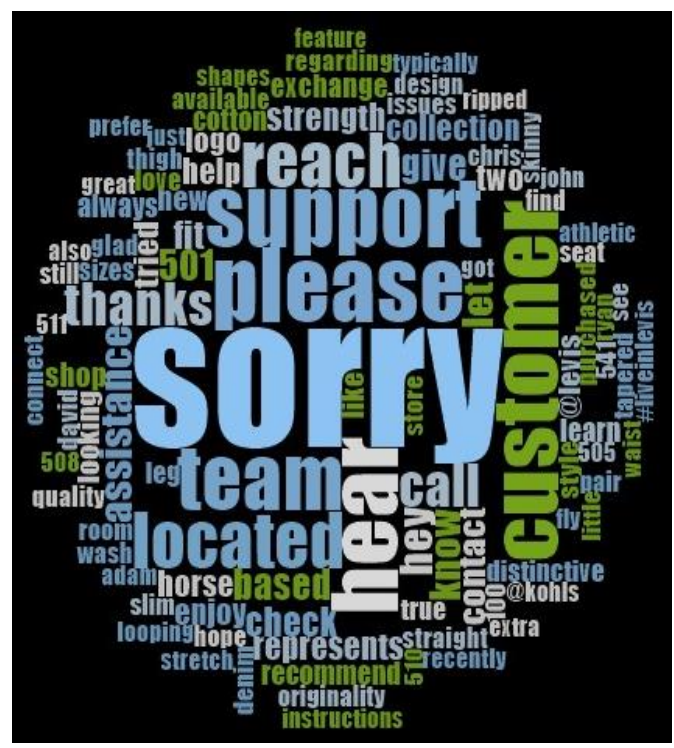

Figure 4. Top 100 words from branded Conversational category 
The most frequent word used was "sorry" (263 count), followed by "please" (119) count. A text query for the word "sorry" revealed that in 263 tweets the brand was apologizing for an error that happened with a purchase, inquired about the location of the customer or was referring their customer service team for further help. For example, @ username Hi there - sorry about your jeans! Please reach out to our Customer Support team at 1-800-USA-LEVI. These tweets were present under the Query and Referral sub-categories. The remaining tweets in Conversational category were either offering recommendations to brand styles or expressing the true meaning of their brand logo. The word cloud gives more prominence to words that appear more often in the data file. The visualization also revealed that "thanks" and "glad" were among the top 100 words meaning that there were conversations in which the consumer may have expressed their satisfaction with the product or brand.

The tweets were then arranged in chronological order to check the months that received the highest number of tweets along with the sub-category that which made most contribution. Figure

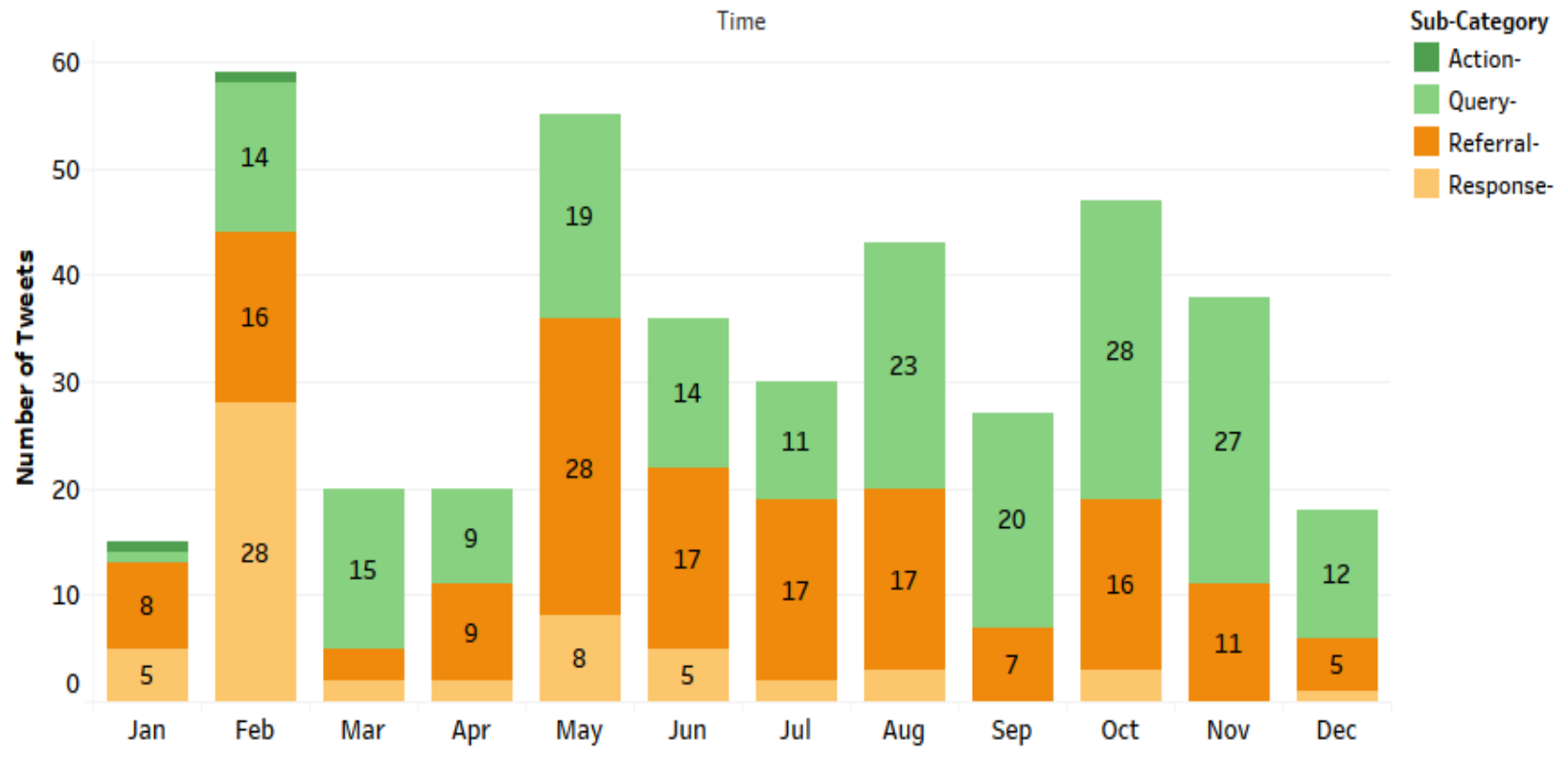

Figure 5. Branded Conversational tweets arranged in chronological order 
5 displays the branded Conversational tweets for 2016. February received the highest number of tweets followed by May. In both the months Query, Referrals, and Responses were posted by the brand, while Action tweets were only present in February as seen in Figure 5. Action tweets were posted in January and February and were low in quantity. However, the remaining three subcategories were mostly present for the months. The tweets did not follow any trend over time and were in response to tweets from consumers. Delving into the content it was revealed that during these months' communication was mostly about problems in purchase. This resonates with the findings from the word frequency query in Table 6 which revealed that most of communication in the Conversational category were customer oriented and apologetic in nature.

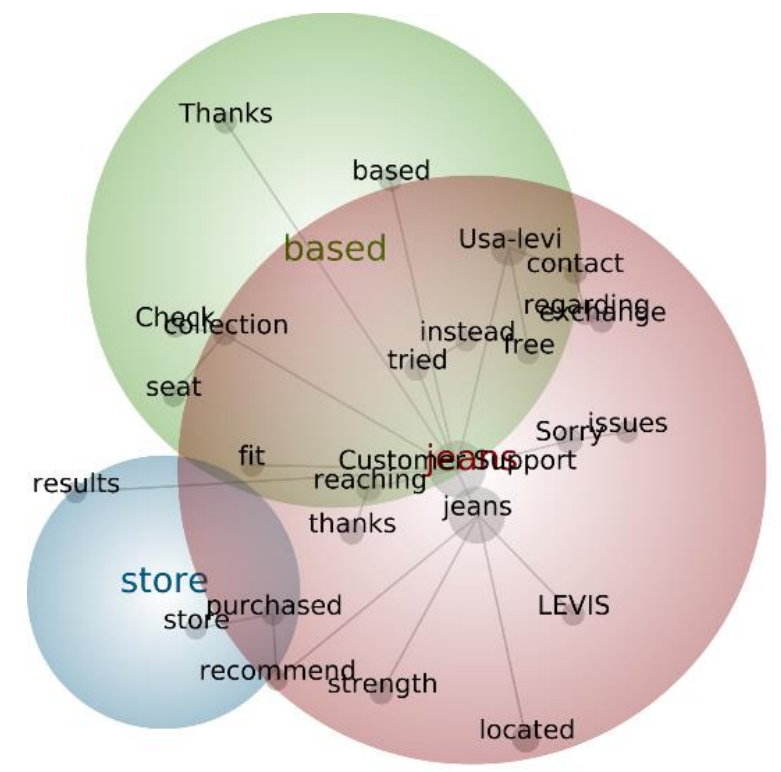

Figure 6. Concept Map for branded Conversational tweets

Conversational tweets from Levi's was next analyzed using Leximancer where themes were automatically developed based on the co-occurrences of the keywords as shown in Figure 6. Three major themes were extracted from this data set namely "jeans", "based" and "store". These are produced based on the recurrence of the terms and their connections to other concepts 
found in the conversations. "Jeans" was the most important theme formed with 449 references which included sub-concepts such as jeans, Customer Support, Usa-levi, Sorry, reaching, thanks, tried, exchange, issues, free and instead. This means that were 449 posts that can be categorized under this theme. Additionally, as shown in figure 6, the concepts customer service, sorry and issues are relatively close to each other indicating that the words were used together. Therefore, nearly all tweets under the "jeans" theme was customer service oriented in which the brand was trying to resolve issues that consumers were experiencing with their jeans. Similarly, the "based" theme was also service oriented and the brand was seen asking for their location so that they can refer to their support team. Under the "store" theme there were 6 references where the brand was seen providing product information to the consumers. The most prominent concept for the themes was Customer support with a 99\% count relevance loosely followed by USA-levis at $34 \%$ and thanks at $6 \%$ (see Appendix A). These three main themes were covering similar concepts that were service oriented and the tweets under these themes were assisting consumers with product or purchase. This finding mirrors the results from the word frequency in Table 7 which revealed customer apologizes major conversational aspect on their tweets.

\subsubsection{Analysis of Pass Along category of Levi's branded tweets}

All tweets in the Pass Along category were promotional in nature that highlighted favourable events about the brand. Levi's posted 8 tweets that were Endorsement, 21 tweets that were UGC while the remaining 76 were retweets from fashion news outlets such as online magazines or blogs. Similar setting was used to create the word cloud to illustrate the top 100 words. The initial query contained several “@users” terms from online fashion new sources such as magazines, bloggers or fashion-conscious users. This indicated that Levi's retweets from 
different members in the community. However, to maintain anonymity their username was removed and a new word clouds was created as shown in Figure 7. “@levis” had the highest frequency. It was repeated 63 times indicating that messages were directed towards the brand for more than half of the tweet quantity. Remaining keywords included style oriented terms such as "iconic", "skinny", "vintage" etc. Additionally, product styles such as 501 and 711 were also shown, indicating specific product oriented messages were used in the tweets.

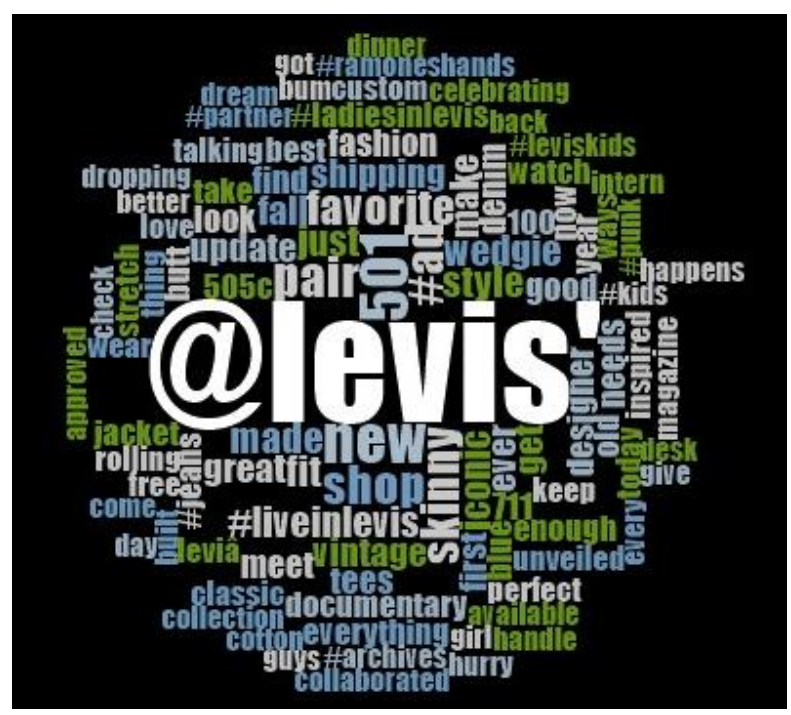

Figure 7. Top 100 words from branded Pass Along category

Organizing the tweets over time revealed that on Levi's posted at least one Pass Along tweet every month. The highest number of tweets from the brand was received on the month of March when it posted 16 Pass Along tweets in total. Eleven of these tweets were Retweet while two were Endorsement and three UGC. June had the least number of tweet with one Retweet from the brand. While Endorsement and UGC is not follow any trend, retweets were mostly from Fashion news outlet such an online magazine or bloggers. 


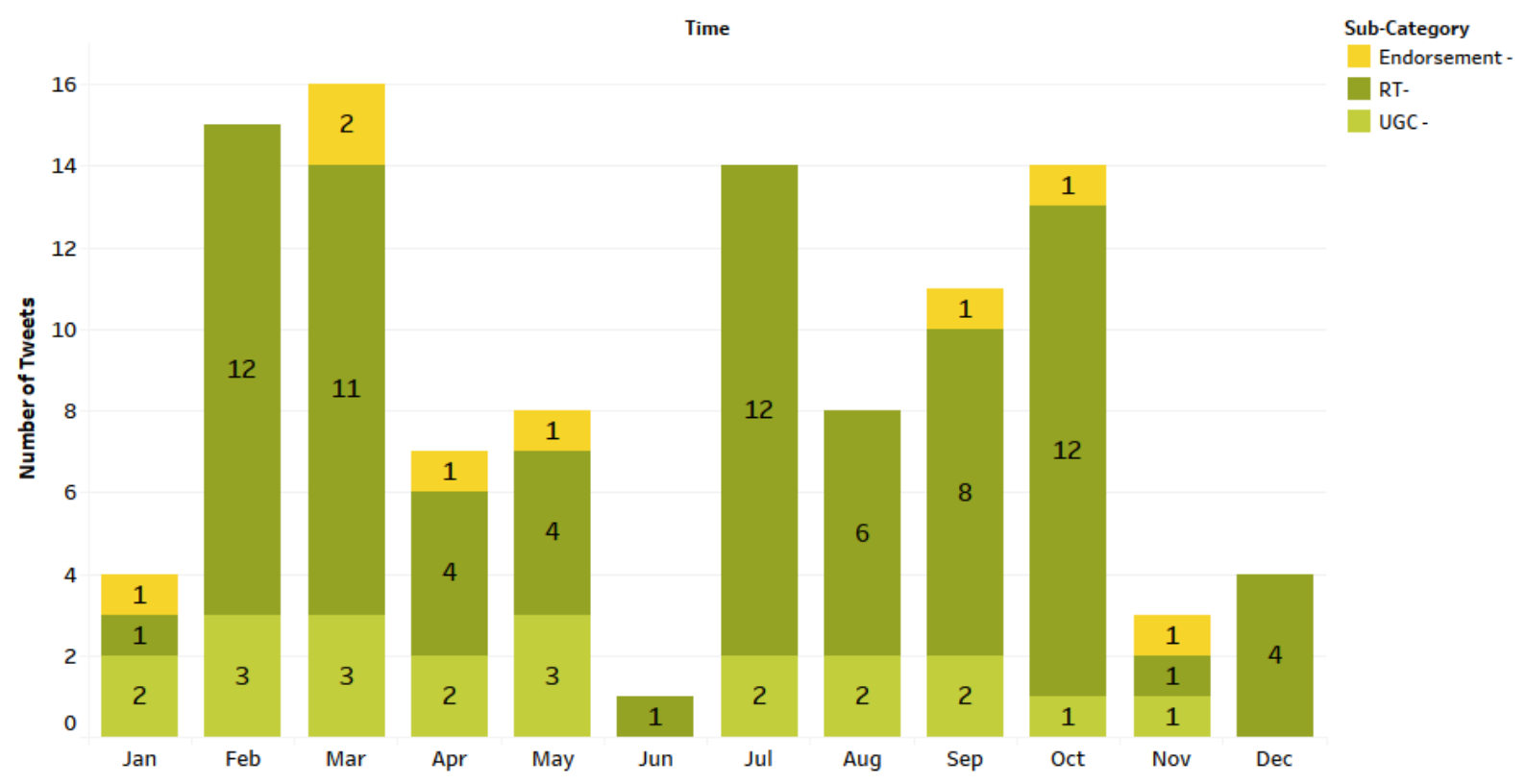

Figure 8. Branded Pass Along tweets in Chronological order

Four themes were created in Leximancer and are shown in Figure 9. With 108 references "jeans" was the largest theme formed along with "shop", "rock" and "stretch". It contained style oriented concepts such as collection, dream and vintage-inspired. This was similar to the concepts formed under the theme "stretch" which were stretch, better, designed, kids, 70s, guys.

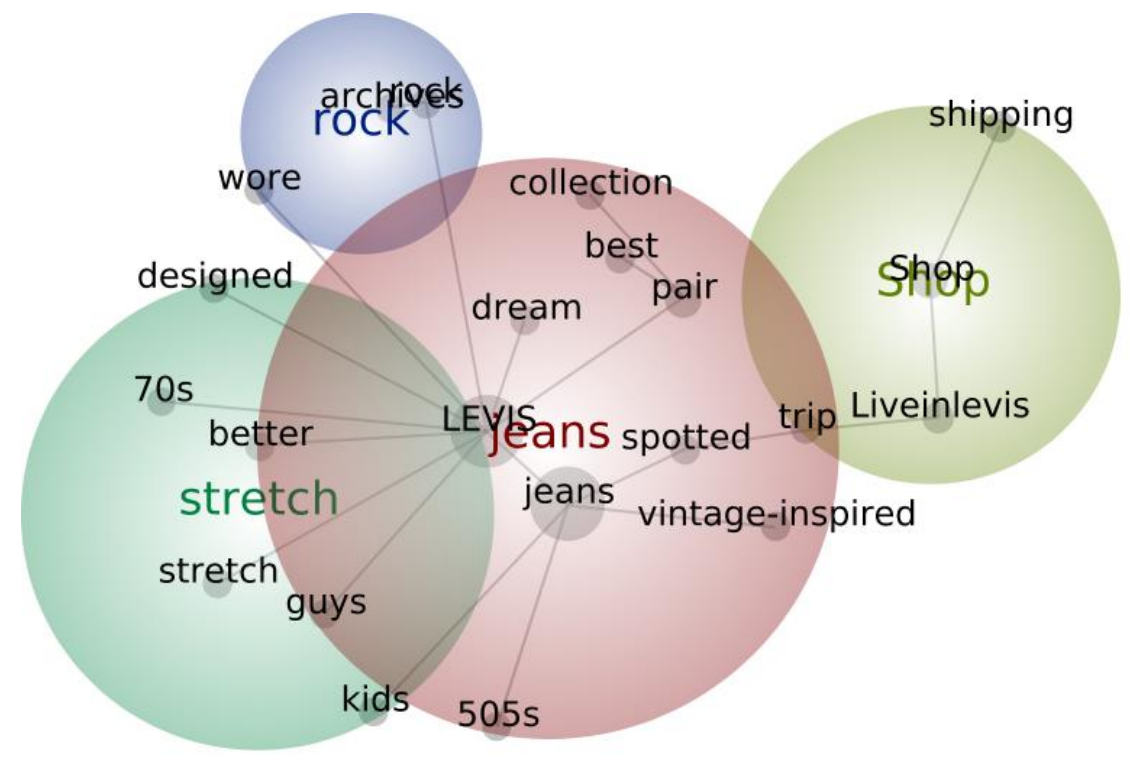

Figure 9. Concept Maps for branded Pass Along tweets 
Both the themes included fashion or style references and the data revealed that the themes contained fashion oriented tweets. "Shop" contained 16 references which included brand hashtag, \#liveinlevis, as a concept. Additionally, it contained other terms such as ship and shop indicating that the tweets in this theme covers topics on purchasing and delivery of a product. All the concepts had similar distances in between therefore even though the concept map provides the concepts it fails to make inferences about the importance of each concept.

\subsection{Analysis of Non-branded Tweets}

\subsubsection{Analysis of Conversational category of non-branded tweets}

\begin{tabular}{|c|c|c|c|c|}
\hline Word & Length & Count & Weighted Percentage (\%) & Similar Words \\
\hline @levis & 6 & 127 & 3.05 & @levis, @levis' \\
\hline wear & 4 & 47 & 1.13 & wear, wearing, wears \\
\hline pair & 4 & 39 & 0.94 & pair, pairs \\
\hline fit & 3 & 31 & 0.74 & fit, fits, fitting \\
\hline like & 4 & 31 & 0.74 & like, likely \\
\hline just & 4 & 27 & 0.65 & just* \\
\hline make & 4 & 23 & 0.55 & make, makes, making \\
\hline new & 3 & 23 & 0.55 & new* \\
\hline wash & 4 & 17 & 0.41 & wash, washes, \\
washing
\end{tabular}

Table 8. Frequency of the top 10 words from non-branded Conversational tweets

Word frequency for Conversational Tweets from non-branded tweets was created and the results for top 10 most used words are illustrated in Table 7. “@levis” is the most used word in the corpus with a count of 127 and weighted percentage of $3.05 \%$. A text search for the word 
revealed that out of the 344 Conversational tweets under non-branded tweets 127 tweets tagged Levi's in their messages even though the conversation was not directed to the brand.

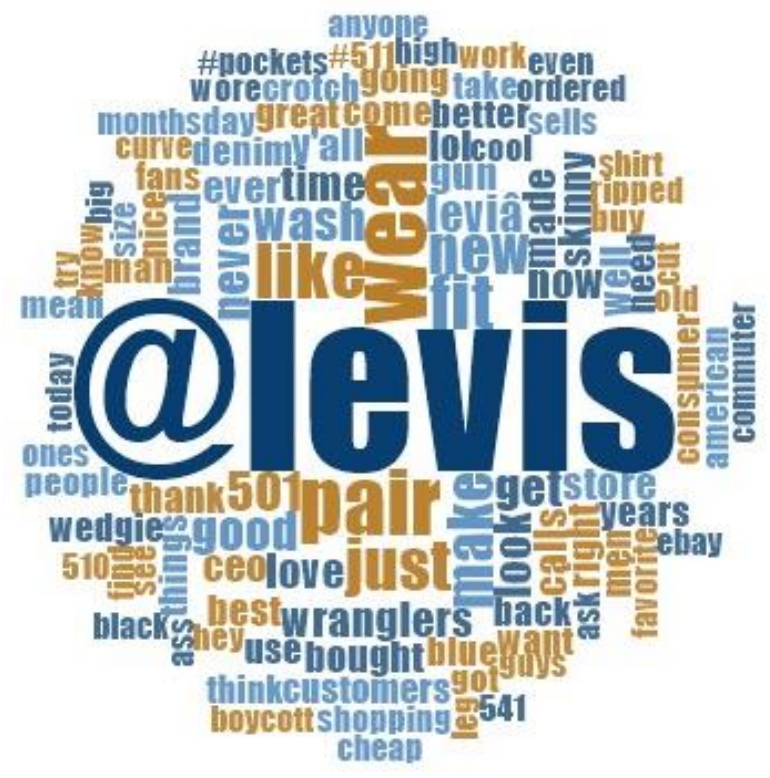

Figure 10. Top 100 words from non-branded Conversational category

Positive words found in the frequency query were "like" (31 count), "thank" (10 count) and "love" (13 count). A text search for these words revealed that members used the word "like" to describe an example and not as their sentiment. For example, “@LEVIS what exactly do you add to your jeans to make them smell like old tortilla chips". However, the words "thank" and "love" were used to express positive feeling or experience with the brand. For Example, "\#thatmomentwhen you splurge on new jeans \& think to yourself"so THAT is how jeans are supposed to fit!" Thank you @LEVIS \#curvygirlprobz". The conversation also included terms like "boycott", "cheap" and competitor brand names like "wrangler". Additionally, productrelated names such as 501, 541 and 511 were also included. 
Delving into the frequency of monthly tweets for the subcategories it was seen that the number of Referral tweets posted each month was nearly double the quantity posted for any other subcategory. Figure 11 demonstrates that the largest quantity of Referral tweets was from December with 33 tweets. Consequently, December also contained the most number of tweets with a total of 49 tweets. The content of the tweets revealed that a spike in the number was due to the brand's decision to ask its customers not to bring guns into stores. Members discussed their option about the brand's decision where majority of the members decided to either boycott the brand or move to competitors like Wrangler. This resonates with the results in the word cloud that found "boycott", "gun" and "wrangler" in the top 100 words.

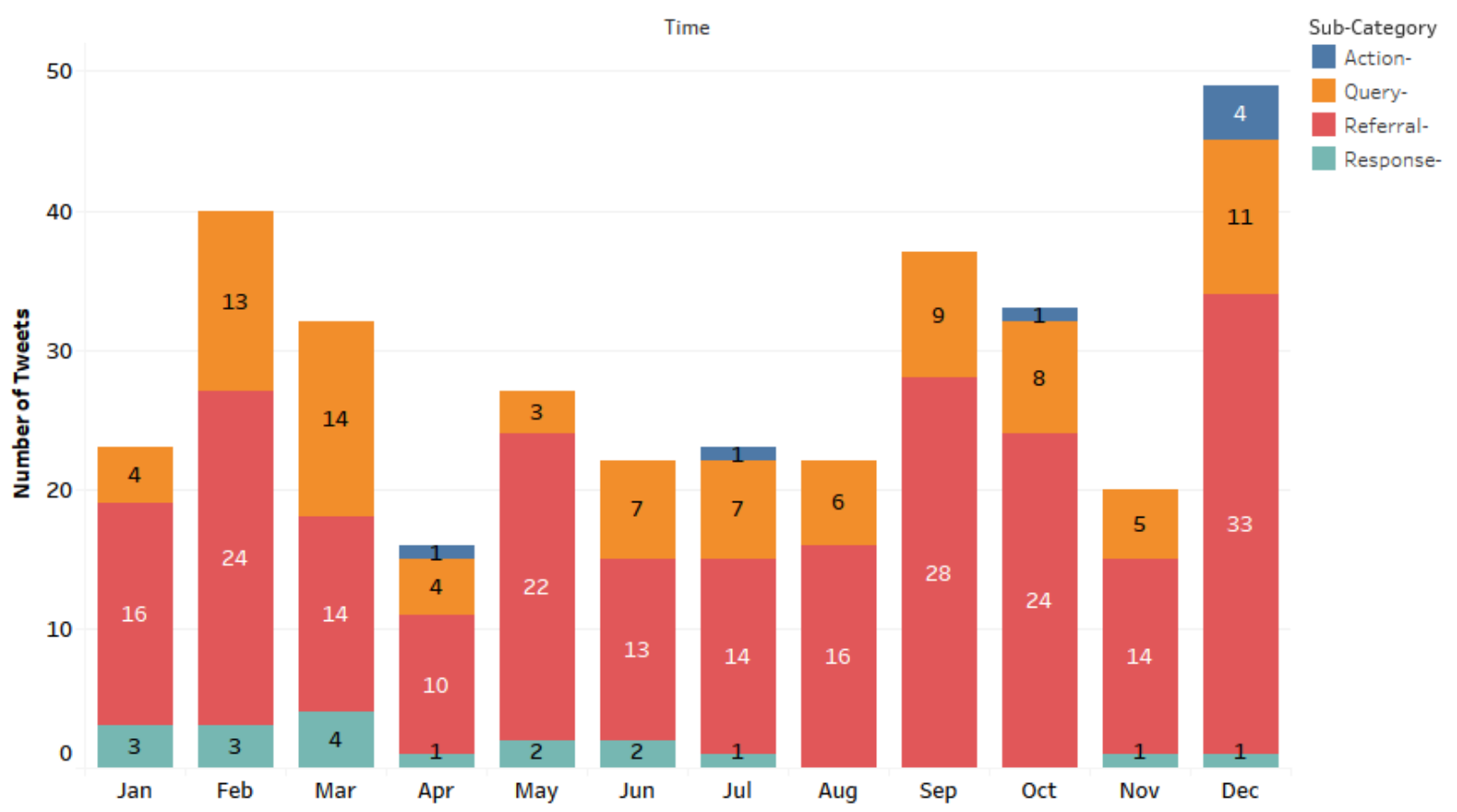

Figure 11. Non-branded Conversational tweets in Chronological order

The month of April, with 16 tweets in total, had the lowest number of tweets however; it contained tweets from all four subcategories. Tweets in the other months included conversations where members discussed either purchasing difficulties, style of the jeans or events related to the 
brand. For example, A query tweet in September, the third highest month, stated “@LEVIS Just received the jeans I ordered from your site \& there's a small hole in them. Can I get a new pair without paying the shipping?".

The concept map for the Conversational tweets from non-branded sources revealed five major themes as shown in Figure 12. The central theme formed was "LEVIS" with $100 \%$ count relevance (see Appendix E). The theme included concepts such as store, skinny and wear among others. The tweets under this category did not follow any patterns such as style orientation or product orientation. Additionally, the concepts skinny and men's were in close proximity which suggests that these concepts co-occur in the messages. Similarly, wearing and lol were also closely positioned revealing their co-occurrence. The content of the tweets under these themes revealed that the messages were related to men's skinny jeans for example, @ username real country singers don't wear snap backs and skinny jeans. The next theme formed was "wash"

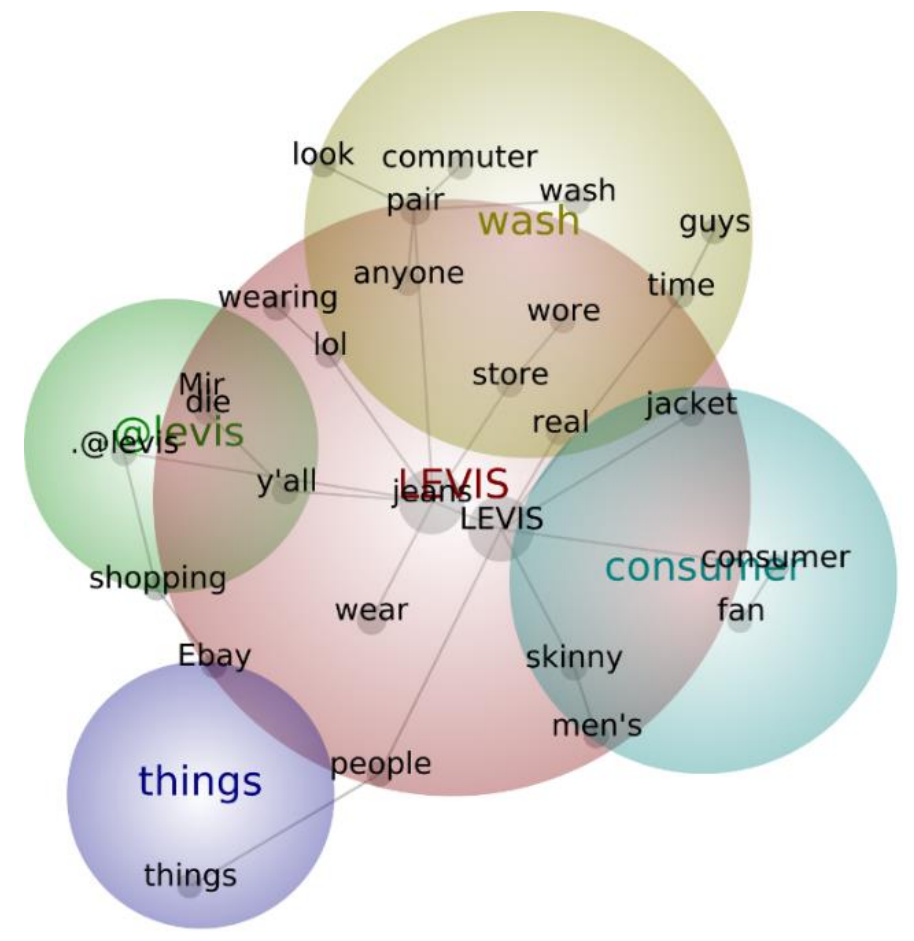

Figure 12. Concept map for non-branded Conversational tweets 
where the tweets revolved around Levi's CEO who stated that jeans don't need to be washed. Most of the authors for the tweets were reinstating the message from the CEO while some passed the message to others. For example, @username The head guys at \#levis say never wash your jeans just put them in the freezer for an hour or two. "Consumer" and "things" were the next two themes formed where the concepts involved product orientated concepts like jacket, men's and things. The last theme formed was “@levis” which indicated that users were directly involving the brand in their conversation. Under this theme authors were discussing Levi's decision to ban guns in their store and were directing their opinion to the brand such as @ LEVIS Thank you for asking customers to leave their guns at home while shopping for jeans! \#gunsafety \#Enough \#stopgunviolence.

\subsubsection{Analysis of Pass Along category of non-branded tweets}

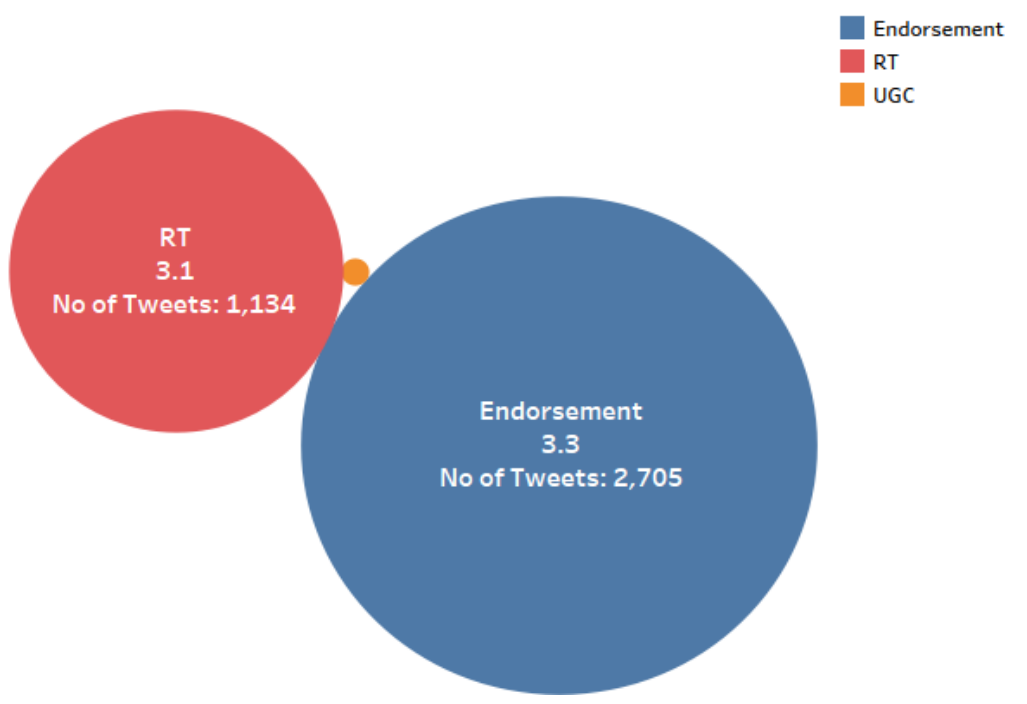

Figure 13. Number of non-branded tweets in Pass Along category

As seen in Figure 13 Endorsement tweets had the highest frequency with an average of 226 tweets per month, indicating that most users endorsed Levi's to their followers. Users motivate other members of different socioeconomic backgrounds to follow the new fashion trends and buy 
their products either through advertisement or promotion of the brand (Rahman, Saleem, Akhtar, Ali, \& Khan, 2014). Therefore, it may be inferred that in the dataset most users recommended the brand to their followers and emphasized its appeal to others. Delving into the content it was seen that more than half of the tweets were advertisements for products on e-commerce sites. Online businesses were tweeting about promotional prices or marketing their products in the community. Endorsements were followed by Retweet which occupied almost $30 \%$ of the tweets from this category. According to Kim et al. (2014, p. 23) "The act of retweeting brand messages can be seen as one's attempt to belong to the brand community." A high number of retweets therefore indicates that users in the brand community are willing to become part of a broader conversation and amplify or spread brand messages to their own users. The last category, UGC, had 8 tweets where the users promoted personally created content to their followers.

Next, the tweets are arranged in chronological order to analyze the number of tweets posted over time. Except for May, June, and July the number of Endorsement tweets were more than double when compared to Retweet. These three months saw a spike in the number of retweets. Delving into the contents for these months it was seen that the spike in May and June was due to the launch of first ever jeans made from $100 \%$ recycled cotton and Father's Day promotional retweets. However, retweets in July did not follow any specific promotion or event. UGC had 8 tweets, 7 of which were scattered in the first 6 month of the year. The total number of tweets for this sub-category was insufficient to learn any trend or purpose of the tweets. Endorsement had approximately 150 or more tweets for each month. The month of February, November and December had the most the number of tweets for this category. February had the third highest number of tweets however there were no specific occasion or event mentioned in the tweets that could be associated with the spike in numbers. The remaining two months, 


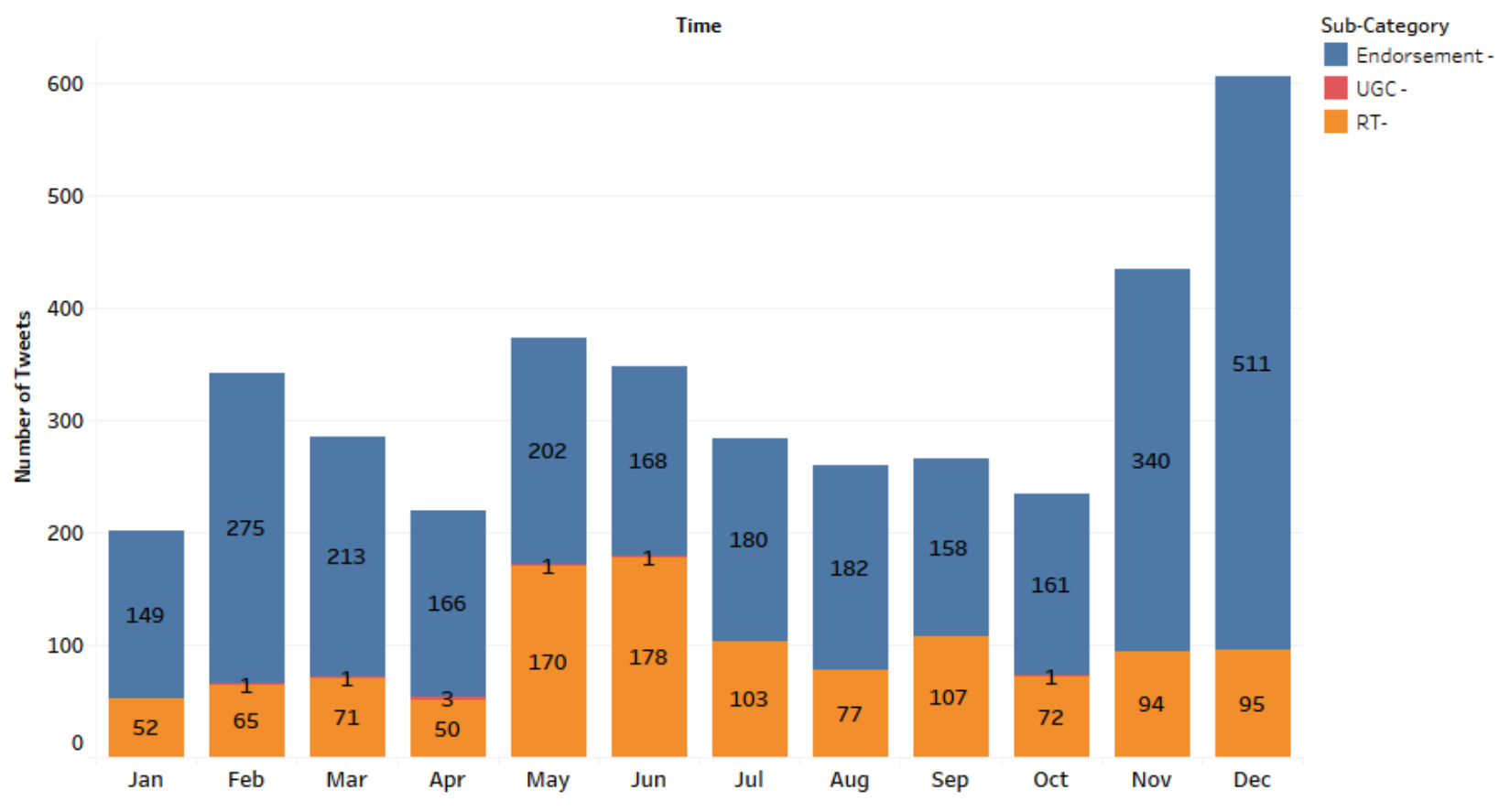

Figure 14. Non-branded Pass Along tweets in Chronological order

November and December, saw an escalated number of tweets, especially December which had the highest number of tweets for every sub-category. Like the tweets from February the content for these two months did not reveal any specific event that may have caused the increase in tweets. However, it can be assumed that the rise may be due to holiday marketing where the members are endorsing products with links to business outside Twitter.

While these charts indicate the numbers and types of tweets in each category they do not reflect much about the Twitter handle from which the tweets originated. Establishing trust and commitment creates loyalty that may influence followers preference and therefore have great impact on reach and marketing of the brand (Kapitan \& Silvera, 2016; Sashi, 2012). Trust and commitment can be increased by creating engagement in the form of membership continuance and participation in the community (Wirtz et al., 2013). Thus, participation and content may depend on the type of accounts from which majority of the tweets originate. Pass Along category 
had the highest number of tweets (3952 tweets) with Endorsement (47.1\%) and Retweet $(19.47 \%)$ covering nearly $67 \%$ of the entire data set. Therefore, the sub categories under Pass Along were further analyzed to assess the types of account and the content in each category.

\subsubsection{Retweets (3.1) - Non-branded Tweets}

The first subcategory under Pass Along is Retweet (3.1). The non-branded retweets were incorporated in Leximancer which generated six themes as displayed in Figure 15. The central theme that was automated was "jeans" with 1,189 references in the data set. It included concepts such as ad, gift, and fashion. These concepts can be described advertisement-oriented, as tweets under the themes were focused on a special promotion due to an event. For example, $R T$ @ username The jeans all the girlswore at fashion week: http:/webaddress cc: @ Levis \#ad.

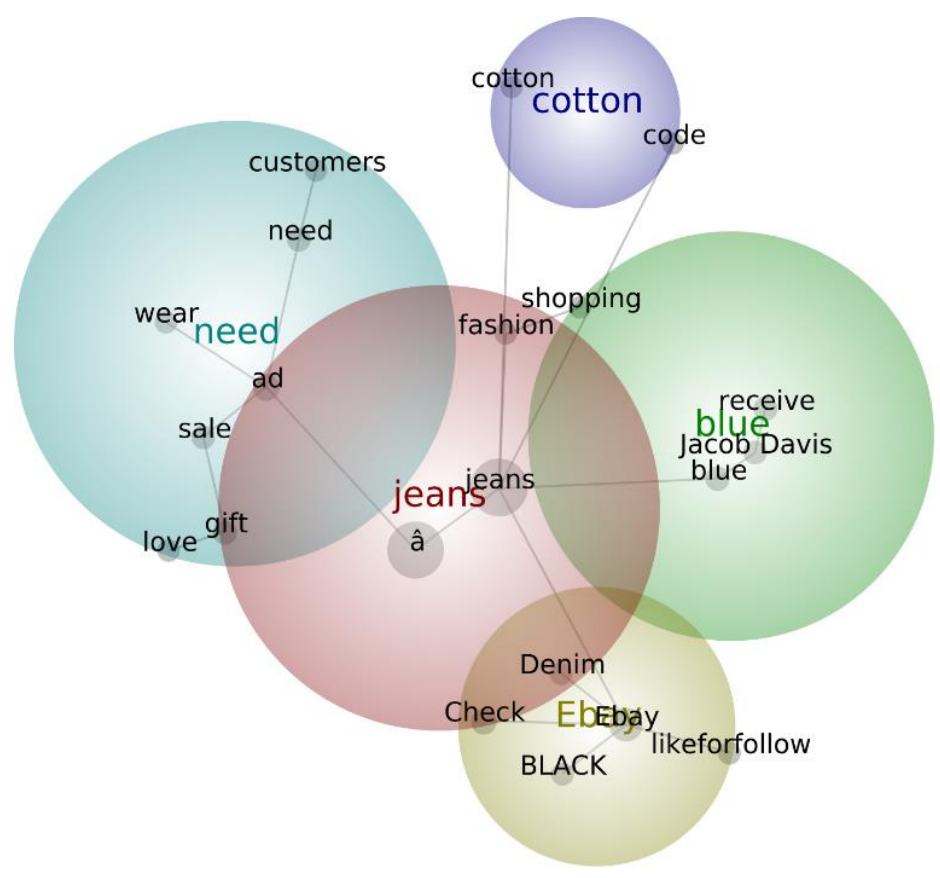

Figure 15. Concept map for non-branded Retweets 
Other themes under Retweet were "cotton", "Ebay", "need", and blue. "Ebay" was the second largest theme with 291 references (see Appendix G). This theme was formed on the retweets made to promote eBay accounts online and contained endorsement-like terms such as likeforfollow, check and via. Less distance between likeforfollow and eBay suggested that these concepts had a stronger connection than the other concepts. This was because most retweets contained the likeforfollow offers such as RT@username \#Levis Men's Jeans \#501 Original Shrink Straight Fit \#retweet \#likeforfollow \#follow \#like http://link. Levi's announced the introduction of jeans from post-consumer cotton waste and the announcement was retweeted several times. Leximancer, thus, picked the word "cotton" as a theme due to repetition and cooccurrence with other key terms such jeans. The concept "code" was formed due to the occurrence of retweets that offered discount if a code is mention. For example, RT @ user Get 40\% OFF Levi Denim Jeans with code: SECRET40 at checkout SHOP HERE: https: webaddress.com. Jacob Davis was a founder of the company and messages were retweeted on the day when he received patent for Levi's blue jeans. Therefore, the concepts of the theme "blue" was formed on these key terms. The last theme of this sub-category was "need" where the conversations revolve around concepts like need, sale, wear, love, customers.

Next, the users in the subcategory was analyzed. To assess members' accounts the top contributors for the subcategories were first measured using Tableau 10.2. Top contributors are members that posted most in the community. Their contribution was measured by the total sum of the number of tweets. Additionally, the authority scores and the number of followers for each member was also assessed to evaluate the overall reach of the member. Figure 16 shows the top contributors along with the authority score and the number of followers for each member. As the 
analysis focused on top contributors, members who had less than 5 retweets were excluded from the Figure 16.

\begin{tabular}{ll} 
Author $\#$ Auth. Score \\
\hline 2 & 7 \\
\hline 35 & 3 \\
\hline 26 & 8 \\
\hline 21 & 8 \\
\hline 27 & 5 \\
\hline 101 & 8 \\
\hline 72 & 7 \\
\hline 213 & 7 \\
\hline 183 & 5 \\
\hline 293 & 5 \\
\hline 150 & 6 \\
\hline 1744 & 9 \\
\hline 415 & 6 \\
\hline 106 & 4 \\
\hline 220 & 7 \\
\hline 161 & 7 \\
\hline 157 & 6 \\
\hline 126 & 6 \\
\hline 93 & 6 \\
\hline 57 & 8 \\
\hline 54 & 5 \\
\hline 53 & 8 \\
\hline 30 & 6 \\
\hline 28 & 6 \\
\hline 24 & 5 \\
\hline
\end{tabular}

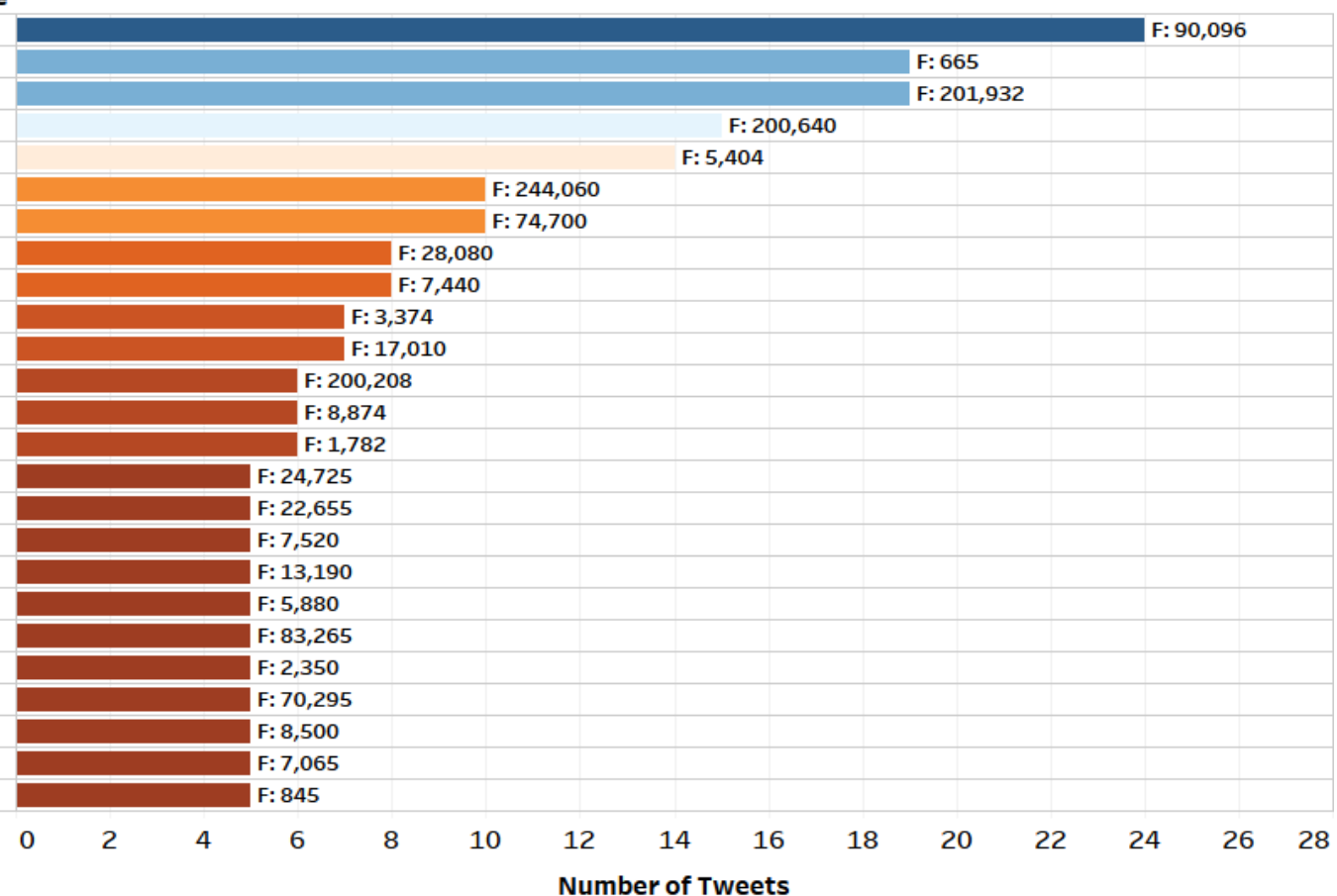

F: Number of followers

Figure 16. Top Contributors for Retweet (non-branded)

The authority score for the top contributors ranged from 3 to 10 while the number of followers ranged from 665 to $8,578,779$. Some contributors with less authority score and followers were listed before others who surpassed them in both categories as the chart is based on the number of post per contributor. Figure 16 shows that the highest number of retweets was from the Author 2 who posted 24 tweets and had an authority of 7 with 90,096 followers. The Twitter page confirmed that the Twitter handle is associated with an eBay account and all posts were promoting products that are sold through an eBay account. Furthermore, all 24 retweets were reposting of tweets from authors who were also associated with online stores. Retweeting is 
a successful mechanism to amplify or share information with new audiences and some of the most visible Twitter contributors retweet others and look to be retweeted (Boyd et al., 2010). Increased exposure through retweets or number of followers may increase the consumer engagement through participation and word of mouth (Hoffman \& Fodor, 2010). Retweets not only help to spread messages to new audience but also foster engagement as it validates information and creates an opportunity to engage with other users (Boyd et al., 2010). Therefore, it can be stated that authors under 3.1 were also trying to increase engagement for their online business by gathering more retweets or followers. This was made evident in the retweets where the original post included hashtags like \#likeforfollow and \#f4f. For example

RT@username \#Levis \#Jeans 559 Relaxed Fit 30x34 Black Gray Straight Leg 0239 @ebay \#F4F \#likeforfollow

In the example above, the author retweeted a post that was originally from the third contributor for 3.1, Author 26. The tweet promoted a Levi's collection, mentioning the available size and colour. It also included hashtags that indicate the offer to follow if the author's Twitter page is followed. Lastly, the tweet contained a link that could take followers to the eBay store. Like the first author, the third contributor was also affiliated with an online eBay store and posted 19 retweets, all of which were reposting of promotional tweets from other eBay stores. However, their authority score was slightly higher (8) while the number of followers were more than double than the first contributor. Thus, it can be assumed that even though they had a lower contribution than the first author, their impact may be more, as they had greater audience reach.

Additionally, the top contributors list also contained individual contributors who were not affiliated with an online business. These individuals reposted promotional tweets that offered 
discounts or free product for retweets. This finding resonates with previous literature which states that brand messages that incorporate incentives receive more engagement when compared to other types of messages (Vargo, 2016) For example, RT @ username Lowest price 1 Visit https://t.co/GUvmEJMozM code 2525 for $25 \%$ off 2 Pr or More! RT for auto-entry to win a FREE pair of Levi's Jeans times to increases their chances to win free product. A few individual authors were retweeting posts from several online business accounts even though they were not associated with any business.

Members in this category, therefore, not only had different influencing power but their intention behind contributions to this category was also different. For example, individual users retweeted in support of messages from others such as RT @username Levi's are the ugliest jeans and RT @username_Levi's has THE best jeans. Additionally, as mentioned above they retweeted with the intention to win a contest or receive gifts, for example, RT @username Levis Jeans at the Lowest Price Anywhere! https://webaddress RT for auto entry to win! Code $1515=$ $15 \%$ discount!!. On the other hand, Bloggers retweeted promotional tweets such as $R T$ @username Check out Levis 505 Med Blue Denim 40 x 30 Men Jeans \#Levis \#Relaxed https://webaddreaavia@eBay. These retweets suggested that they may be acting brand ambassadors for Levi's either voluntarily or with paid partnership. Similarly, online businesses promoted their products through retweets and increased their followers using the reciprocal hashtags such as likeforfollow while individual users retweeted to win free giveaways or highlight a popular event. For example, RT @ username \#Levis \#Jeans 510 Teal Blue \#Jeans Skinny Fit Low Rise 62209-0034 28293032 @ebay \#F4F \#likeforfollow https:/webaddress. 
While the top contributor represented all the authors that participated in this category, the type of author could not be differentiated. From a marketing perspective, it may be beneficial for the brand to know which type of members are facilitating conversations through retweets. Some of the members may also be contributing to the conversations according to their requirement. Others can be influenced to participate if the brand addresses their needs. However, all the retweets are placed under one subcategory as per the framework created by Dann (2010). This also includes Levi's own account where message circulation was expanded through retweets. Therefore, authors in the category cannot be distinguished from one another.

\subsubsection{UGC (3.2) - Non-branded Tweets}

The user-generated category had only 8 tweets from different individual authors. All the tweets were created by the authors to display their clothing styles or ideas. Additionally, all the tweets included pictures, three of which were linked to the authors' Instagram account. Four authors had an authority score of 5, however, the highest authority score for the sub-category is 7 while the lowest is 1 . The author with authority score of 7 was also the one with the highest number of followers (2911 followers). These authors demonstrated a medium to low impact on the overall community in Twitter. This is because their authority scores and the number of followers was quite low when compared to authors from other sub-categories. Additionally, the total number of tweets in this sub-category was very small low. Therefore, UGC category did not make much contribution to the conversations in Twitter. 


\subsubsection{Endorsement (3.3) - Non-branded Tweets}

A word cloud was created with Nvivo 11 Pro to find the most used words for the Endorsement category. Words such as jeans, levis and https were removed from the top 100 hundreds words. Additionally, Twitter handles that were included due to recurrences were also removed. "eBay" was the most used word followed by “@levis" then "size”. This indicates that most of the endoremsents were to promote products for eBay accounts. Another prominent word was "mens" revealing that a lot of the tweets were related to mens products. The word cloud also contained words such as "striaght", " fit", and "vintage", suggesting that a lot of the tweets were style oriented. Similarly the collection names from Levi's, such as 501 and 505, were also mentioned signifying that the tweets posted were collection specific.

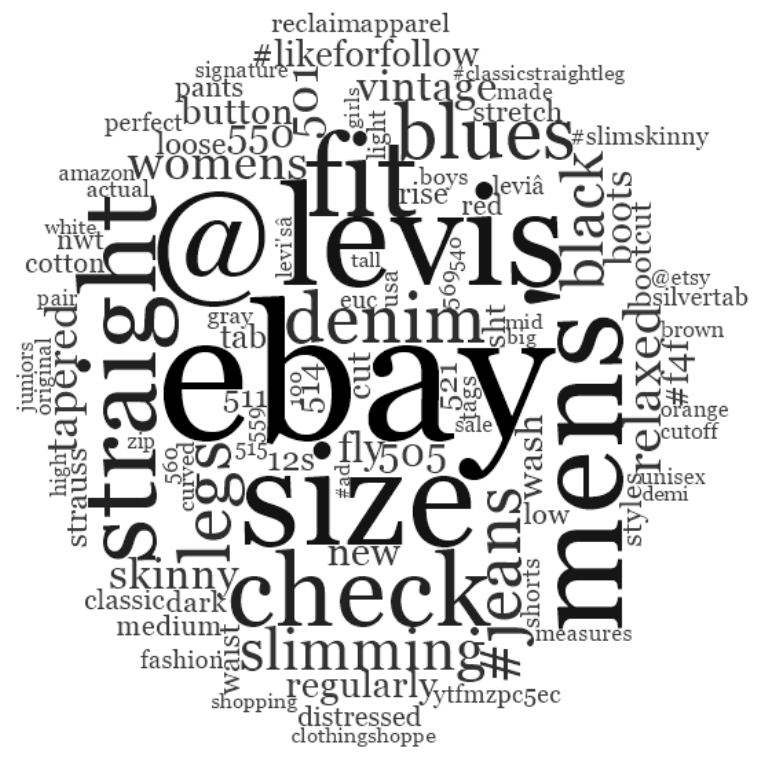

Figure 17. Top 100 words from non-branded Endorsement sub-category

Themes for Endorsement subcategory were next created as portrayed in Figure 18. Three major themes were created namely, Ebay, vintage and etsy. Ebay was the largest theme with 2,415 mentions in this category. The concepts for this theme are all product oriented terms such as fit, 
jeans, size, straight, black, eBay, relaxed, Slimskinny, wash and Bootcut. The theme strengthens the findings from word cloud, Figure 17, which revealed eBay as the most used word in the Endorsement category. Similarly, the concepts that arose in this theme also appeared in the top 100 words used for Endorsement, further confirming the results. The concepts formed were also closely positioned revealing a strong co-occurrence among the words. For example, Mens $33 \mathrm{X}$ 34 Levis 550 Relaxed Fit $\sim$ Stonewashed Denim Blue Jeans via eBay

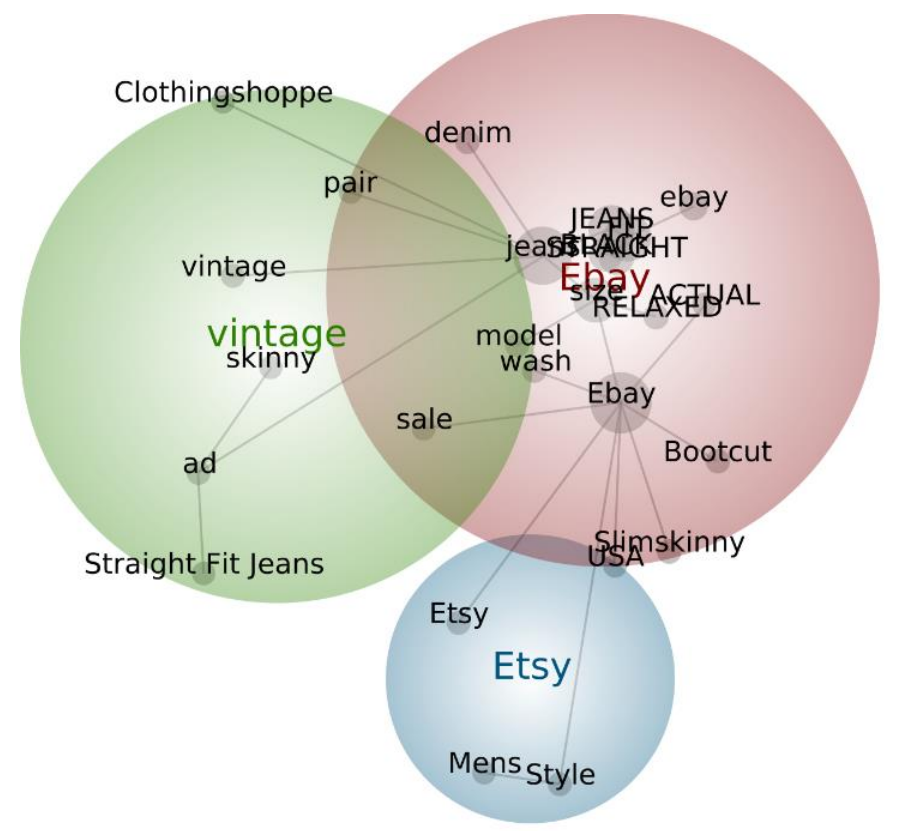

Figure 18. Concept map for non-branded Endorsement tweets

The second largest theme formed was "vintage" with 171 references and contained concepts such as sale, skinny and straight fit. The last theme, "etsy" also contained four concepts namely Etsy, Style, USA, and Mens. Mens and style were closely located indicating a strong relation among the concepts. All the themes and concepts formed under Endorsement are product oriented and as result it can be assumed that the endorsed tweets are associated with an online store where the message describes product attributes. 
To delve more into the type of contribution to this subcategory, the members were assesed based on their contribution and followers. Figure 18 illustrates the top contributor for the Endorsement category. The contribution was measured in Tableau 10.2 by calculating the total number of tweets posted by each Twitter handle for Endorsement category. The chart also shows the authority score of each account along with their number of followers. From the chart it is

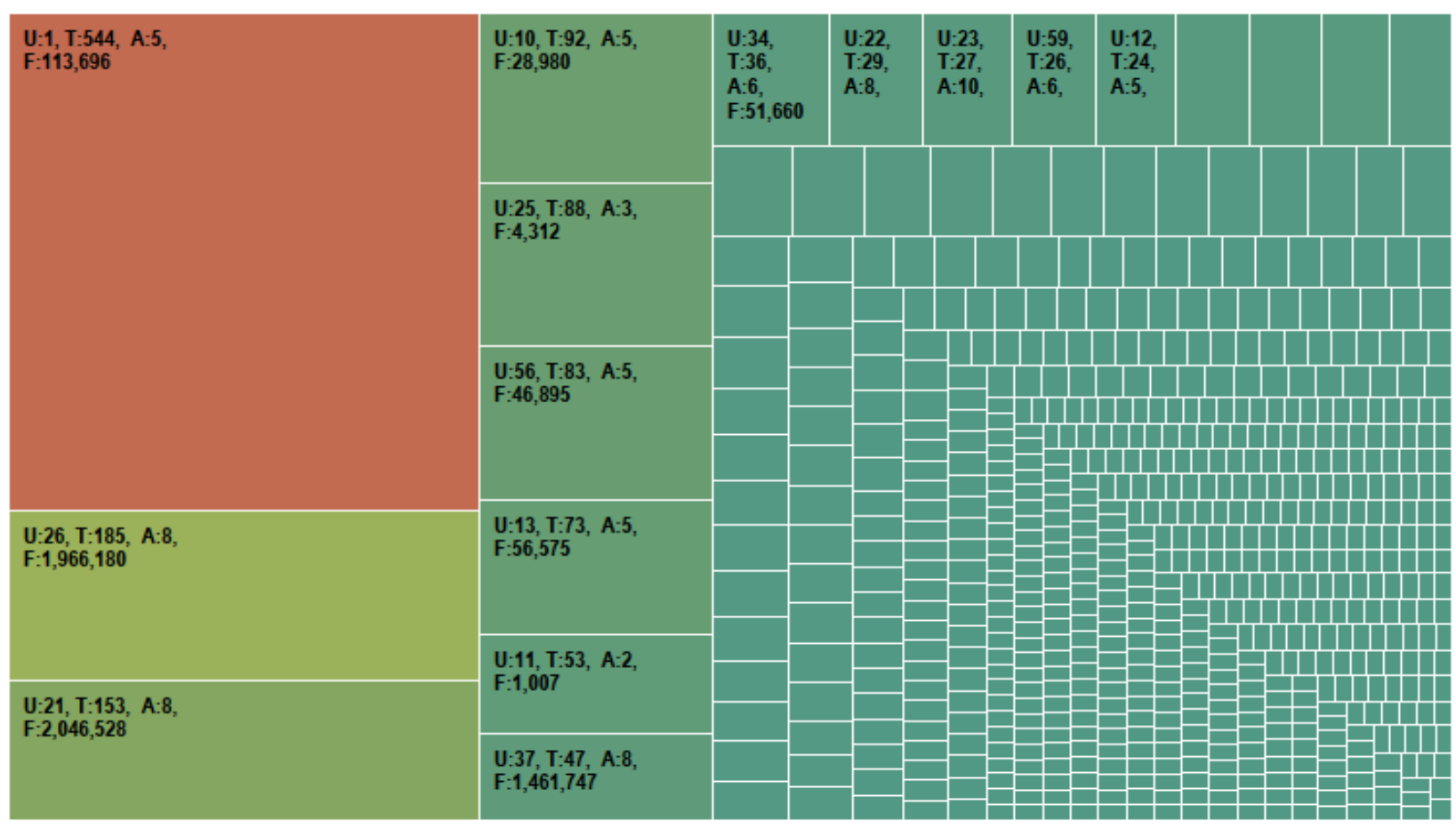

U:Author Number, T:Number of Tweets, A: Authority Score, F: Number of Followers

Figure 19. Top Contributors for Endorsement (non-branded)

seen that the account named Author 1 had the highest number of tweets (544 tweets) with over a million followers and has an authority score of 5 out of 10 . Even though the account does not have a high authority score or contains the largest number of followers in the brand community, it is considered as a top contributor because it contributed more than $20 \%$ of the conversation in the endoresement category. The Twitter page of the account and the tweets posted revealed that the account belongs to an online store where most posts were promoting a product available in 
the ebay account associated with the Twitter handle. This finding was consistent for the top ten contributors where each account was associated with an e-commerce business and a majority of the tweets were advertisements for products that they sold online. The authority score varied from 8 to 3 signifying that high reach and influence over other members differed greatly among the top contributors.

\begin{tabular}{|c|c|c|c|}
\hline Author \# & Auth. Score & Followers & Number of Tweets \\
\hline 201 & 10 & $8,766,408$ & 4 \\
\hline 23 & 10 & $2,098,710$ & 27 \\
\hline 21 & 8 & $2,046,528$ & 153 \\
\hline 1212 & 10 & $2,036,662$ & 1 \\
\hline 26 & 8 & $1,966,180$ & 185 \\
\hline 37 & 8 & $1,461,747$ & 47 \\
\hline 95 & 10 & $1,444,134$ & 2 \\
\hline 132 & 9 & $1,261,524$ & 19 \\
\hline 1367 & 10 & 668,189 & 1 \\
\hline 22 & 8 & 515,011 & 29 \\
\hline 1128 & 10 & 412,290 & 2 \\
\hline 1197 & 10 & 373,161 & 1 \\
\hline 1436 & 10 & 256,331 & 1 \\
\hline 1198 & 10 & 249,734 & 1 \\
\hline 1440 & 10 & 238,119 & 1 \\
\hline 399 & 9 & 178,929 & 3 \\
\hline 430 & 9 & 170,949 & 3 \\
\hline 1005 & 10 & 152,787 & 1 \\
\hline 725 & 10 & 148,846 & 1 \\
\hline 1433 & 10 & 143,071 & 1 \\
\hline
\end{tabular}

Table 9. $\quad$ Authors with high number of followers in Endorsement subcategory

To check the contribution of members who had a larger reach, authors with highest number of followers were tabulated as shown in Table 8 . The Table illustrates the top 20 authors categorized by the number of followers along with the authority score and number of tweets 
posted. Examining the Twitter pages reveled that all the accounts were associated with an online business with an authority score of 8 or above and contained more than a million followers. Unlike the top contributors, these accounts belonged to members from industry ranging from online stores to news channels. The message appeal for these tweets were functional where different product specifications were indicated. The author 201 had the highest number of followers with an authority of 10 . However, there were only 4 tweets from the account indicating that even though author had very high reach and influence he had minimal participation in the brand community. Two authors from the Table 8, were also top contributors indicating that these accounts may be creating a greater impact with high reach and more tweets. From the remaining accounts thirteen authors made less than five posts in the brand community.

These findings indicate that in a brand community, accounts that are posting the most may not have the largest reach, whereas accounts with the largest reach and influence may not be posting enough about the brand. Analyzing tweets from these accounts also revealed that the tweet contents for accounts associated with online stores differed from that content from a news channel. The online stores focused more on product details such as size, availability and price whereas the news outlets announced significant events such as product launch or store unveiling. However, these differences cannot be distinctively categorized with classification suggested by Dann (2010). 


\subsection{Inferences}

Analysis of non-branded and branded communication revealed that the brand was dependent on user-generated content while they focused on resolving customer complaints or queries. The qualitative software used automated techniques to analyze word frequency, create themes and evaluate community members for sub-categories. At least two software programs were used to triangulate the results which further strengthened the findings. Based on these findings, the communication approach for Conversational and Pass Along categories can be distinguished in into different classifications for branded and non-branded tweets as shown in Table 9.

\begin{tabular}{|c|c|c|c|c|}
\hline & \multirow{2}{*}{$\begin{array}{l}\text { CATEGORY } \\
\text { IMPRESSIONS }\end{array}$} & \multicolumn{3}{|c|}{ Automated techniques } \\
\hline & & $\begin{array}{l}\text { NVIVO } 11 \text { PRO } \\
\text { (Word frequency) }\end{array}$ & $\begin{array}{c}\text { LEXIMANCER } \\
\text { (Themes) }\end{array}$ & TABLEAU \\
\hline $\begin{array}{l}\text { Non-branded } \\
\text { conversational }\end{array}$ & RESPONSIVE & $\begin{array}{l}\text { - @LEVIS } \\
\text { - thank } \\
\text { - boycott }\end{array}$ & - @LEVIS & $\begin{array}{l}\text { Responses to } \\
\text { Levi's events } \\
\text { during high } \\
\text { frequency } \\
\text { months }\end{array}$ \\
\hline $\begin{array}{l}\text { Branded } \\
\text { conversational }\end{array}$ & $\begin{array}{l}\text { CUSTOMER } \\
\text { SUPPORT }\end{array}$ & $\begin{array}{l}\text { - Sorry } \\
\text { - Please } \\
\text { - Support }\end{array}$ & $\begin{array}{l}\text { - } \text { Customer } \\
\text { support } \\
\text { - Issues } \\
\text { - Sorry } \\
\text { - Thanks } \\
\end{array}$ & $\begin{array}{l}\text { Discussions } \\
\text { of problems } \\
\text { in purchase }\end{array}$ \\
\hline $\begin{array}{l}\text { Non-branded } \\
\text { Pass Along }\end{array}$ & $\begin{array}{c}\text { ENDORSEMENT } \\
\text { OF ECOMMERCE } \\
\text { SITES }\end{array}$ & $\begin{array}{l}\text { - eBay } \\
\text { - Sale } \\
\text { - likeforlike }\end{array}$ & $\begin{array}{l}\text { - eBay } \\
\text { - etsy } \\
\text { - sale } \\
\text { - likeforlike }\end{array}$ & $\begin{array}{l}\text { - Endorsing } \\
\text { products } \\
\text { with links to } \\
\text { ecommerce } \\
\text { business } \\
\text { - eBay users }\end{array}$ \\
\hline $\begin{array}{l}\text { Branded Pass } \\
\text { Along }\end{array}$ & $\begin{array}{l}\text { PROMOTIONAL/ } \\
\text { STYLE } \\
\text { ORIENTATION }\end{array}$ & $\begin{array}{l}\text { - } \text { iconic } \\
\text { - skinny } \\
\text { - vintage } \\
\text { - } 505\end{array}$ & $\begin{array}{l}\text { - \#liveinlevis } \\
\text { - Vintage } \\
\text { - Inspired } \\
\text { - } 505\end{array}$ & \\
\hline
\end{tabular}

Table 10. Category Impressions for Conversational and Pass Along category 
The non-branded Conversational category contained tweets that were reactive to announcements from Levi's. Members responded to these events and often directed their responses to the brand. Similarly, the branded Conversational category also contained responses however, these were focused on resolving customer complaints and queries that required a customer support orientation. The Pass Along category for branded and non-branded communication were promotional in nature. Non-branded Pass Along tweets comprised endorsements for ecommerce businesses by using links in their tweets that shifted the users to ecommerce site. These tweets also prompted the like for follow practice where users followed another with the expectation to be liked or followed in return. Lastly, the Branded Pass Along category comprised on promotional tweets where the brand advertised their product using fashion oriented messages and hashtags.

\section{Discussion}

Online community has been defined as a social group that originates on the internet when people converse in this communication channel and gradually build relationships within the virtual space (Rheingold, 1993). For a span of less than one year nearly seventy thousand tweets from were downloaded from Twitter. Pre-processing and cleansing provided more than five thousand tweets from multiple users who interacted with each other based on their personal or business needs. This confirms the presence of Levi's brand community where members communicated with each other forming a connection within themselves and also with the brand. Examples include conversations on customer service issues, and sharing information such as user-generated content. While this research examined the Levi's Twitter community for nearly a 
year, it did not measure how these relationships evolved or the strength of ties between actors in the community. Additional research using a different methodology, such as social network analysis, would be required (Gruzd, Paulin, \& Haythornthwaite, 2016). Members of the community ranged from online businesses to individual users and illustrated different posting patterns. According to Jin \& Kim (2006) participation in online communities is influential in establishing consumer opinions and actions. Behaviour within virtual communities exhibits a complex process that includes acquiring knowledge, evaluate alternatives and share feedback (Thomas, Peters, \& Tolson, 2007). The Levi's online community was found to be member driven where $98 \%$ of the conversation was user generated indicating that the brand relied on online users to direct conversation in the community. Analysing the overall content of the tweets revealed that members' actions mainly focused on sharing a diverse set of product details. The tweets posted in the data sample were about size, style, availability or events.

Comparing branded and non-branded tweets disclosed that non-branded users were more active in social media than Levi's. The brand tweeted 520 tweets in a span of one year while non-branded sources provided more than the five thousand tweets used in the sample data set. Therefore, the brand was not the primary source of brand communication. As most of the nonbranded users were associated with an online business, participation from non-branded sources peaked at the end of the year when most retailers opt for holiday sales. Content created from non-branded sources produces opportunities for brands to increase brand communication through user-generated social media communication (Schivinski \& Dabrowski, 2015). The messages from non-brand sources may involve different topics, including style and products attributes. In case of Levi's Twitter community, majority of the messages from non-brand sources (73.6\%) were categorized under Pass Along category from Dann's classification (2010) while most of the 
tweets from Levi's were under the Conversational category. Comparison between these two categories revealed that tweets from Levi's were service oriented while the messages from nonbrand sources had a marketing orientation.

\subsection{Branded Communication}

Brands select a communication strategy approach and message appeal that will help build or create brand experiences, identity, responses, and relationships (Swani, Brown, \& Milne, 2014). A majority of the brands belonging to the clothing industry use social media platforms, such as Facebook and Twitter, to communicate information about new products, latest styles, and seasonal fashions (Schivinski \& Dabrowski, 2015). This research suggests that Levi's main strategy was dedicated to resolving customer issues and in turn recuperate or strengthen relationship. Brand relationship motivates customer loyalty and trust within the community that may eventually lead to long-term brand commitment (Brodie, Ilic, Juric, \& Hollebeek, 2013). One key driver of brand commitment is positive post-consumption evaluation of a product or service that leads to customer satisfaction (Popp \& Woratschek, 2017). In Levi’s Conversational tweets, the themes formed for branded tweets depicted a customer service orientation in the messages where the brand was more focused on guiding customers to solve any complaints. Concepts such as "sorry" and "customer support" were formed for the Conversational category that further showed customer service orientation in the messages. The brand emphasized on solving problems as a means to create positive interactions, which may lead increases customer satisfaction. A higher level of customer satisfaction influences loyalty which in turn increases positive WOM (Popp \& Woratschek, 2017). As the community is driven 
by user-generated content, positive WOM may create a strong supportive behavior toward Levi's.

The brand also indulged in marketing practices using product attribution in their messages, which was visible in their Pass Along category that had 105 messages. The results did not find any indication that the brand was utilising their heritage as a means to capture consumer interest. There were 29 original tweets that were posted by Levi's while the remaining 76 were retweets. Therefore, the brand mostly depended on user-generated content for creating awareness or promotion as most of their contribution was in communicational tweets. Levi's branded communication may provide reassurance in instances of cognitive dissonance. Cognitive Dissonance refers to inconsistent thought or doubts about a decision that has already been made (Babin, Murray, \& Harris, 2014). For example, Tweets or retweets where fashion products are advertised differently may provide positive reinforcement for the consumer, reducing cognitive dissonance. Additionally, online customer service and support may also counter cognitive dissonance and create a positive evaluation that may lead to repeat business and, eventually, loyalty.

\subsection{Non-branded Communication}

For non-branded communication, Endorsement and Retweet comprised of the largest quantity of tweets when compared to other sub-categories created by Dann (2010). Pass Along tweets from non-branded sources promoted the brand using product attributes. These tweets were generated from members that are associated with an online business outside Twitter like eBay and Etsy where product promotion heavily relies on creating online awareness. This resonates 
with the results from Jin \& Kim (2006) which state that online apparel retailers with no brickand-mortar stores are more committed to hosting online communities. These members were more frequent posters and had high interaction with each other through tweets or retweets which ensured that there is enough information flow to keep the virtual community active. Additionally, their tweets followed the similar content structure and therefore, it was easy to follow and craft a response. An analysis of the Pass Along category for non-branded tweets revealed that a majority of the contributors were comprised of e-commerce accounts who were promoting their product through Twitter. eBay was the most prominent online business that was mentioned in the tweets, followed by Etsy. Tweets from these categories included product description and links that can be used to visit the e-commerce website.

In Levi's community, non-branded retweets were used prominently by online stores either to broadcast a significant event or to promote their products. For online businesses, retweets from other members ensures that their messages reach new audiences which may, in turn, increase the number of followers (Boyd et al., 2010). It creates visibility, spreadability, and reputation that are crucial to attaining commitment and trust from followers. Boyd et al. (2010) suggested that the practice of retweeting was the way to amplify or spread tweets to new audiences. Retweeting assists members to gain followers or reciprocity from more visible contributors. Themes created for the Retweet category contained the concept "likeforfollow" which was also one of the top 100 words used in the non-branded retweet corpus. This suggests that online users strived to increase their reach and number of followers by offering to like or follow other members if their messages were liked or followed. Therefore, while some online businesses may retweet altruistically, there were plenty who sought out attention from the authors they retweeted with the expectation that the action would be reciprocated in the future. 
Additionally, there were individual users with no business affiliations. A user retweets a tweet if it is recognised as valuable information that should be shared with other members. Additionally retweeting may act as a catalyst to start a conversation and stay connected with other members (Lee, Kim, \& Kim, 2015). It enables members to share information, build social relations and express themselves. Lee, Kim, \& Kim (2015) pointed that members retweets for greater social interactions, more intimacy with other members on their network and to exert more influence on their followers. This also resonates with Whiting \& Williams (2013) who identified social interaction, information exchange, and self-expression as a few reasons for social media usage. Contents of retweets in Levi's community echoed their findings as the messages varied from promotional tweets to messages related to personal needs. Moreover, the retweets also included messages about product launches, brand events or other news that may trigger strong feeling about the brand. "Messages that contained product information negatively influenced engagement" (Vargo, 2016, p. 10). However, in the case of Levi's numerous individual users, retweeted messages contained product information. Individual users who have close relationships with the brands are more likely to retweet brand messages to their followers to ensure reinforcement the brand messages (Kim et al., 2014).

Like Retweets, the majority of the tweets in the Endorsement subcategory were also from members with online stores. This sub-category had the largest volume of tweets where members promoted their products with a description or discount offers. Most of the tweets contained the item description, a link to the item, relevant hashtags, and a photo, indicating that several members were using the same format to encourage other members to respond to the message. The tweets contained cues for direct calls to purchase such as "sale", "check out" or "grab a pair" which emphasised selling products and encouraging impulsive, short-term sales rather than 
long term relations (Swani, Brown, \& Milne, 2014). The message content for some the tweets reflected the findings from Vargo (2016) which identified giveaways, contests, and sweepstakes as common marketing practices on social media. Promotions on social media may create a more visible contributory engagement, where members may click on the link, like, or retweet the message, or leave a comment for the message originator.

In addition to online stores, the Endorsement category also contained members from other online business such as fashion bloggers, news portals individual users etc. Bloggers or news portals may directly influence members in their network through suggestions or recommendations that may affect purchase decisions and products usage (Uzunoglu \& Kip, 2014). Furthermore, fashion blogs and media outlets may be valuable for brands as members may send links to others with brand offerings extending the reach of the brand. The audience reach for some of the fashion blogs and news outlets were higher than the others; however, in contrast to the members affiliated with the online stores the contributions they made in the community were relatively low.

Tweets are a low-cost form of business promotion due to which both Retweets and Endorsement experience a large volume of tweets. However, for both the categories the distinction in the types of authors was unclear. With Dann's classification (2010), different types of authors were grouped under one sub category even though the business type was different. Different businesses may have different purposes for interacting in Twitter, therefore, the intent for the messages may be different. However, using Dann's classification (2010) the results provided an overall snapshot of tweets in each subcategory without considering any difference in the author type. 


\subsection{Marketing Implications}

From a marketing perspective, the grouping of all members in one sub-category, regardless of the account type, may result in missing valuable information. Levi's can leverage online interactions for marketing purposes (de Valck, van Bruggen, \& Wierenga, 2009), however, due to the difference in author's intentions each type of author may require a different way of presenting brand message. Online sellers aiming to boost their audience reach will use promotional tweets that are targeted to reach specific groups at the right time and place (Swani et al., 2014). These accounts are focused on creating more followers and influencers. On the other hand, individual members aim to fulfill their psychological motivations such as social interaction, expression of opinions among others (Whiting \& Williams, 2013). According to Wirtz et al (2013) participation in an online community form a social identity by psychological membership which boosts positive self-esteem and satisfies social needs. Therefore, segmenting the authors' account according to their types may allow Levi's s to precisely reach a consumer with specific needs and wants. The brand can better utilize the conversation occurring in the community and understand the contributions different types of authors offer. For example, companies can engage with individual users to create a positive experience in a virtual community. They can offer exclusive monetary incentives such as loyalty points, lucky draws and price promotions to foster engagement. Such interactions give rise to customer engagement behaviors including word-of-mouth recommendations, helping other consumers and positive written reviews about the brand (Wirtz et al., 2013). Participation in an online community may increase a sense of satisfaction which in turn strengthen consumer trust and loyalty to the brand 
(Casaló, Flavián, \& Guinalíu, 2007). In addition, enhanced relationships in the brand community may help convert consumers into evangelists of the community and the brand.

Similarly, brands can utilize the influence of bloggers and fashion news channels to generate interest, drive action, enhance image, develop expertise, and create dialog with their online customers (Uzunoglu \& Kip, 2014). “Invoking a brand's heritage generates positive emotions and trust, which promote attachment and commitment, thereby increasing purchase intention" (Rose, Merchant, Orth, \& Horstmann, 2016, p. 941). As heritage brand, Levi's may collaborate with influential bloggers or fashion enthusiast to highlight the trust-enhancing qualities of a brand's heritage to generate stronger attachments and trust with the brand. Additionally, Levi's may contact fashion magazines to focus on the brand's heritage in their messages to trigger positive emotions and commitments through nostalgic memories, which in turn may increase purchase intent.

The brand's awareness and understanding of content from distinct author type may enable marketers to leverage the communication occurring in the community. However, with the existing classifications created by Dann, such distinction is not possible. Therefore, these classification needs to be modified and segregated to remove the overlap of different author types.

Tweets from the Conversational category for branded and non-branded sources totaled to less than 500 for each category. Therefore, there was not sufficient data to deduce any pattern based on the types of author contributing to each category. Similarly, the Pass Along category from Levi's tweets did not provide sufficient data. As a result, the Pass Along category from non-branded sources were used to infer further suggestions. 
Based on findings, the Retweet category is divided into two user groups, one for online sellers and the other for individual users. Alternatively, the Endorsement category may be divided into three groups: online sellers such as eBay, Etsy and Amazon, online businesses entities such as online fashion magazines and news outlets, and individual users. In Table 10, the scholarly literature is used to explain the aim of each user group.

\begin{tabular}{|c|c|c|c|}
\hline Sub-Category & Aim & Reference/Literature & Example \\
\hline \multicolumn{4}{|l|}{ RETWEET } \\
\hline Online sellers & $\begin{array}{l}\text { Amplify or spread } \\
\text { message }\end{array}$ & Boyd et al. (2010) & $\begin{array}{l}\text { RT @user \#Levis \#Jeans } \\
513 \text { Slim Straight Fit } \\
\text { Trousers Jogger Line } 8 \\
\text { @ebay \#F4F } \\
\text { \#likeforfollow }\end{array}$ \\
\hline Individual users & $\begin{array}{l}\text { Information sharing, } \\
\text { self- expression }\end{array}$ & $\begin{array}{l}\text { (Whiting \& Williams, } \\
\text { 2013) } \\
\text { Lee, Kim, \& Kim } \\
\text { (2015) }\end{array}$ & $\begin{array}{l}\text { RT @ user I remember } \\
\text { rocking Levi's now I rock } \\
\text { designer jeans }\end{array}$ \\
\hline \multicolumn{4}{|c|}{ ENDORSEMENT } \\
\hline Online sellers & $\begin{array}{l}\text { Emphasize on direct call } \\
\text { for purchase through sale } \\
\text { and giveaways }\end{array}$ & $\begin{array}{l}\text { (Swani et al., 2014), } \\
\text { (Vargo, 2016) }\end{array}$ & $\begin{array}{l}\text { Get } 20 \% \text { Off } 2 \text { Items Or } \\
30 \% \text { Off } 3+\text { Items @ Levis } \\
\text { with code thru Oct } 24 \text { th } \\
\text { \#Denim \#Jeans } \\
\text { \#SkinnyJeans \#Vintage }\end{array}$ \\
\hline $\begin{array}{l}\text { Online business } \\
\text { entity such as } \\
\text { online forums, } \\
\text { paid bloggers, } \\
\text { news channels etc. }\end{array}$ & $\begin{array}{l}\text { Share information about } \\
\text { product, trends or events } \\
\text { encompassing the brand. }\end{array}$ & $\begin{array}{l}\text { (de Valck et al., 2009; } \\
\text { Uzunoglu \& Kip, } \\
\text { 2014) }\end{array}$ & $\begin{array}{l}\text { \#IdleMan How to Wear } \\
\text { Levi's } 501 \text { Jeans. Read } \\
\text { Blog: https:// }\end{array}$ \\
\hline Individual users & $\begin{array}{l}\text { Information sharing, } \\
\text { social interactions }\end{array}$ & $\begin{array}{l}\text { (Whiting \& Williams, } \\
\text { 2013; Wirtz et al., } \\
\text { 2013) }\end{array}$ & $\begin{array}{l}\text { Here's how I style } \\
\text { \#mylandsend jacket my } \\
\text { \#levis jeans and \#mydsw } \\
\text { booties }\end{array}$ \\
\hline
\end{tabular}

Table 11. Proposed subdivision of Pass Along sub-categories 
Dividing the categories into additional groups will help to identify the types of authors with most contributions. Marketers may, therefore, create engagement strategies or a campaign that is tailored to the specific author type that is dominant in their community. Additionally, marketers may strategize to gain followers for other categories that may be under-represented, but important. Measuring the success of a campaign may depend on the involvement of the types of audiences that the brand is targeting. Isolating business users from individual users or consumers may also help the marketers understand how their products are re-marketed and sold on social sites. This gives them an opportunity to know more about product's success and how they are promoted from online retailers. In addition, a business may be able to evaluate the activity of online sellers for slow-moving products to check the price or strategy used for the same product online.

Similarly, brands can distinctly monitor the activities of individual users to understand their perception of the brands that may have not been affected by their business intentions. Moreover, Bloggers or online personalities who make constant or valuable contributions as nonbranded authors can be evaluated as potential online influencers to enlarge customer reach and influence. With the new categories found in this thesis, brands may be able to gauge the success or gaps in their campaign depending on the type of users that became involve in their community due to the campaigns.

There are many ways to create engagement for a brand which vastly depends on the industry the brand belongs to and its target audience. However, some general activities can be utilized to create engagement, such as being available for its customers at any time and understanding consumer intention to engage with the brand. The results from this thesis will help 
marketers to identify the types of users that are contributing to their online communities. They can create an engagement strategy accordingly to achieve the most from their approach.

\section{Limitations and Future Research}

The paper is an initial attempt to apply Dann's classification (2010) for customer engagement and further research is essential to develop several aspects of the framework. Using qualitative methods for support, the research was based on a single product from a heritage brand with a background and characteristic that may restrict generalisation. Therefore, the results may be only applicable to similar types of online communities, and cannot be assumed for all brand communities. Twitter data was used for the thesis and further research is required before implementing the findings in other social media platforms such as Facebook and YouTube.

Data collection depended on Sysomos Map, where the selection of tweets vastly depended on the Boolean search. However, the Boolean search terms used in the research are extensive and thus, it can be assumed that data selected contained all relevant information. Additionally, software used in the study were unable to detect 'emoji' symbols due to which tweets were removed during the data cleansing process. Use of emoticons is popular with social media users and marketers, thus removing them may eliminate useful information. Nevertheless, as the data source was large, sufficient data was retained for the thesis.

This research sheds some light on the Twitter discussions of a heritage brand however future research is required to gain a complete understanding of conversations. Future research should be done on other categories to investigate their potential to be divided further for 
improved interpretation of brand and non-branded conversations. For future studies on exploring Dann's (2010) classification or the relationship between brand and non-branded messages, researchers may use this thesis as a reference for literature and themes, and how they interrelate. An interesting avenue for research is to apply Dann's (2010) classification to other social media platforms like Instagram and Facebook. Results from the investigation may support generalization of the findings from this research across different online platforms. Moreover, a researcher may utilize the proposed sub-categories with other brands to see if they may be generalized across multiple online brand communities.

\section{Conclusion}

This thesis outlines some of the factors that are necessary to assess consumer engagement on Twitter. The research was undertaken to study Dann's (2010) classification using a recognised heritage brand in an online platform. Using a grounded theory approach 5,743 tweets were coded and the analyzed with qualitative software to develop two major categories from Dann's classification - Conversational and Pass Along. Further classification of these categories is expected to help marketers in the creation of their online campaign and assist in evaluating the success of the campaigns. Analysis of non-branded communications aided to understand the nature of users that acted as the primary content creators for the community. Using the results, the Pass Along category was expanded which enables to identify the type of users for each subcategory. In being able to identify the contribution from non-branded content creators, marketers can create or modify their online strategies to increase their reach and strength their online presence. 
Online communities provide inherent advantages of the vast reach, low cost, and high communication efficiency with varied customers (Laroche, Habibi, Richard, \& Sankaranarayanan, 2012). Popularity and acceptance of products online may have potentially important implications for a wide range of management activities, such as brand building, relationship marketing, customer acquisition and retention (Dellarocas, 2003). Understanding customer perception and creating an engagement strategy accordingly builds relationships that are defined by trust and commitment (Sashi, 2012). The results and discussions presented in the paper show why retailers and brand manufacturers who engage in social media marketing should implement Dann's (2010) classification with the additional categories. With a better understanding of the audience, businesses may recognize valuable possibilities that may well be the new frontier in their marketing strategy. 


\section{Appendices}

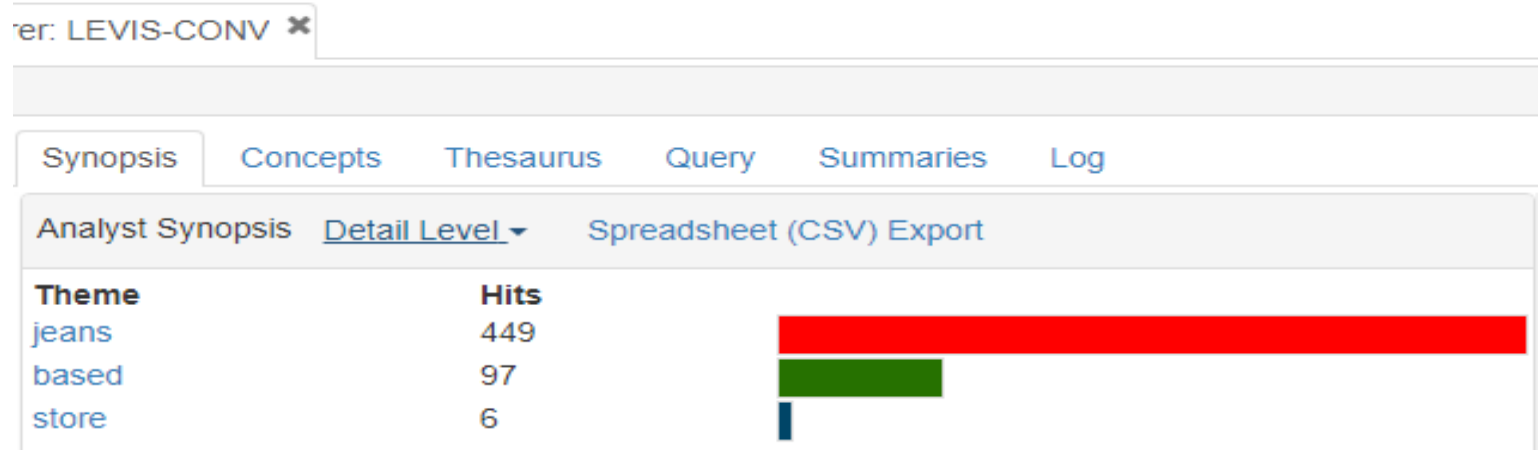

Appendix A. Thematic Synopsis for Branded Conversational Category

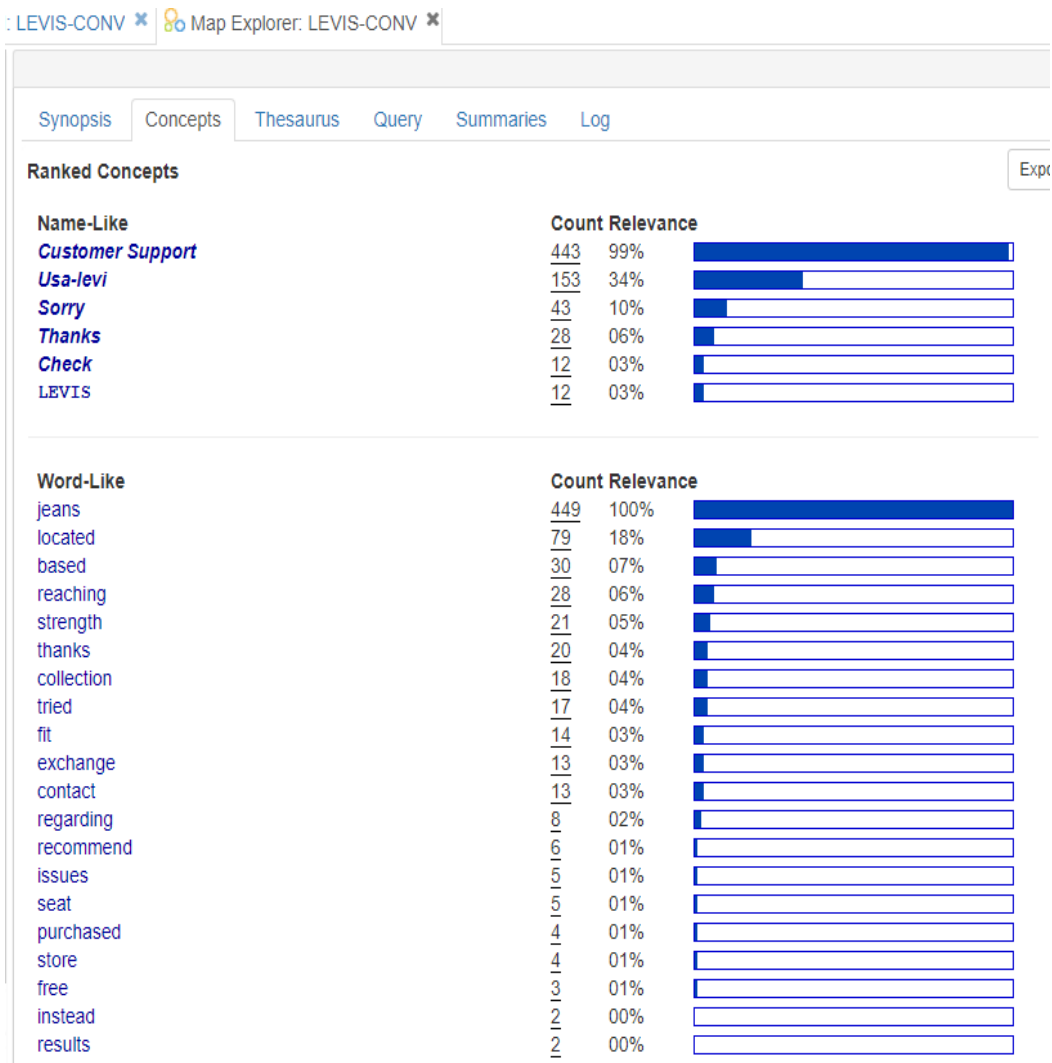

Appendix B. Ranked Concepts Branded Conversational Category 
ALONG $\mathbf{x}$

\begin{tabular}{|c|c|c|c|c|c|}
\hline Synopsis & Concepts & Thesau & Query & Summaries & $\log$ \\
\hline \multicolumn{4}{|c|}{ Ranked Concepts } & & Export- \\
\hline \multicolumn{2}{|c|}{ Name-Like } & \multicolumn{2}{|c|}{ Count Relevance } & & \\
\hline \multicolumn{2}{|c|}{ LEVIS } & 101 & $94 \%$ & & \\
\hline \multicolumn{2}{|c|}{ Shop } & $\underline{11}$ & $10 \%$ & & \\
\hline \multicolumn{2}{|c|}{ Liveinlevis } & $\overline{5}$ & $05 \%$ & & \\
\hline \multicolumn{2}{|c|}{ Word-Like } & \multicolumn{2}{|c|}{ Count Relevance } & & \\
\hline \multicolumn{2}{|c|}{ jeans } & 108 & $100 \%$ & & \\
\hline \multicolumn{2}{|l|}{ pair } & $\overline{12}$ & $11 \%$ & & \\
\hline \multicolumn{2}{|l|}{ shipping } & $\overline{6}$ & $06 \%$ & & \\
\hline \multicolumn{2}{|l|}{ stretch } & $\overline{3}$ & $03 \%$ & & \\
\hline \multicolumn{2}{|l|}{ trip } & $\overline{2}$ & $02 \%$ & & \\
\hline \multicolumn{2}{|l|}{ spotted } & $\overline{2}$ & $02 \%$ & & \\
\hline \multicolumn{2}{|l|}{ best } & $\overline{2}$ & $02 \%$ & & \\
\hline \multicolumn{2}{|l|}{ collection } & $\overline{2}$ & $02 \%$ & & \\
\hline \multicolumn{2}{|l|}{ dream } & $\overline{2}$ & $02 \%$ & & \\
\hline \multicolumn{2}{|c|}{ rock } & $\underline{2}$ & $02 \%$ & & \\
\hline \multicolumn{2}{|c|}{ vintage-inspired } & $\underline{2}$ & $02 \%$ & & \\
\hline better & & $\underline{2}$ & $02 \%$ & & \\
\hline designed & & $\underline{2}$ & $02 \%$ & & \\
\hline kids & & $\underline{2}$ & $02 \%$ & & \\
\hline wore & & $\underline{2}$ & $02 \%$ & & \\
\hline archives & & 1 & $01 \%$ & & \\
\hline $505 s$ & & 1 & $01 \%$ & & \\
\hline $70 \mathrm{~s}$ & & 1 & $01 \%$ & & \\
\hline guys & & 1 & $01 \%$ & & \\
\hline
\end{tabular}

Appendix C. Ranked concepts branded Pass Along Category

$\times$ 80 Map Explorer: LEVIS- PASS ALONG $\mathbf{x}$

Synopsis Concepts Thesaurus Query Summaries Log

Analyst Synopsis Detail Level - Spreadsheet (CSV) Export

Theme Hits

jeans 108

Shop 16

stretch 11

rock 4

Appendix D. Thematic Synopsis for Branded Pass Along Category 


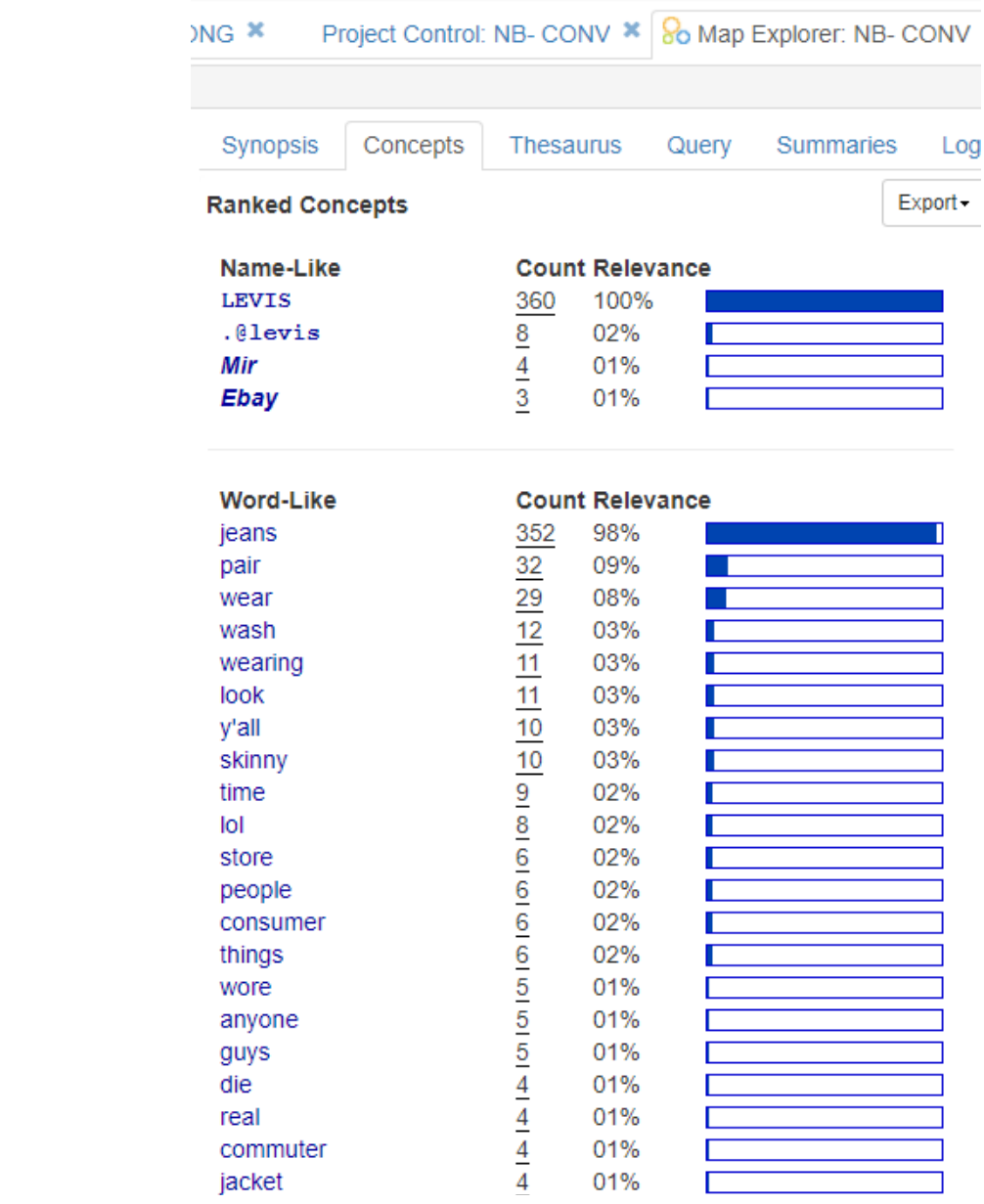

Appendix E. Ranked Concepts non-branded Conversational Category

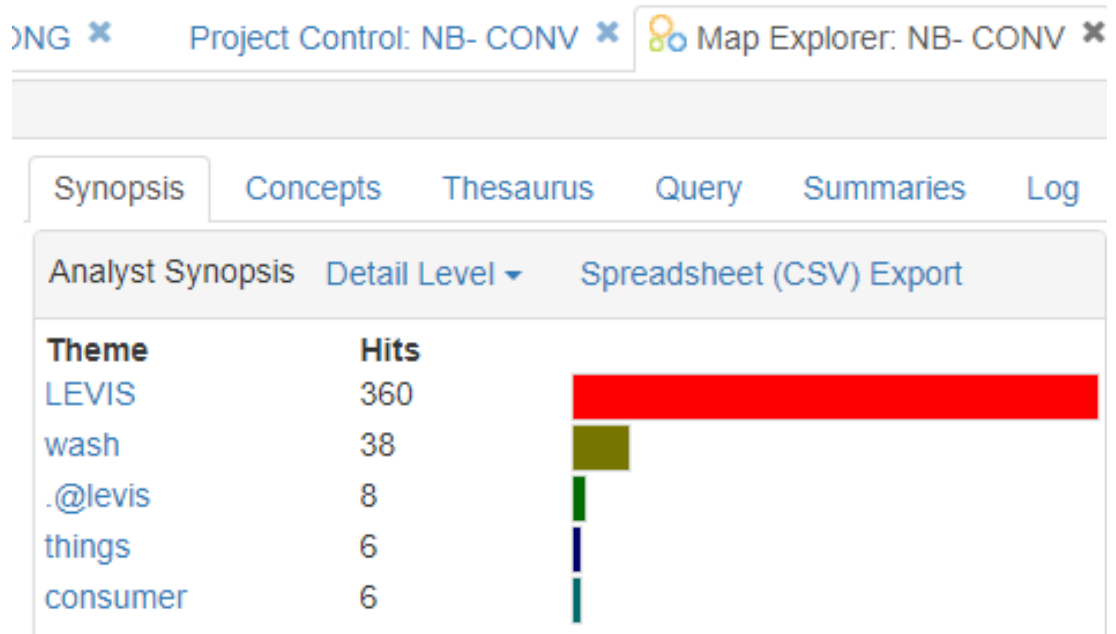

Appendix F. Thematic Synopsis for non-branded Conversational Category 


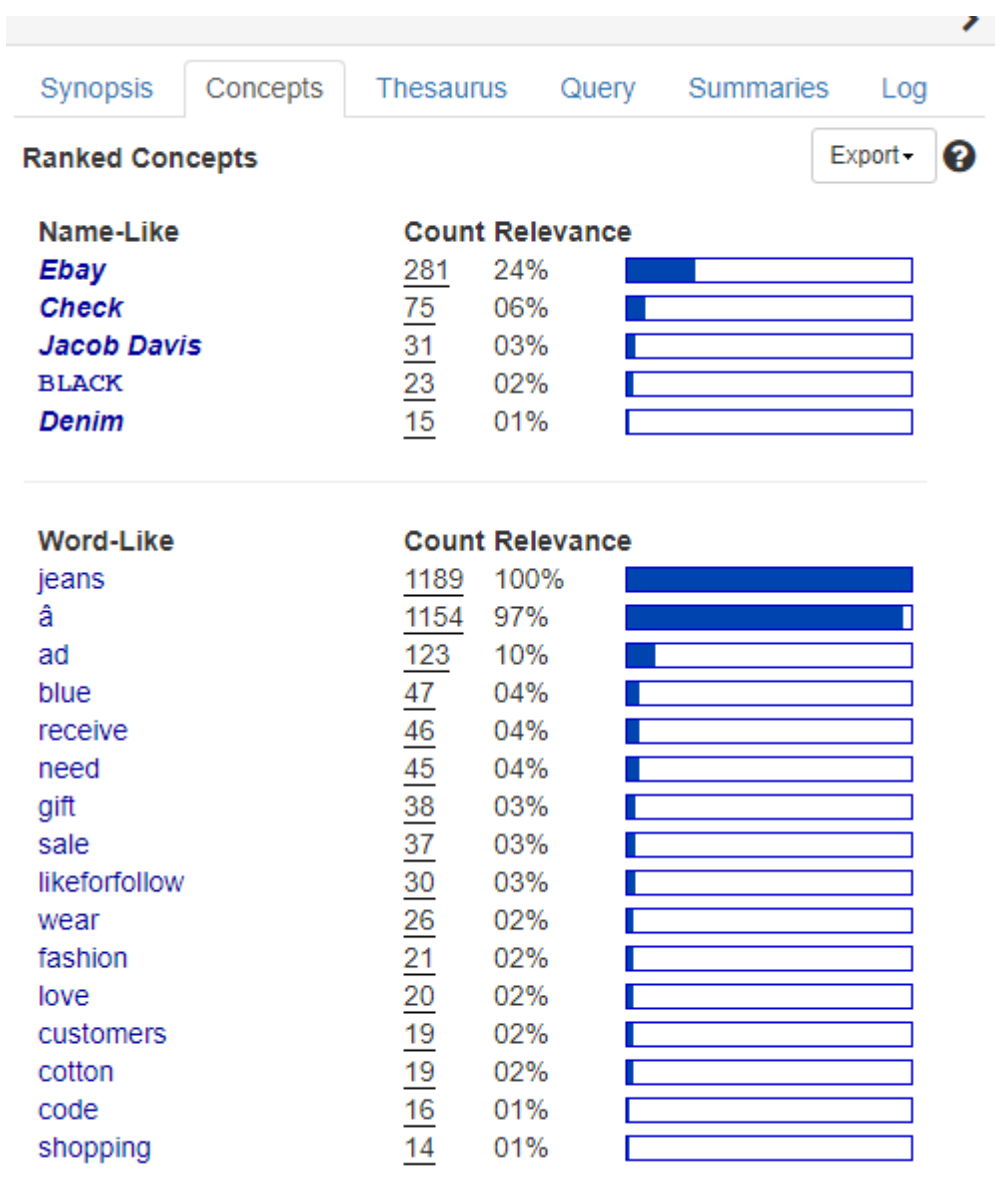

Appendix G. Ranked Concepts non-branded Retweet in Pass Along Category

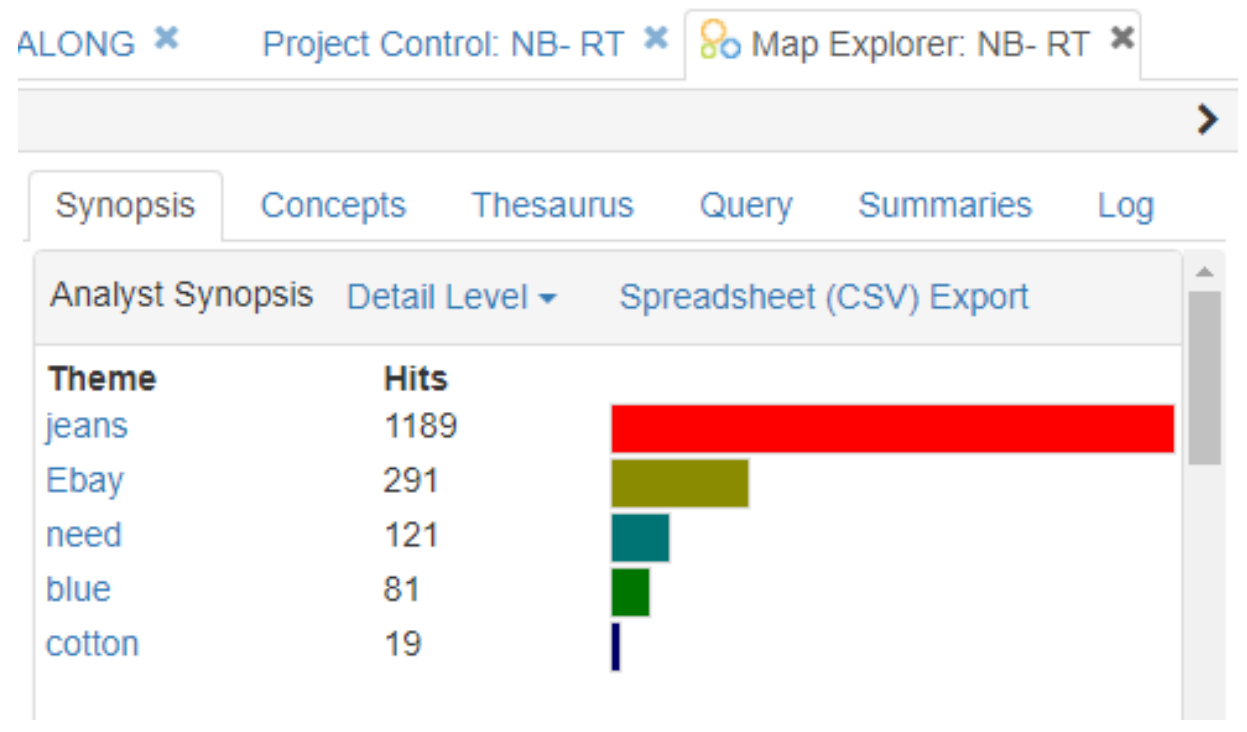

Appendix H. Thematic Synopsis for non-branded Retweet in Pass Along Category 


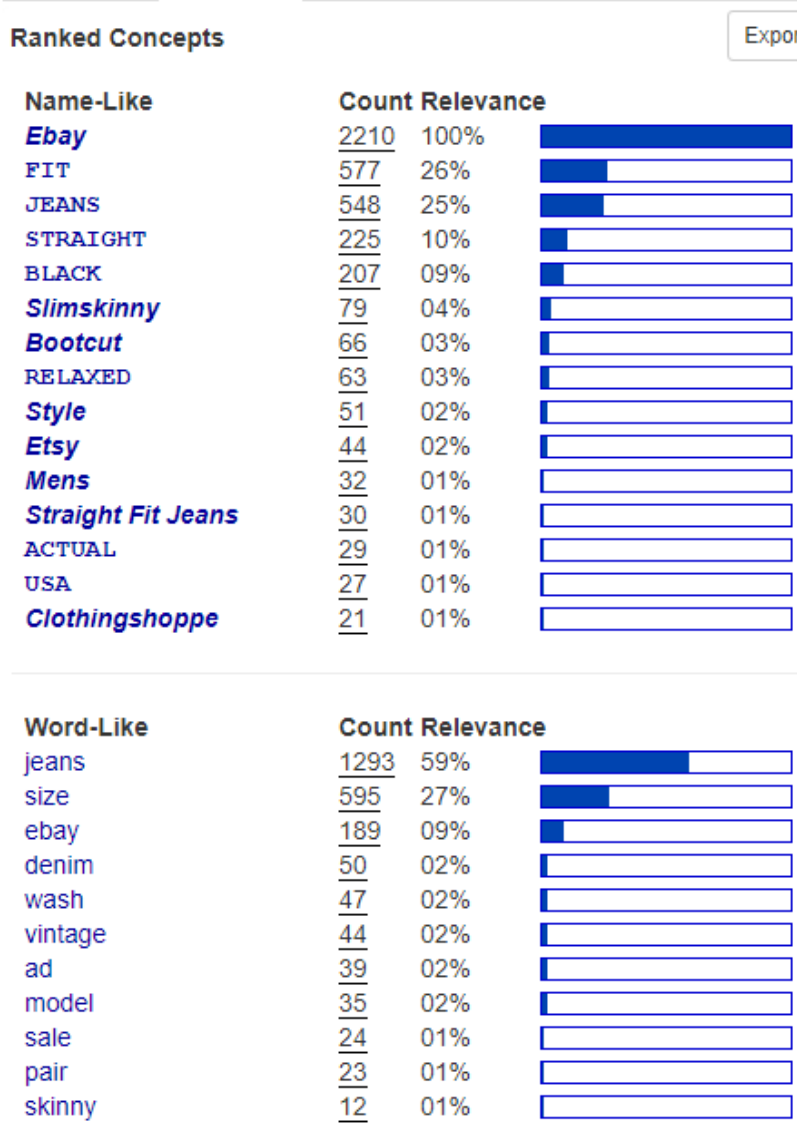

Appendix I. Ranked Concepts non-branded Retweet in Pass Along Category

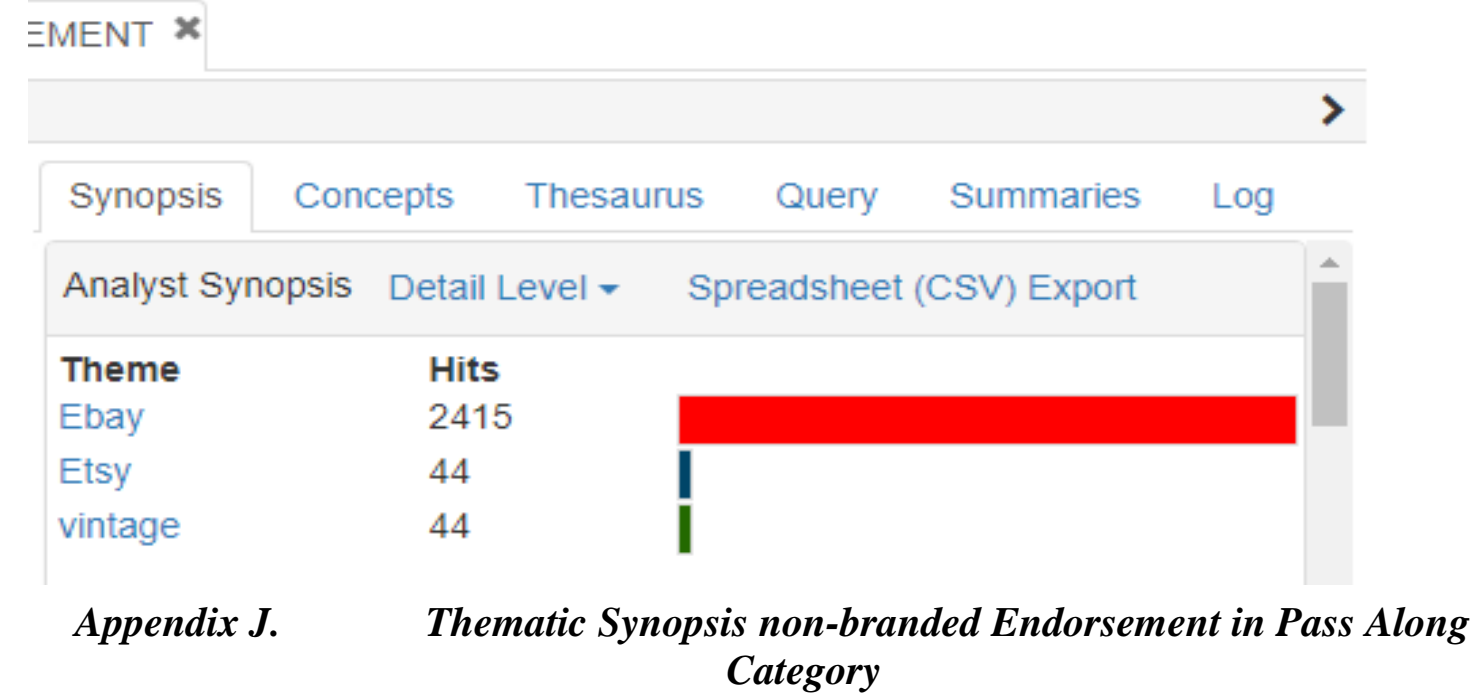


Chi-Square Tests

\begin{tabular}{|l|r|r|r|}
\hline & Value & df & Asymp. Sig. (2-sided) \\
\hline Pearson Chi-Square & $38832.901^{\mathrm{a}}$ & 56 & .000 \\
Likelihood Ratio & 10147.005 & 56 & .000 \\
Linear-by-Linear Association & 5513.675 & 1 & .000 \\
N of Valid Cases & 5743 & & \\
\hline
\end{tabular}

a. 47 cells $(65.3 \%)$ have expected count less than 5 . The minimum expected count is .00 .

Appendix K. SPSS output showing degree of significance of Kappa calculation 


\section{References}

Adjei, M. T., Noble, S. M., \& Noble, C. H. (2010). The influence of C2C communications in online brand communities on customer purchase behavior. Journal of the Academy of Marketing Science, 38(5), 634-653. https://doi.org/10.1007/s11747-009-0178-5

Albaum, G., \& Smith, S. (2010). An Introduction to Marketing. https://doi.org/10.1111/j.14784408.1970.tb02927.x

Andéhn, M., Kazeminia, A., Lucarelli, A., \& Sevin, E. (2014). User-generated place brand equity on Twitter: The dynamics of brand associations in social media. Place Branding and Public Diplomacy, 10(2), 132-144. https://doi.org/10.1057/pb.2014.8

Andersen, P. H. (2005). Relationship marketing and brand involvement of professionals through web-enhanced brand communities: The case of Coloplast. Industrial Marketing Management, 34(3), 285-297. https://doi.org/10.1016/j.indmarman.2004.07.007

Audi, R. (2014). Epistemology: A Contemporary Introduction to the Theory of Knowledge. Routledge. Retrieved from https://ebookcentral-proquestcom.ezproxy.lib.ryerson.ca/lib/ryerson/reader.action?docID=240430\#

Babin, B. J., Murray, K. B., \& Harris, E. G. (2014). CB-Canadian Edition.

Baboushkin, T. (2013). YouTube Case Study: Old Spice — Social Media Delivered. Retrieved May 24, 2017, from https://www.socialmediadelivered.com/blog/2013/08/29/youtube-casestudy-old-spice

Bazeley, P., \& Jackson, K. (2013). Qualitative data analysis with NVivo. SAGE Pubications.

Berg, B. L. (2009). Qualitative research methods for the social sciences (7th ed.). Allyn \& Bacon.

Berger, J., \& Milkman, K. L. (2012). What Makes Online Content Viral? Journal of Marketing Research, 49(2), 192-205. https://doi.org/10.1509/jmr.10.0353

Blaikie, N. (2010). Designing Social Research. Designing social research The logic of anticipation (2nd ed.). Polity Press. https://doi.org/10.1177/0957926512440660

Boyd, D., Golder, S., \& Lotan, G. (2010). Tweet, tweet, retweet: Conversational aspects of retweeting on twitter. Proceedings of the Annual Hawaii International Conference on System Sciences, 1-10. https://doi.org/10.1109/HICSS.2010.412

Brodie, R. J., Ilic, A., Juric, B., \& Hollebeek, L. (2013). Consumer engagement in a virtual brand community: An exploratory analysis. Journal of Business Research, 66(1), 105-114. https://doi.org/10.1016/j.jbusres.2011.07.029 
Brogi, S. (2014). Online Brand Communities: A Literature Review. Procedia - Social and Behavioral Sciences, 109(0), 385-389. https://doi.org/http://dx.doi.org/10.1016/j.sbspro.2013.12.477

Bruining, A. (2017). Pinterest Success: Nordstrom's, Tory Burch, Wayfair, and Lowe's Pinning Strategies. Retrieved May 3, 2017, from http://www.brittonmdg.com/the-brittonblog/brands-that-are-successful-on-pinterest

Bryman, A. (2015). Social Research Methods (5th ed.). Oxford University Press.

Bulearca, M., \& Bulearca, S. (2010). Twitter: a Viable Marketing Tool for SMEs? Global Business \& Management Research, 2(4), 296-309.

Cabiddu, F., Carlo, M. De, \& Piccoli, G. (2014). Social media affordances: Enabling customer engagement. Annals of Tourism Research, 48, 175-192. https://doi.org/10.1016/j.annals.2014.06.003

Casaló, L., Flavián, C., \& Guinalíu, M. (2007). The impact of participation in virtual brand communities on consumer trust and loyalty: The case of free software. Online Information Review, 31(6), 775-792. https://doi.org/10.1108/14684520710841766

Chahal, M. (2016). Social commerce: How willing are consumers to buy through social media? Marketing Week. Retrieved July 23, 2017, from https://www.marketingweek.com/2016/03/23/social-commerce-how-willing-are-consumersto-buy-through-social-media/

Chan, K. W., \& Li, S. Y. (2010). Understanding consumer-to-consumer interactions in virtual communities: The salience of reciprocity. Journal of Business Research, 63(9-10), 10331040. https://doi.org/10.1016/j.jbusres.2008.08.009

Charmaz, K. (2005). Grounded theory in the 21 st Century: Applications for Advancing Social justice Studies. In The SAGE Handbook of Qualitative Research (pp. 507-535).

Chou, C., Yang, K. P., \& Jhan, J. (2015). Empowerment Strategies for Ideation through Online Communities. Creativity and Innovation Management, 24(1), 169-181. https://doi.org/10.1111/caim.12104

Coelho, R. L. F., Oliveira, D. S. de, \& Almeida, M. I. S. de. (2016). Does Social Media Matter for Post Typology? Impact of Post Content on Facebook and Instagram Metrics. Online Information Review, 40(4), 458-471. https://doi.org/10.1108/09574090910954864

Corbin, J. M., \& Strauss, A. (1990). Grounded theory research: Procedures, canons, and evaluative criteria. Qualitative Sociology, 13(1), 3-21. https://doi.org/10.1007/BF00988593

Creswell, J. W. (2007). Qualitative Inquiry and Research Design: Choosing Among Five Approaches. Book (Vol. 2nd ed). https://doi.org/10.1016/j.aenj.2008.02.005 
Creswell, J. W. (2009). Research Design: Qualitative, Quantitative and Mixed Approaches (3rd Edition). Sage Publications. https://doi.org/10.2307/1523157

Dann, S. (2010). Twitter Content Classification. First Monday, 15(12).

Darban, A., \& Li, W. (2012). The impact of online social networks on consumers 'purchasing decision, (June), 57. https://doi.org/10.1007/978-3-319-09450-2_7

de Valck, K., van Bruggen, G. H., \& Wierenga, B. (2009). Virtual communities: A marketing perspective. Decision Support Systems, 47(3), 185-203. https://doi.org/10.1016/j.dss.2009.02.008

Dellarocas, C. (2003). The Digitization of Word of Mouth: Promise and Challenges of Online Feedback Mechanisms. Management Science, 49(10), 1407-1424. https://doi.org/10.1287/mnsc.49.10.1407.17308

Dhanasobhon, S., Chen, P., \& Smith, M. (2007). An analysis of the differential impact of reviews and reviewrs at Amazon.com. In International Conference on Information Systems (ICIS) (p. Paper 94). Retrieved from http://aisel.aisnet.org/icis2007/94

Dickey, I. J., \& Lewis, W. F. (2011). An Overview of Digital Media and Advertising. In Handbook of Research on Digital Media and Advertising: User Generated Content Consumption (p. 1). IGI Global.

Donald, L. J. (2015). Marketing Campaign Success - Old Spice - Transformation Marketing. Retrieved May 24, 2017, from http://transformationmarketing.com/marketing-campaingsuccess-old-spice/

Dove. (2017). Real Beauty Sketches | Dove Campaigns - Dove. Retrieved May 24, 2017, from http://www.dove.com/ca/en/stories/campaigns/real-beauty-sketches.html

Drula, G. (2012). Social and Online Media Research--Data, Metrics and Methods. Review of Applied Socio-Economic Research, 3(1), 77-86.

Duan, W., Gu, B., \& Whinston, A. B. (2008). The dynamics of online word-of-mouth and product sales-An empirical investigation of the movie industry. Journal of Retailing, 84(2), 233-242. https://doi.org/10.1016/j.jretai.2008.04.005

Edwards, J. (2012). We need to talk about epistemology: orientations, meaning, and interpretation within music therapy research. Journal of Music Therapy, 49(4), 372-94. https://doi.org/10.1093/jmt/49.4.372

Eriksson, P., \& Kovalainen, A. (2016). Qualitative methods in business research. Sage (2nd ed.). Sage.

Euromonitor International. (2016). Jeans in Canada. Euromonitor, (March). 
Euromonitor International. (2017a). Digital Consumer in the USA, (May).

Euromonitor International. (2017b). Jeans in the US, (February).

facebook. (2014). Testing a New Way for People to Discover and Buy Products on Facebook. Retrieved July 23, 2017, from https://www.facebook.com/business/news/Discover-andBuy-Products-on-Facebook-Test

Fuller, J., Matzler, K., \& Hoppe, M. (2008). Customers as a Source of Innovation. The Journal of Product Innovation Management, 25(6), 608-619.

Gruzd, A., Mai, P., \& Kampen, A. (2017). A How-to for using Netlytic to collect and analyze social media data: A case study of the Twitter use during the 2014 Euromaidan Revolution in Ukraine. In The SAGE Handbook of Social Media Research Methods.

Gruzd, A., Paulin, D., \& Haythornthwaite, C. (2016). Analyzing social media and learning through content and social network analysis: A facet methodological approach. Journal of Learning Analytics, 3(3), 46-71. https://doi.org/10.18608/jla.2016.33.4

Gruzd, A., Staves, K., \& Wilk, A. (2012). Connected scholars: Examining the role of social media in research practices of faculty using the UTAUT model. Computers in Human Behavior, 28(6), 2340-2350. https://doi.org/10.1016/j.chb.2012.07.004

Gruzd, A., \& Wellman, B. (2014). Networked Influence in Social Media: Introduction to the Special Issue. American Behavioral Scientist, 58(10), 1251-1259. https://doi.org/10.1177/0002764214527087

Gruzd, A., Wellman, B., \& Takhteyev, Y. (2011). Imagining Twitter as an Imagined Community. American Behavioral Scientist, 55(10), 1294-1318. https://doi.org/10.1177/0002764211409378

Gu, B., Park, J., \& Konana, P. (2012). Research Note- The Impact of External Word-of-Mouth Sources on Retailer Sales of High-Involvement Products. Information Systems Research, 23(1), 182-196. https://doi.org/10.1287/isre.1100.0343

Haenlein, M., \& Kaplan, A. M. (2010). An empirical analysis of attitudinal and behavioral reactions toward the abandonment of unprofitable customer relationships. Journal of Relationship Marketing, 9(4), 200-228. https://doi.org/10.1080/15332667.2010.522474

Harmeling, C. M., Moffett, J. W., Arnold, M. J., \& Carlson, B. D. (2016). Toward a theory of customer engagement marketing. Journal of the Academy of Marketing Science, 1-24. https://doi.org/10.1007/s11747-016-0509-2

Hoffman, D. L., \& Fodor, M. (2010). Can You Measure the ROI of Your Social Media Marketing? MIT Sloan Management Review (Vol. 52).

Jang, H. Y. H. ., Ko, I. S., Koh, J., Olfman, L., Ko, I. S., Koh, J., ... Olfman, L. (2007). The 
Influence of On-Line Brand Community Characteristics on Community Commitment and Brand Loyalty. In 40th Hawaii International Conference on System Sciences (Vol. 12, pp. 57-80). https://doi.org/10.2753/JEC1086-4415120304

Jin, B., \& Kim, H.-S. (2006). Exploratory study of virtual communities of apparel retailers. Journal of Fashion Marketing and Management, 10(1), 41-55. https://doi.org/10.1108/13612020610651114

Jothi, P. S., Neelamalar, M., \& Prasad, R. S. (2011). Analysis of social networking sites : A study on effective communication strategy in developing brand communication. Journal of Media and Communication Studies, 3(7), 234-242.

Kapitan, S., \& Silvera, D. H. (2016). From digital media influencers to celebrity endorsers: attributions drive endorser effectiveness. Marketing Letters, 27(3), 553-567. https://doi.org/10.1007/s11002-015-9363-0

Khan, S. A., Ramzan, N., Shoaib, M., \& Mohyuddin, A. (2015). Impact of Word of Mouth on Consumer Buying Decision. Age, 18(21), 78. https://doi.org/10.5901/mjss.2011.v2n3p497

Kim, A. J., \& Ko, E. (2010). Impacts of Luxury Fashion Brand's Social Media Marketing on Customer Relationship and Purchase Intention. Journal of Global Fashion Marketing, 1(3), 164-171. https://doi.org/10.1080/20932685.2010.10593068

Kim, E., Sung, Y., \& Kang, H. (2014). Brand followers' retweeting behavior on Twitter: How brand relationships influence brand electronic word-of-mouth. Computers in Human Behavior, 37, 18-25. https://doi.org/10.1016/j.chb.2014.04.020

Kim, J. H., Bae, Z. T., \& Kang, S. H. (2008). The Role of Online Brand Community in New Product Development : Case Studies on Digital Product Manufacturers in Korea. International Journal of Innovation Management, 12(3), 357-376. https://doi.org/10.1142/S1363919608002011

Kim, J. W., Choi, J., Qualls, W., \& Han, K. (2008). It Takes a Marketplace Community to Raise Brand Commitment: the Role of Online Communities. Journal of Marketing Management, 24(3-4), 409-431. https://doi.org/10.1362/026725708X306167

Kim, S., \& Park, H. (2013). Effects of various characteristics of social commerce (s-commerce) on consumers' trust and trust performance. International Journal of Information Management, 33(2), 318-332. https://doi.org/10.1016/j.ijinfomgt.2012.11.006

Kozinets, R. (2002). The Screen: Using Netnography Marketing Communities. Journal of Marketing, 39(1), 61-72.

Kumar, V., \& Mirchandani, R. (2012). Increasing the ROI of Social Media Marketing. MIT Sloan Management Review, 54(1).

Kwon, E. S., Kim, E., Sung, Y., \& Yoo, C. Y. (2014). Brand followers: Consumer motivation 
and attitude towards brand communications on Twitter. International Journal of Advertising, 33(4), 657-680. https://doi.org/10.2501/IJA-33-4-657-680

Lai, L. S. L., \& To, W. M. (2015). Content Analysis of Social Media: A Grounded Theory Approach. Journal of Electronic Commerce Research, 16(2), 138-152.

Laroche, M., Habibi, M. R., \& Richard, M. O. (2013). To be or not to be in social media: How brand loyalty is affected by social media? International Journal of Information Management, 33(1), 76-82. https://doi.org/10.1016/j.ijinfomgt.2012.07.003

Laroche, M., Habibi, M. R., Richard, M. O., \& Sankaranarayanan, R. (2012). The effects of social media based brand communities on brand community markers, value creation practices, brand trust and brand loyalty. Computers in Human Behavior, 28(5), 1755-1767. https://doi.org/10.1016/j.chb.2012.04.016

Lee, M., Kim, H., \& Kim, O. (2015). Why do people retweet a tweet?: altruistic, egoistic, and reciprocity motivations for retweeting. Psychologia, 58, 189-201.

Levi Strauss \& Co. (2017). Levi Strauss \& Co. Retrieved April 16, 2017, from http://www.levistrauss.com/our-story/

Leximancer. (2017). Leximancer. Retrieved from https://info.leximancer.com/

Lovejoy, K., \& Saxton, G. D. (2012). Information, Community, and Action: How Nonprofit Organizations Use Social Media. Journal of Computer-Mediated Communication, 17(3), 337-353. https://doi.org/10.1111/j.1083-6101.2012.01576.x

Lutz, A. (2013). How Nordstrom Is Using Pinterest - Business Insider. Retrieved May 3, 2017, from http://www.businessinsider.com/how-nordstrom-is-using-pinterest-2013-7

Mangold, W. G., \& Faulds, D. J. (2009). Social media: The new hybrid element of the promotion mix. Business Horizons, 52(4), 357-365. https://doi.org/10.1016/j.bushor.2009.03.002

McAlexander, J. H., Schouten, J. W., \& Koenig, H. F. (2002). Building Brand Community. Journal of Marketing, 66(1), 38-54.

McCay-Peet, L., \& Quan-Haase, A. (2017). What is Social Media and What Questions Can Social Media Research Help Us Answer? In The SAGE Handbook of Social Media Research Methods.

Mollen, A., \& Wilson, H. (2010). Engagement, telepresence and interactivity in online consumer experience: Reconciling scholastic and managerial perspectives. Journal of Business Research, 63(9-10), 919-925. https://doi.org/10.1016/j.jbusres.2009.05.014

Muniz, A. M., \& O'Guinn, T. C. (2001). Brand Community. Journal of Consumer Research, 27(4), 412-432. https://doi.org/10.1086/586911 
Murthy, D. (2017). The Ontology of tweets: Mixed Methods Approaches to the Study of Twitter. In The SAGE Handbook of Social Media Research Methods.

Nishioka, C., Scherp, A., \& Dellschaft, K. (2016). Comparing tweet classifications by authors' hashtags, machine learning, and human annotators. Proceedings - 2015 IEEE/WIC/ACM International Joint Conference on Web Intelligence and Intelligent Agent Technology, WIIAT 2015, 1, 67-74. https://doi.org/10.1109/WI-IAT.2015.69

Pak, A., \& Paroubek, P. (2010). Twitter as a Corpus for Sentiment Analysis and Opinion Mining. In Proceedings of the Seventh Conference on International Language Resources and Evaluation, 1320-1326. https://doi.org/10.1371/journal.pone.0026624

Park, J., \& Stoel, L. (2009). Effect of brand familiarity, experience and information on online apparel purchase. International Journal of Retail \& Distribution Management, 33(2), 148 160. https://doi.org/10.1108/09590550510581476

Parrott, G., Danbury, A., \& Kanthavanich, P. (2015). Online behaviour of luxury fashion brand advocates. Journal of Fashion Marketing and Management, 19(4), 360-383. https://doi.org/http://dx.doi.org/10.1108/MRR-09-2015-0216

Pennington, D. R. (2017). Coding of Non-Text Data. In The SAGE Handbook of Social Media Research Methods (pp. 363-389).

Pinterest. (2017). Pinterest. Retrieved from https://business.pinterest.com/en/successstories/nordstrom

Popp, B., \& Woratschek, H. (2017). Consumers' relationships with brands and brand communities - The multifaceted roles of identification and satisfaction. Journal of Retailing and Consumer Services, 35(November), 46-56. https://doi.org/10.1016/j.jretconser.2016.11.006

Pothong, C., \& Sathitwiriyawong, C. (2016). Factors of s-commerce influencing trust \& purchase intention. In IEEE (Ed.), 20th International Computer Science and Engineering Conference: Smart Ubiquitos Computing and Knowledge, ICSEC 2016 (pp. 1-5). IEEE. https://doi.org/10.1109/ICSEC.2016.7859879

QRS International. (2017). www.qsrinternational.com. Retrieved March 5, 2017, from www.qsrinternational.com

Quinton, S., \& Harridge-March, S. (2010). Relationships in online communities: the potential for marketers. Journal of Research in Interactive Marketing, 4(1), 59-73.

https://doi.org/10.1108/17505931011033560

Radhakrishnan, B. (2016). Starbucks "Tweet-a-Coffee" Twitter Campaign Turned Tweets to Sales. Retrieved March 6, 2017, from http://www.digitalvidya.com/blog/starbucks-tweet-acoffee-campaign-turned-tweets-to-sales/\# 
Rahman, S. U., Saleem, S., Akhtar, S., Ali, T., \& Khan, M. A. (2014). Consumers' Adoption of Apparel Fashion: The Role of Innovativeness, Involvement, and Social Values.

International Journal of Marketing Studies, 6(3), 49-64.

https://doi.org/10.5539/ijms.v6n3p49

Rheingold, H. (1993). The Virtual Community: Homesteading on the Electronic Frontier.

Retrieved from http://www.rheingold.com/vc/book/

Rodgers, S., \& Wang, Y. (2011). Electronic Word of Mouth and Consumer Generated Content: From Concept to Application. In Handbook of Research on Digital Media and Advertising: User Generated Content Consumption (pp. 212-231). https://doi.org/10.4018/978-1-60566792-8

Rosa, K. Dela, Shah, R., Lin, B., Gershman, A., \& Frederking, R. (2011). Topical Clustering of Tweets. SIGIR 3rd Workshop on Social Web Search and Mining, cited 2. https://doi.org/10.1.1.207.4287

Rose, G. M., Merchant, A., Orth, U. R., \& Horstmann, F. (2016). Emphasizing brand heritage: Does it work? And how? Journal of Business Research, 69(2), 936-943. https://doi.org/10.1016/j.jbusres.2015.06.021

Roshanaei, M., \& Mishra, S. (2015). Studying the attributes of users in Twitter considering their emotional states. Social Network Analysis and Mining, 5(1), 1-13. https://doi.org/10.1007/s13278-015-0278-9

Sashi, C. M. (2012). Customer engagement, buyer-seller relationships, and social media. Management Decision, 50(2). https://doi.org/10.1108/00251741211203551

Schivinski, B., \& Dabrowski, D. (2015). The impact of brand communication on brand equity through Facebook. Journal of Research in Interactive Marketing, 9(1), 31-53. https://doi.org/10.1108/JRIM-02-2014-0007

Shannon, G., Andrew, P., \& Maeve, D. (2016). Demographics of Social Media Users in $2016 \mid$ Pew Research Center.

Shih-Tse, E., Lily, W., Chen, S.-L., \& Tsai, B.-K. (2012). Investigating member commitment to virtual communities using an integrated perspective. Internet Research, 22(2), 199-210. https://doi.org/10.1108/10662241211214566

Singh, R. (2016). Traditional Media vs. Social Media Advertising - CPM Comparison. Retrieved May 12, 2017, from https://www.linkedin.com/pulse/traditional-media-vs-socialadvertising-cost-digital-strategist

Sloan, L., \& Quan-Haase, A. (2017). A Retrospective on State of the Art Social Media Research Methods: Ethical Decisions, Big-small Data Rivalries and the Spectre of the 6V. In The SAGE Handbook of Social Media Research Methods (pp. 917-933). 
Smith, A. (2017). Blog — Leximancer. Retrieved July 12, 2017, from https://info.leximancer.com/blogb/

Smith, D., Hernández-García, Á., Peregrina, Á. F. A., \& Hair, J. F. (2016). Social Network Marketing : A Segmentation Approach to Understanding Purchase Intention. In In Proceedings of the 7th 2016 International Conference on Social Media \& Society. ACM (p. 20). https://doi.org/10.1145/2930971.2930992

Song, K., Hwang, S., Kim, Y., \& Kwak, Y. (2013). The effects of social network properties on the acceleration of fashion information on the web. Multimedia Tools and Applications, 64(2), 455-474. https://doi.org/10.1007/s11042-012-1068-2

Stampler, L. (2013). How Dove's "Real Beauty Sketches" Became The Most Viral Ad Video Of All Time. Retrieved May 24, 2017, from http://www.businessinsider.com/how-doves-realbeauty-sketches-became-the-most-viral-ad-video-of-all-time-2013-5

Statista. (2015). Number of internet users worldwide 2005-2016. Retrieved May 14, 2017, from https://www.statista.com/statistics/273018/number-of-internet-users-worldwide/

Stelzner, M. A. (2016). 2016 Social Media Marketing Report : How Marketers Are Using Social Media to Grow Their Businesses. Social Media Examiner. https://doi.org/10.1007/BF02653755

Stemler, S. E., \& Tsai, J. (2008). Best Practices in Interrater Reliability. In J. W. Osborne (Ed.), Best Practices in Quantitative methods (pp. 29-49). SAGE Pubications.

Stieglitz, S., \& Dang-Xuan, L. (2013). Emotions and Information Diffusion in Social MediaSentiment of Microblogs and Sharing Behavior. Journal of Management Information Systems, 29(4), 217-248. https://doi.org/10.2753/MIS0742-1222290408

Swani, K., Brown, B. P., \& Milne, G. R. (2014). Should tweets differ for B2B and B2C? An analysis of Fortune 500 companies' Twitter communications. Industrial Marketing Management, 43(5), 873-881. https://doi.org/10.1016/j.indmarman.2014.04.012

Sysomos. (2009). Inside Twitter. Sysomos, (June). Retrieved from https://sysomos.com/insidetwitter

Sysomos. (2017). Sysomos. Retrieved April 15, 2017, from https://sysomos.com/insidetwitter/twitter-rankings/

Tableau. (2017). Tableau. Retrieved March 20, 2017, from https://www.tableau.com

Taecharungroj, V. (2016). Starbucks' marketing communications strategy on Twitter. Journal of Marketing Communications, 7266(February), 1-19.

https://doi.org/10.1080/13527266.2016.1138139

Tafesse, W. (2016). An experiential model of consumer engagement in social media. Journal of 
Product \& Brand Management, 25(5), 424-434. https://doi.org/10.1108/JPBM-05-20150879

Thomas, J. B., Peters, C. O., \& Tolson, H. (2007). An exploratory investigation of the virtual community MySpace.com: What are consumers saying about fashion? Journal of Fashion Marketing and Management, 11(4), 587-603. https://doi.org/10.1108/13612020710824625

Twitter. (2017). Twitter. Retrieved March 1, 2017, from https://about.twitter.com/company

Uzunoglu, E., \& Kip, S. M. (2014). Brand communication through digital influencers:

Leveraging blogger engagement. International Journal of Information Management, 34(5), 592-602. https://doi.org/10.1016/j.ijinfomgt.2014.04.007

Van Der Heijden, H., Verhagen, T., \& Creemers, M. (2003). Understanding online purchase intentions: contributions from technology and trust perspectives. European Journal of Information Systems, 12(October 2002), 41-48. https://doi.org/10.1057/

VanBoskirk, S. (2014). US Digital Marketing Forecast, 2014 To 2019.

Vargo, C. J. (2016). Toward a Tweet Typology: Contributory Consumer Engagement with Brand Messages by Content Type. Journal of Interactive Advertising, (July). https://doi.org/10.1080/15252019.2016.1208125

Wakefield, K. J. (2012). How Twitter Helps Starbucks Brew Up an Excellent Customer Experience - The Content Strategist. Retrieved March 6, 2017, from https://contently.com/strategist/2012/02/23/starbucks-twitter-strategy/

Wang, Y. J., Butt, O. J., \& Wei, J. (2011). My identity is my membership: A longitudinal explanation of online brand community members $\mathrm{a}^{\mathrm{TM}}$ behavioral characteristics. Journal of Brand Management, 19(1), 45-56. https://doi.org/10.1057/bm.2011.28

Weare, C., \& Lin, W. (2008). Content Analysis of the World Wide Web. Social Science Computer Review, 18(3), 272-292.

Weller, K., Bruns, A., Burgess, J. E., Mahrt, M., \& Puschmann, C. (2014). Twitter and Society: An Introduction. Peter Lang.

Whiting, A., \& Williams, D. (2013). Why people use social media: a uses and gratifications approach. Qualitative Market Research: An International Journal, 16(4), 362-369. https://doi.org/10.1108/QMR-06-2013-0041

Wirtz, J., Ambtman, A. den, Bloemer, J., Horva, C., Ramaseshan, B., Klundert, Kj. van de, ... Kandampully, J. (2013). Managing brands and customer engagement in online brand communities. Journal of Service Management, 24(3), 223-244. https://doi.org/10.1108/09564231311326978

Zailskaite-Jakste, L., \& Kuvykaite, R. (2012). Consumer Engagement in Social Media by 
Building the Brand. Electronic International Interdisciplinary Conference 2012, 194-202.

Zhang, M., Jansen, B. J., \& Chowdhury, A. (2011). Business engagement on Twitter: A path analysis. Electronic Markets, 21(3), 161-175. https://doi.org/10.1007/s12525-011-0065-z 